\title{
PROSOCIALITY WITHOUT MORALITY: A HUMEAN CONSTRUCTIVIST APPROACH TO PROSOCIAL PRACTICAL REASON FOR MORAL SKEPTICS
}

By

Nicholas Drake

\author{
A thesis \\ submitted to the Victoria University of Wellington \\ in fulfilment of the requirements for the degree of \\ Master of Arts \\ in Philosophy
}

Victoria University of Wellington 



\section{Acknowledgements}

I am very grateful to Richard Joyce, my primary thesis supervisor, for his support, encouragement, and advice. I am also grateful to Simon Keller, my secondary supervisor, for his insightful and helpful comments. 


\begin{abstract}
The moral skeptic frequently encounters the view that without a belief in moral facts she has insufficient justification for acting in prosocial ways, such as acting with concern for the interests or welfare of others. This thesis is an argument against that view. The thesis is in two parts, each employing a different type of philosophy. Part one is empirical philosophy, and draws on evidence from psychology and history to show that morality is neither a necessary nor a sufficient condition of prosociality, and may in fact be an obstacle to it. Part two is in the fields of metaethics and practical reason, and addresses the question of how a moral skeptic can employ rationality to develop robust, stable, and coherent practical reasons for prosociality. I argue that this can be done by employing a Humean constructivist view. Finally, I use John Stuart Mill as a case study, arguing that he is a noncognitivist and thus a moral skeptic, and that a Humean constructivist reading of his utilitarian theory accounts for the harmony between his moral skepticism and his prosocial normative theory. Mill thus offers an example of prosociality and moral skepticism within a Humean constructivist framework.
\end{abstract}




\section{Table of Contents}

Acknowledgements i

Abstract ii

Table of Contents iii

Chapter One: Introduction 1

1.1 The Fear of Moral Skepticism 1

1.2 Morality and Prosociality 5

1.3 Moral Skepticism 13

Part One: The Necessary and Sufficient Conditions of Prosociality 15

Chapter Two: The Elements of Prosociality 16

Chapter Three: Morality is Not a Necessary Condition of Prosociality 22

3.1 Introduction 22

3.2 Clarification of Terms 23

3.3 Evidence from Steven Pinker 25

3.4 Evidence from Jonathan Haidt 26

3.5 Evidence from the Character of Moral Skeptics 31

3.6 Conclusion 34

Chapter Four: Morality is not a Sufficient Condition of Prosociality 35

4.1 Introduction 35

4.2 Don't Psychopaths Lack Morality? 37

4.3 Hinckfuss's Instrumental Arguments against Morality 42 
4.4 Moral Conviction 49

4.5 Loyalty, Authority and Sanctity as Antisocial Values 55

4.6 Conclusion 64

\section{Part Two: Living Without Morality 67}

Chapter Five: Humean Constructivism 68

5.1 Introduction 68

5.2 Values and Desires 70

5.3 Humean Constructivism and Obligations 74

5.4 Humean Constructivism and Moral Skepticism 75

5.5 Conclusion 76

Chapter Six: Prosociality and Personal Practical Reason 77

6.1 Introduction 77

6.2 Practical Reason in Non-Moral Reasons Internalism 78

6.3 Practical Reason in Ideal Observer Theory 83

6.4 Smith's Moral Ideal Observer Theory 85

6.5 How Can Moral Skeptics Disagree With Others' Normative Views? 97

6.6 Conclusion 99

Chapter Seven: A Case Study: John Stuart Mill 100

7.1 Introduction 100

7.2 Mill's Noncognitivism 102

7.3 Mill's View of Proof in Moral Theory 107

7.4 Mill's View of Practical Reason 109

7.5 Mill's Argument from Desire 118 
7.7 Conclusion 125

Chapter Eight: Conclusion 127

References 130 



\section{Chapter One: Introduction}

\subsection{The Fear of Moral Skepticism}

Moral skepticism is often challenged not only on epistemic grounds, but also on instrumental grounds. It is commonly believed that belief in morality is necessary for the maintenance and promotion of desirable social behaviour. Simon Blackburn poses the problem in discussing a particular form of moral skepticism:

Can the projectivist take such things as obligations, duties, the 'stern daughter of the voice of God', seriously? How can he if he denies that these represent external, independent, authoritative requirements? Mustn't he in some sense have a schizoid attitude to his own moral commitments - holding them, but also holding that they are ungrounded? (Blackburn 1984: 197; quoted in Miller 2013: 39)

Can the consistent projectivist really avoid ending up with the morals of a French gangster? (Ibid.)

He notes of moral anti-realism (itself a step short of moral skepticism):

It is, I think, undeniable that moral anti-realism is often seen as a dangerous doctrine, a more or less surreptitious denial of the importance of ethics ... It is thought to consort with lack of real seriousness ... (Blackburn 1993: 208)

Alasdair MacIntyre writes of another form of moral skepticism, "What is the key to the social content of emotivism? It is the fact that emotivism entails the obliteration of any genuine distinction between manipulative and non-manipulative social relations" (Maclntyre 1985: 23).

Alex Miller presents the problem as follows: "How can we take our moral commitments seriously when we realize, in our moments of philosophical lucidity, that there is no 
realm of distinctively moral facts to ground them?"(2013: 71). Crispin Wright asks, "If it is of the essence of moral discourse to aim at the truth, and if philosophy teaches us that there is no moral truth to hit, how are we supposed to take ourselves seriously in thinking the way we do about any issue which we regard as of major moral importance?" (1996: 2). Michael Pianalto writes that "We certainly want people to have appropriate moral beliefs and to believe them sincerely and firmly" as a person without moral convictions "simply goes with the flow. If society expects him to treat others kindly, he does so; if society expects him to abuse others, he does what's expected" (2011: 383-384).

Michael Smith talks of moral error theory in vague but ominous tones, warning that "Moral nihilism . . looms" and holding that his metaethical theory saves us from "plunging into moral nihilism" (Smith 1994: 13).

Peter Singer goes so far as to say that The denial of objective truth in ethics thus leads ... to skepticism about reaching any meaningful conclusions at all about what we ought to do. (2011: 199-200)

I commonly encounter these views in personal experience. When philosophers and nonphilosophers alike find out that I am a moral skeptic they tend to ask if I really don't oppose Nazism or some scenario in which a person harms another. When they find out that I make an effort to act prosocially, particularly with regard to those I don't encounter personally, they tend to ask how that behaviour can be reconciled with my moral skepticism. And when they find that I favour a particular normative view they tend to ask how I can justify that position without recourse to morality. These questions are as common to the moral skeptic as "Where do you get your protein?" is to the 
vegetarian. The implication of these questions is that without morality there is insufficient reason to act with concern for others.

This thesis will argue against these views. I will propose that morality has two meanings, "belief in, or action based on, facts about right and wrong actions" and "serving or refraining from undermining the interests or welfare of others". Although the two definitions are often conflated, they are distinct. I call only the first meaning morality, and call the second prosociality, and will argue that we can have prosociality without morality.

I employ two different philosophical approaches, part 1 being empirical philosophy and part 2 being in the field of metaethics and practical reason.

Part 1 draws on empirical evidence from psychology, history, and political science. In chapter 2 I argue that empathy and fairness are the primary elements of prosociality, drawing in particular on evidence on Antisocial Behaviour Disorders. In chapter $3 \mathrm{I}$ argue that morality is not necessary for prosociality. There are three grounds for this position. Firstly, there has been a dramatic historical increase in prosocial behaviour and ideas, which has not been accompanied by an increase in belief in moral facts, and may have been accompanied by a decrease. Secondly, there is strong evidence that practically all people - pathological and other marginal cases aside - hold prosocial values regardless of their belief in moral facts. Lastly, the lives and character of known moral skeptics are not characterized by antisociality, and in several cases are characterized by unusually high levels of prosociality. Chapter 4 argues that morality is not a sufficient condition of prosociality. This chapter weakens the common association between morality and prosociality. I begin by discussing evidence that suggests that psychopaths, despite being 
highly antisocial, believe in moral facts. I then examine lan Hinckfuss's arguments that morality is antisocial. Although I find most of these arguments unsuccessful, there is good reason to think Hinckfuss correct that morality is an obstacle to conflict resolution. This is in part due to the phenomenon of moral conviction, in which perceiving oneself to have a moral mandate leads to judging the fairness of processes by whether they achieve a supposedly morally mandated outcome, and to believing that antisocial means are justified by moral ends. I then discuss evidence that some values have a strong tendency to promote antisociality, and that these values correlate with belief in moral facts.

Part 2 turns to metaethics and practical reason, and aims to show that Humean constructivism provides a framework that enables the moral skeptic to apply rationality to her values and desires to develop robust, stable, and coherent reasons for prosociality. In chapter 5 I describe Sharon Street's account of Humean constructivism and discuss some of its distinctive features. Chapter 6 examines the rational tools at the disposal of the Humean constructivist in Bernard Williams's reasons internalism and Peter Railton's ideal observer theory. Ideal observer theory is taken to be a moral success theory by Michael Smith, which would make it incompatible with moral skepticism. I argue that Smith's ideal observer theory fails to justify belief in moral facts, thus leaving ideal observer theory a possibility for the moral skeptic. Finally, chapter 7 offers a case study, that of John Stuart Mill, known for his actively prosocial life and ideas and his development of an influential normative theory, his version of utilitarianism. I argue that Mill is a noncognitivist, and thus a moral skeptic, and that his utilitarian theory can be interpreted as having a Humean constructivist metaethical 
basis. Mill thus exemplifies the way in which Humean constructivism offers a framework for prosociality for moral skeptics.

\subsection{Morality and Prosociality}

In philosophy morality is often thought to mean something like "facts about right and wrong acts". However, the philosophers quoted above also seem to mean by morality platitudinously moral acts and attitudes. This is apparent in the oddity of questions such as "How can we take morality seriously without believing in moral facts?" There is little point in asking how we can take facts about right and wrong seriously if there are no such facts; it seems obvious and unproblematic that we can't rationally do so. Whether or not we can take ourselves seriously in regarding ourselves and others to have reasons for platitudinously moral behaviour without believing in facts about right and wrong seems, on the other hand, like a reasonable question, and seems to be what, for example, Blackburn, Miller, and Wright are getting at. As Singer says, we tend to rely on moral facts to provide reasons to behave in particular ways. The fear of moral skepticism, then, is the fear that without morality we have insufficient reasons for certain desirable kinds of behaviour. This would explain Blackburn's question about the moral skeptic ending up with "the morals of a French gangster". As far as we know, criminals believe in moral facts as much as anyone does, but their behaviour tends to be antisocial (Sedikides et al. 2014). I will use prosociality to describe the desirable actions and attitudes philosophers are referring to (I explain the term more fully below).

Morality and prosociality are often thought of as practically equivalent: 
"Moral behavior is, at the most general level, altruistic behavior, motivated by the desire to promote not only our own welfare but the welfare of others." (Rachels 2000: 81)

"[O]ne central assumption motivating ethical theory in the Analytic tradition is that the function of ethics is to combat the inherent egoism or selfishness of individuals. Indeed, many thinkers define the basic goal of morality as 'selflessness' or 'altruism'." (Schroeder 2000: 396)

"Why are people more likely to act immorally when drunk? Alcohol is perhaps the single greatest source of antisocial behaviour in our society." (Heath and Hardy-Vallée 2015: 1)

Even moral skeptics sometimes conflate morality and prosociality. Walter SinnottArmstrong identifies practical moral skepticism as a non-epistemological form of moral skepticism (Sinnott-Armstrong 2006: 12). This form of skepticism, he says, addresses the question "Why be moral?" However, Sinnott-Armstrong here seems to using a contentladen definition of moral, one that assumes that moral action is prosocial action:

\footnotetext{
Almost everyone admits that there is sometimes some kind of reason to do some moral acts. However, many philosophers deny various claims, including the claims that there is always some reason to be moral, that there is always a distinctively moral (as opposed to self-interested) reason to be moral, and/or that there is always an adequate reason to that makes it irrational not to be moral or at least not irrational to be moral. (Sinnott-Armstrong 2006: 12)
}

But surely a moral skeptic who believes that moral judgements are unjustified or are never true cannot believe that there is a species of action we can rightly call moral,

\footnotetext{
${ }^{1}$ The first two examples are from Doris and Stich (2014: §5.1)
} 
because if we are justified and correct in identifying a moral action we have then made a justified, true moral judgement - so moral here cannot be referring to facts about right and wrong, but to particular, presumably prosocial, actions. Further, why is a moral reason necessarily not a self-interested reason? That surely begs the question against the ethical egoist. The passage makes sense only if Sinnott-Armstrong is conflating morality with prosociality (specifically, altruistic prosociality), in which case morality would be necessarily opposed to self-interested action, and in which case whether or not there are practical reasons for morality (as prosociality) is a question independent of whether or not there are any facts about right and wrong actions.

Some philosophers, then, seem to believe that belief in morality is necessary for prosociality, or even that the two are synonymous. Thus a major concern with moral skepticism is not whether it is true, but whether or not it is pragmatically desirable; not whether it is epistemically justified, but whether it is instrumentally justified. It is important to note that the former does not rely on the latter; that those who value beliefs primarily for being true may not see the lack of instrumental justification for moral skepticism as an obstacle. Nevertheless, the fears surrounding moral skepticism seem strong enough to make assuaging those fears necessary for its promotion.

An important aspect of this thesis is the distinction between the two meanings of "moral" I have already indicated, one concerned with facts about right or wrong and the other concerned with particular acts and attitudes. Joshua Greene and Bernard Gert each offer definitions along these lines.

Greene describes the two meanings of "moral" as follows: 
moral $_{1}$ : of or relating to the facts concerning right and wrong, etc.

moral $_{2}$ : of or relating to serving (or refraining from undermining) the interests of others (2002: 19-20)

Thus morality ${ }_{1}$ refers to the existence of matters of fact about right and wrong actions, and morality $_{2}$ refers to behaviours and attitudes such as kindness and fairness. ${ }^{2}$ Moral

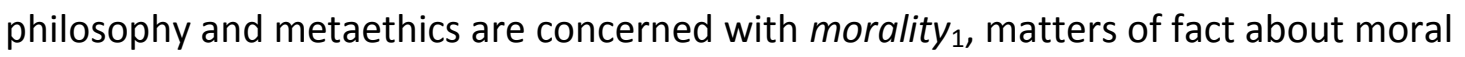
rightness and wrongness. Morality ${ }_{2}$ describes prosocial behaviours, voluntary actions intended to benefit others. What some moral philosophers seem to fear is that without morality $_{1}$ there will be no morality . $_{2}$

Bernard Gert identifies the two definitions more precisely (in reverse order), as follows.

The term "morality" can be used either

1. descriptively to refer to some codes of conduct put forward by a society or,

a. some other group, such as a religion, or

b. accepted by an individual for her own behavior or

2. normatively to refer to a code of conduct that, given specified conditions, would be put forward by all rational persons. (Gert 2011)

Gert's distinction between prescriptive and descriptive morality is more useful than

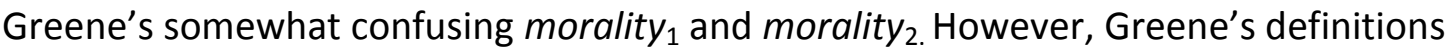

\footnotetext{
${ }^{2}$ William Frankena likewise proposes to define a moral code "as one that calls for at least a certain minimum of consideration of others and at the same time is taken as rationally supremely authoritative" the first aspect corresponding with Greene's second definition and the second aspect with his first definition (Frankena 1970: 172), and J. L. Mackie distinguishes between morality in a "narrow sense", which is "a system of a particular sort of constraints on conduct - ones whose central task is to protect the interests of persons other than the agent", and morality in a "broad sense", which is "a general, allinclusive theory of conduct", again corresponding to Greene's two definitions (Mackie 1977: 106).
} 
are more useful than Gert's, as Gert's definition of the prescriptive morality is specifically rationalist and thus too narrow (excluding Humean moral success theories for example), and his definition of the descriptive morality is too broad for my purposes, as the fears some philosophers have surrounding moral skepticism are not concerned with sufficient justification for codes of behaviour in general, but specifically with justification for liberal, Western codes of behaviour.

As indicated already, I will stipulatively call the descriptive definition of morality prosociality. Prosociality is a psychological term, and is defined as "voluntary behavior aimed at benefiting others" and as involving "altruism, cooperation, trust" and the related emotions (Batson 1998: 302, Penner et al. 2005: 366, Luengo Kanacri et al. 2013, Zaki and Mitchell 2013: 466). The term encompasses "a broad range of biological, motivational, cognitive, and social processes" (Penner et al. 2005: 366), few of which I will need to address in any detail. I use prosociality as a summary notion intended to capture the broad range of behaviours and attitudes that philosophers tend to associate with the descriptive content of morality. Although prosociality is a feature of many species, among which its characteristics vary considerably, it is only human prosociality that I will discuss in this thesis; for simplicity I will refer to "prosociality" rather than "human prosociality".

Thus my terms are as follows:

Morality: belief in or actions based on facts concerning right and wrong actions 
Prosociality: serving (or intentionally refraining from undermining) the interests

or welfare (broadly conceived) of others, for the purpose of their benefit ${ }^{3}$

I stipulatively refer to the normative sense of morality as morality simpliciter in keeping with a metaethical approach, in which morality is concerned with facts about right or wrong rather with particular kinds of behaviour or dispositions.

Note that many people consider other considerations, such as loyalty, authority, and sanctity as aspects of the descriptive content of morality with equal weight to considerations of interests and welfare. As those people are overwhelmingly conservative or non-Westerners (Haidt 2012: 95-98), and those values seem to carry relatively little weight in discussions within moral philosophy, I will not include them as aspects of prosociality for the purposes of this thesis. Chapter 3 will discuss these issues and suggest that those values play an important role in making morality an obstacle to prosociality.

I will pay attention primarily to altruistic motives for prosociality. My reasons for this are twofold. Firstly, the common view that morality is necessary for prosociality seems to assume that in the absence of morality motives are predominantly self-interested. I wish to argue against that assumption. Secondly, self-interest is an unstable and shallow reason for prosociality: prosocial behaviour from self-interest will be heavily mitigated when it is costly, and is unlikely to be extended towards strangers, remote people, or other species. I will argue that moral skeptics have reasons for prosociality that stem from their genuine value of the interests of others, and that these values can be stable

\footnotetext{
${ }^{3}$ There is no consensus among philosophers on the definition of morality, so this discussion should not be taken as dismissing other views out of hand. Rather, I am discussing the definitions most relevant to the fear of moral skepticism. For some other views on the definition of morality see (Wallace and Walker 1970).
} 
and deeply-held. I do not mean the term prosociality to require that a person gain no benefit from the relevant behaviour; it may give them pleasure, peace of mind, and a good reputation. But the behaviour I call prosocial is not performed directly for those ends but from a genuine concern for the interests of others.

Thus the term prosocial captures the descriptive definition of morality well; when philosophers discuss the question "Why should I be moral?" they seem to have in mind something like "Why should I be prosocial?" (See for example (Singer 1969, 2009, Huang 2008, Paletta 2011).

It should be kept in mind that acting in the interests of others does not require acting in the interests of each particular person. A serial killer may have a strong interest in not being stopped, but it is nevertheless a prosocial act to stop a serial killer. Because a person is prosocial to the extent that her concern is for others in general, prosociality does not preclude, and in fact encourages, acting for the general benefit when that is at a certain cost to the interest of a particular person or persons.

What prosociality does not capture about the descriptive content of morality are strictly moral notions such as respect for natural rights or autonomy and some concepts of flourishing. It could be that some moralists (by which I mean those who believe in moral facts) have such concerns in mind when they express concern about the effects of moral skepticism. To the extent that natural rights, autonomy, and flourishing can be reduced to happiness, interests, and felt wellbeing we can talk of them in non-moral terms, as prosociality. To the extent to which natural rights, autonomy, and flourishing are independent of prosociality they are not related to happiness, interests, or the 
functioning of societies, in which case the fear of moral skepticism for the moralist who believes in such principles can only properly be directed to the breach of those principles in itself. The concern for the observance of such strictly moral principles, those independent of prosociality, is not one I will address - I readily admit that the moral skeptic does not have good reason to observe purported principles that are not related to effects on persons. However, it seems to be prosociality, rather than the observance of such principles, that is involved in the fears surrounding moral skepticism.

I will argue that there are two primary elements of prosociality (again, leaving selfinterest as a motive aside). One is empathy: person may care about others. She may have a concern for others' interests and welfare, and wish to see them happy, fulfilled, and free from pain and suffering. The other is fairness: she may value fairness, and thus wish the interests of persons to be subject to equal consideration. It is possible for a person to value fairness without having empathy, having a dislike for the unequal treatment of interests simply because it is rationally unjustified. Similarly, it is possible for a person to be empathetic without caring about fairness. In this case the person will not feel that her concern for others' wellbeing should be equally or universally applied. A person will have reasons for prosociality to the extent that she is both empathetic and fair; the extent of her empathy is the extent to which she values the wellbeing of others, and the extent of her fairness is the extent to which she values the application of empathy to all persons equally. (For fuller discussion see chapter 2.)

I will use as the antithesis of prosocial the term antisocial, by which I mean voluntary actions intended to harm others, or that do not refrain from harming others, without the aim of a greater prosocial end, or beliefs and attitudes that support such actions. 


\subsection{Moral Skepticism}

Moral skepticism is most commonly understood as skepticism about moral knowledge (Sinnott-Armstrong 2006: 10, Joyce, forthcoming: 1). Richard Joyce proposes that if knowledge requires at least justified true belief we can identify three main kinds of moral skepticism:

1. Noncognitivism: the denial that moral judgements are beliefs.

2. Error theory: the acceptance that moral judgements are beliefs while denying that those beliefs are ever true.

3. Justification skepticism: the acceptance that moral judgements are beliefs while denying that we are ever justified in holding these beliefs. (Joyce, forthcoming)

I will employ this definition of moral skepticism with two amendments.

Firstly, presented in this form noncognitivism is incompatible with error theory and justification skepticism: noncognitivism denies that moral judgements are beliefs, while error theory and justification skepticism hold that they are beliefs. However, the noncognitivism defined above is only one of two kinds of noncognitivism; it is descriptive noncognitivism, a theory concerning the nature of moral judgements or moral language. The other form of noncognitivism is prescriptive noncognitivism, which is a normative theory about what the nature of moral judgements and moral language should be. ${ }^{4}$ For example, Joyce's moral fictionalism is a form of prescriptive noncognitivism: "were it adopted, moral discourse would cease to be assertoric, and would therefore be something towards which we ought to be noncognitivists" (Joyce 2001: 200). Joyce

\footnotetext{
${ }^{4}$ It is important not to confuse prescriptive noncognitivism, the position that moral judgements and language ought to be noncognitivist, with prescriptivism, the descriptive position that moral judgements are prescriptive.
} 
prescribes noncognitivism, in the form of fictionalism, as he believes that no moral judgements are true but wishes to continue the use of moral language. J. L. Mackie ascribes to Hume another form of prescriptive noncognitivism, interpreting Hume's view that moral judgements are expressions of approbation or disapprobation as saying that "this is what you ought to mean, because that is all that, on reflection, you could maintain" (Mackie 1980: 58). Prescriptive noncognitivism holds that some moral judgements are beliefs, but that they properly should not be. It is then itself not a form of moral skepticism, but an instrumental proposal based on moral skepticism in the form of error theory or justification skepticism.

Secondly, the moral justification skeptic need not hold to the positive claims that moral judgements are beliefs or that any such beliefs are unjustified. Rather, moral justification skepticism can involve only the absence of the belief that any moral judgements are justified. Such a moral skeptic need hold no position on whether moral judgements are beliefs or whether any justification for moral beliefs is possible. She merely lacks belief in moral facts because she has not seen sufficient justification for them. This is in fact my position. 
Part One: The Necessary and Sufficient Conditions of Prosociality 


\section{Chapter Two: The Elements of Prosociality}

I propose that there are two primary elements of prosociality (again, leaving self-interest aside), empathy and fairness. A person will have reasons for prosociality to the extent that she is both empathetic and fair; the extent of her empathy is the extent to which she values the wellbeing of others, and the extent of her fairness is the extent to which she values the application of empathy to all persons equally. ${ }^{5}$ A person with a high degree of fairness but without empathy might attempt to achieve equality at the cost of the welfare of all concerned, even the poorest and most vulnerable (something similar perhaps being a contributing factor to the Khmer Rouge and other oppressive Communist regimes), and a highly empathetic person without fairness is likely to favour those with whom she has close connections and fail to apply her empathy sufficiently to those not close to her.

An effective way of determining the primary elements of prosociality may be to examine cases of people without prosociality, and find what characteristics such people lack that people with prosociality have. The psychologist Simon Baron-Cohen does this in his book The Science of Evil: Emotion and the Origins of Cruelty (2011). As indicated by the title, Baron-Cohen stresses the importance of emotion - in the form of empathy - as the basis of prosociality, though as we will see he views fairness as important as well. ${ }^{6}$

\footnotetext{
${ }^{5}$ A person could also be conditioned to act prosocially and thus do so out of habit; it seems likely though that such conditioning would involve internalizing the relevant concerns for empathy and fairness rather than internalizing prosocial habits directly without such motivational content.

${ }^{6}$ Certain other psychological faculties are necessary for prosociality, such as at least normal levels of intelligence, executive function, and emotional regulation; as these faculties are necessary for normal function in a wide range of areas, not just prosociality, I will leave these aside and ask that it be read that I am referring in this chapter to persons with at least normal functionality in these areas.
} 
Baron-Cohen defines empathy as "our ability to identify what someone else is thinking or feeling and to respond to their thoughts and feelings with an appropriate emotion" (Baron-Cohen 2011: 16). There are thus two stages in empathy, recognition and response. Baron-Cohen implies that an appropriate empathetic emotion is one that will motivate an action, such as helping a person one sees struggling with a suitcase.

All people lie somewhere on an empathy spectrum, with degrees of empathy across the population falling on a bell curve, and Baron-Cohen holds that people considered evil or cruel are at one extreme of that spectrum (Baron-Cohen 2011: 15, 19-20). Baron-Cohen categorizes levels of empathy on a scale from 0 to 6 . At Level 6 are people with a natural gift for knowing how others are feeling and a deep and genuine concern for them which expresses itself in compassionate action; Baron-Cohen gives Desmond Tutu as an example of a Level 6 person (Baron-Cohen 2011: 27, 179). At the other end of the spectrum there is a strong correlation between low empathy and Antisocial Personality Disorder, which is "a pervasive pattern of disregard for and violation of the rights of others that begins in childhood or adolescence, and continues into adulthood" (BaronCohen 2011: 67). Baron-Cohen divides people with the lowest levels of empathy into two categories, Zero-Negative and Zero-Positive. The Zero-Negative categories are so called because they "they have nothing positive to recommend them. They are unequivocally bad for the sufferer and for those around them" (Baron-Cohen 2011: 4445; empasis original). Having Zero-Positive empathy in contrast involves benefits both for the person and society, alongside some difficulties.

There are three types of Zero-Negative persons, those with Borderline Personality Disorder (BPD), those with Narcissistic Personality Disorder (NPD), and those with 
Psychopathic Personality Disorder (PPD). They represent 2, 1, and 1 percent of the population respectively (Baron-Cohen 2011: 55, 68, 92 ). As overlaps between the three disorders are rare, it can be estimated that around 4 percent of the general population are Zero-Negative (Baron-Cohen 2011: 156). Although people with BPD and NPD tend to be antisocial and deeply unhappy (suicidal, in cases of BPD) and very difficult for family, friends, and colleagues, they tend to have no wish to physically harm others. People with PPD, however, pose a great danger to others. For such people a lack of empathy means you have no brakes on your behaviour, leaving you free to pursue any object of your desires, or to express any thought in your mind, without considering the impact of your actions or words on any other person ... your lack of empathy might lead you to commit murder or rape. (Baron-Cohen 2011: 44-45)

When it is pointed out to people with PPD that they have hurt another person it means nothing to them; “They cannot experience remorse or guilt because they just don't understand what the other person is feeling" (Baron-Cohen 2011: 23). They are thus capable of crimes including murder, assault, torture, and rape, and see themselves as blameless in retrospect (Baron-Cohen 2011: 23). Although all Zero-Negative people are antisocial, people with PPD are extremely antisocial.

Baron-Cohen's category of Zero-Positive applies primarily to people with Asperger's syndrome, an autism spectrum condition. People with Asperger's syndrome (or Aspies) face many social difficulties and are often perceived as aloof or inconsiderate despite being generally very good-willed towards others, as they do not interpret other's moods and meanings as easily as neurotypical people do. Aspies have "remarkably precise, exact minds" - a highly functioning Systemizing Mechanism - and this is the cause of 
their low levels of empathy: "If you have a highly-tuned Systemizing Mechanism, you are less focussed on unlawful phenomena such as emotions, in part because of a need for precision" (Baron-Cohen 2011: 95, 117). Despite frequently being characterized as having little empathy, Aspies are in many ways highly prosocial (though not social). Leading Asperger's researcher Tony Attwood characterizes Aspie adults as "direct, speaking their mind and being honest and determined and having a strong sense of social justice" (Attwood 2014).

Baron-Cohen attributes high prosociality in Aspies to the same systemizing tendency that causes their low levels of empathy:

[T]hese individuals have developed their moral codes through systemizing. They have a strong desire to live by rules and expect others to do the same for reasons of fairness ... [R]ecent theories see superdeveloped moral codes in people with autism . . . People with Asperger syndrome are often the first to leap to the defense of someone who is being treated unfairly because it violates the moral system they have constructed by brute logic alone. (Baron-Cohen 2011: 122-123; emphasis original)

It seems likely that by moral Baron-Cohen here means prosocial, and as is often the case replacing the former word with the latter in the quote above renders it more comprehensible, as there is no evidence that Aspies tend to believe in moral facts but there is evidence that they tend to have codes and systems of prosociality.

As Baron-Cohen says, Aspies care about whether information is true, and apply this to people as well: "Is my neighbour's behaviour consistent ... Do his words match his actions?" (Baron-Cohen 2011: 116). To Aspies, the arbitrariness and inconsistency of saying one thing while doing another, and the differential treatment of interests, are 
unbearable. Thus their low capacity for empathy is compensated for by a high degree of fairness.

That people with Antisocial Personality Disorders suffer from an absence of empathy indicates that empathy is an important cause of prosociality; the only people who seem to have low empathy and high prosociality are Aspies, but according to Baron-Cohen's view (it should be noted that he is director of Cambridge's Autism Research Centre) their lack of empathy is due to an overwhelming degree of mental precision and focus on system-ready stimuli rather than an inherent deficit in concern for others. A capacity for empathy is thus almost certainly a necessary condition of prosociality. As noted above, it is not a sufficient condition of prosociality, as a person with a high degree of empathy but little sense of fairness is likely to greatly favour those she feels strongly for, such as friends and family, even at the cost of causing harm to others.

It seems clear then that the primary elements of prosociality are at least normal levels of empathy and fairness. It also seems likely from the case of Aspies that a lack of either empathy or fairness can be, to a certain extent, compensated by a high degree of the other. People such as Aspies who struggle with empathy can have high degrees of prosociality due to their unusually high degree of fairness, and it may be possible that people with low degrees of fairness can have high degrees of prosociality if they have high enough degrees of empathy. There must be limits to such compensation however: a story in The Little Flowers of St Francis tells of Brother Juniper, a simple-minded Franciscan known for his readiness to do anything to help those in need, who on visiting a sick man who asked for a meal of pig's feet caught a pig in a nearby field and cut off its foot. 
If prosociality requires empathy and fairness, does it not also require morality? I will argue in the next chapter that it does not. 


\section{Chapter Three: Morality is Not a Necessary Condition of Prosociality}

\subsection{Introduction}

The view that morality is necessary for prosociality tends to be assumed rather than demonstrated; I have yet to see a statement of the position accompanied by much in the way of argument. Whether or not people in general maintain a desirable level of prosocial behaviour without morality is an empirical matter. If people are directed towards prosocial behaviour and away from selfish behaviour by a belief in moral facts, this is something that can in principle be determined by empirical research. However, it is something that, in all cases I have seen, is assumed to be the case by philosophers without any supporting evidence.

Section 3.2 will clarify an issue arising from my use of evidence from moral psychology. I will then discuss evidence from Steven Pinker's The Better Angels of Our Nature in section 3.3, from Jonathan Haidt's Moral Foundations Theory in section 3.4, and from the character of moral skeptics in section 3.5. I will argue that the empirical evidence discussed shows that morality is not necessary for prosociality.

I have the uncomfortable feeling that in this and the next chapter I have easy targets. Surely few philosophers would, on reflection, think that a person cannot be prosocial without a belief in moral facts. Nevertheless, something like that view seems to be required by the fears surrounding moral skepticism and the equivalence between morality and prosociality that we saw examples of in the introduction. It thus seems worth putting this view to rest. 


\subsection{Clarification of Terms}

In this section I will be discussing moral psychology, and a few words are necessary to avoid confusion. I will argue that evidence from empirical moral psychology shows that the value of prosociality is extremely widespread, being held by almost all people. This may seem to imply that prosociality is widely held to be a moral value, or that most people regard prosociality as a measure, or the measure, of what is morally right or wrong. This is not the case.

Recall that the words moral and morality may refer either to facts about right and wrong or to prosocial behaviour. The two definitions are frequently conflated, but are distinct, and as discussed in the introduction I am calling belief in and action based on facts about right and wrong morality, and voluntary action to benefit others and the disposition towards such action prosociality. The studies discussed here make no such distinction; they are not concerned with whether people's views about right and wrong or preferable and undesirable behaviour are about purported facts or not. Thus, for example, that Jonathan Haidt's Moral Foundation Theory suggests that most people value fairness does not show that most people believe that it is a fact that unfairness is wrong and fairness right; the question of factuality is not put to the respondents in the relevant surveys.

For example, Haidt's Moral Foundations Questionnaire asks respondents to rate their agreement with the following statements, among others:

Compassion for those who are suffering is the most crucial virtue.

When the government makes laws, the number one principle should be ensuring that everyone is treated fairly. 
I am proud of my country's history. (MoralFoundations.org 2014)

No matters of fact about right and wrong are involved in these statements; a person can strongly agree or disagree with them without believing in any moral facts. Agreement or disagreement with such statements can thus be taken to indicate a person's values rather than her moral beliefs. This is clear in Haidt's own definition of morality:

Moral systems are interlocking sets of values, virtues, norms, practices, identities, institutions, technologies, and evolved psychological mechanisms that work together to suppress or regulate self-interest and make cooperative societies possible. (Haidt 2012: 270)

This definition relates to the descriptive, not prescriptive definition of morality, and does not involve moral facts.

The Moral Foundations Questionnaire does mention right and wrong however. The first section asks, "When you decide whether something is right or wrong, to what extent are the following considerations relevant to your thinking?" (MoralFoundations.org 2014). There are two reasons to think that answers to that section of the questionnaire do not indicate belief in moral facts on the part of respondents. Firstly, the question does not mention morality. The "right or wrong" it asks about could be interpreted in a number of ways, including whether or not something is conventionally right or wrong or is desirable or undesirable; expressivists would argue that such language is not intended to be factual, for example. Secondly, the question asks "When you decide whether something is right or wrong ..." The position that things are right are wrong in some way is assumed and the position that nothing is right or wrong is not allowed for by the question, so respondents can reasonably be expected to give answers whether they believe there are facts about right or wrong or not. Thus the question does not require respondents to have a belief in moral facts. 
To avoid confusion between prosociality and belief in moral facts I will refer to the values and intuitions in the empirical literature as practical or social values and practical or social intuitions, rather than moral values and moral intuitions, except where belief in moral facts is explicitly involved.

\subsection{Evidence from Steven Pinker}

Steven Pinker, in his extensive review of the evidence for the causes of historical reductions in violence, lists several contributing factors, none of which is an increase in the strength or breadth of belief in moral facts. They are the establishment of strong centralized states, increased trade, the feminization of society, the expansion of the circle of empathy by contact with other perspectives through literacy, cosmopolitanism, and education, and an increasing application of rationality that results in a greater realization of the equivalent value of different persons' interests (Pinker 2011: 671-691). This increasing application of rationality is caused by the same factors as the expansion of the circle of empathy, along with the brute fact that one's own interests have, objectively, no greater value than those of others (Pinker 2011: 680-692). ${ }^{7}$ Rationality also reduces violence because many harmful moral practices are supported by irrational beliefs about non-moral facts (Pinker 2011: 690-691). All of these factors are independent of morality. Pinker's evidence thus suggests that morality is not necessary for prosociality.

There is a remarkable lack of evidence on whether or not people believe in moral facts, let alone whether or not levels of belief in moral facts have changed over time. There is though some reason to think that moral skepticism has increased since the start of last

\footnotetext{
${ }^{7}$ Note that Pinker's view supports my contention that empathy and fairness are the primary elements of prosociality.
} 
century. In folk use moral relativism and moral subjectivism are synonymous with practical moral skepticism or laissez-faire morality (for examples see section 4.5), and the consensus seems to be that belief in subjectivism, relativism, and explicit moral skepticism have increased over time. James Flynn expresses a common view when he writes "Ever since the sixteenth century, thinkers have been walking away from [belief in] ethical truth, and the prevailing mood was captured by Max Weber when he pleaded with youth not to lose all their ideals along the way" (Flynn 2000: 3). Steven Finlay notes that "relativism ... is rampant today: it is commonly remarked that large numbers of undergraduate students gravitate towards it" (Finlay 2008). Without hard evidence it would be a mistake to make too much of this, but it seems likely. ${ }^{8}$ If true, it would mean that the great increase in prosociality that Pinker describes has been accompanied by an increase in moral skepticism. That there is no positive correlation between morality and prosociality indicates that belief in morality is not necessary for prosociality.

\subsection{Evidence from Jonathan Haidt}

Further evidence that morality is not a necessary condition of prosociality comes from research by Jonathan Haidt. His studies show that moral judgements are (perhaps marginal cases aside) the result of emotive intuitions, and that articulations of moral judgements are post-hoc rationalizations of those intuitions (Haidt 2001).

Haidt and colleagues presented respondents with a number of hypothetical situations and asked them whether the act involved was morally right or wrong. With some stories

\footnotetext{
${ }^{8}$ Research on folk metaethical views has focussed on whether people's views are objectivist or relativist (Sarkissian et al. 2011, Goodwin and Darley 2008). This makes the results a little obscure, as objectivism is not opposed to relativism but to subjectivism; and relativism is not opposed to objectivism but to absolutism. In metaethics then, the subjectivism vs. objectivism and relativism vs. absolutism polarities are orthogonal to each other (Joyce 2009). Nevertheless, the studies indicate that folk metaethical views lean towards subjectivism and relativism. We cannot conclude from this whether folk metaethical views tend to involve belief in moral facts or not, as facts can be subjective and relative.
} 
respondents typically had strong views, but were unable to give explanations for those views. For example, in one story a brother and sister decide to have sex. The story makes explicit that no one is ever harmed in any way by the incident, which both people regard as a valuable experience. Nevertheless, people overwhelmingly view it as morally wrong. When asked why, people typically offer explanations that don't stand up, such as explanations that say, contrary to the story, that someone is harmed. When pressed for a working explanation typical responses are "I don't know, I can't explain it, I just know it's wrong" (Haidt 2001: 814). (Haidt and colleagues call this phenomenon moral dumbfounding (Haidt, Bjorklund, and Murphy 2000).) This indicates that people do not make moral judgements based on reason which then influence their emotional intuitions; rather, moral judgements are expressions of emotional intuitions and rational explanations are post-hoc.

If moral judgements are post-hoc rationalizations it follows that when people hold certain prosocial actions to be morally obligatory that view is a post-hoc rationalization. If so, the emotional intuitions that cause prosocial judgements would still exist without that post-hoc view. The moral aspect of practical judgements is therefore not necessary for the prosocial aspect of practical judgements. ${ }^{9}$

Haidt's later research seeks to identify which practical values are commonly held, and to what extent. Haidt's candidate values are chosen by analyzing lists of virtues from around the world and connecting them to the adaptive challenges of social life identified by evolutionary psychology (Haidt 2012: 122). Haidt and his colleague Craig Joseph employ the idea of "modularity", in which cognitive modules are innate systems that

\footnotetext{
${ }^{9}$ It seems likely that some intuitions are strengthened by such post-hoc rationalizations, which will result in either prosocial or antisocial effects depending on the nature of the intuition (see section 4.4).
} 
change behaviour in response to particular stimuli (Haidt 2012: 123). The result is the following list of cognitive modules (Fig. 1), shown with the adaptive challenges they evolved to deal with, their original triggers (the kinds of social patterns they evolved to react to), their current triggers (the kind of social pattern they react to in a modern Western society; some of Haidt's examples seem unnecessarily trivial), their characteristic emotions, and the virtue terms we tend to employ about persons who trigger them.

\begin{tabular}{|c|c|c|c|c|c|}
\hline & Care/harm & Fairness/cheating & Loyalty/betrayal & Authority/subversion & $\begin{array}{l}\text { Sanctity/ } \\
\text { degradation }\end{array}$ \\
\hline $\begin{array}{l}\text { Adaptive } \\
\text { challenge }\end{array}$ & $\begin{array}{l}\text { Protect and } \\
\text { care for } \\
\text { children }\end{array}$ & $\begin{array}{l}\text { Reap benefits of } \\
\text { two-way } \\
\text { partnerships }\end{array}$ & $\begin{array}{l}\text { Form cohesive } \\
\text { coalitions }\end{array}$ & $\begin{array}{l}\text { Forge beneficial } \\
\text { relationships within } \\
\text { hierarchies }\end{array}$ & $\begin{array}{l}\text { Avoid } \\
\text { contaminants }\end{array}$ \\
\hline $\begin{array}{l}\text { Original } \\
\text { triggers }\end{array}$ & $\begin{array}{l}\text { Suffering, } \\
\text { distress, or } \\
\text { neediness } \\
\text { expressed by } \\
\text { one's child }\end{array}$ & $\begin{array}{l}\text { Cheating, } \\
\text { cooperation, } \\
\text { deception }\end{array}$ & $\begin{array}{l}\text { Threat or } \\
\text { challenge to } \\
\text { group }\end{array}$ & $\begin{array}{l}\text { Signs of dominance } \\
\text { and submission }\end{array}$ & $\begin{array}{l}\text { Waste } \\
\text { products, } \\
\text { diseased } \\
\text { people }\end{array}$ \\
\hline $\begin{array}{l}\text { Current } \\
\text { triggers }\end{array}$ & $\begin{array}{l}\text { Baby seals, } \\
\text { cute cartoon } \\
\text { characters } \\
\end{array}$ & $\begin{array}{l}\text { Marital fidelity, } \\
\text { broken vending } \\
\text { machines }\end{array}$ & $\begin{array}{l}\text { Sports teams, } \\
\text { nations }\end{array}$ & $\begin{array}{l}\text { Bosses, respected } \\
\text { professionals }\end{array}$ & $\begin{array}{l}\text { Taboo ideas } \\
\text { (communism, } \\
\text { racism) }\end{array}$ \\
\hline $\begin{array}{l}\text { Character } \\
\text {-istic } \\
\text { emotions }\end{array}$ & Compassion & $\begin{array}{l}\text { Anger, gratitude, } \\
\text { guilt }\end{array}$ & $\begin{array}{l}\text { Group pride, } \\
\text { rage at traitors }\end{array}$ & Respect, fear & Disgust \\
\hline $\begin{array}{l}\text { Relevant } \\
\text { virtues }\end{array}$ & \begin{tabular}{|l} 
Caring, \\
kindness
\end{tabular} & $\begin{array}{l}\text { Fairness, justice, } \\
\text { trustworthiness }\end{array}$ & $\begin{array}{l}\text { Loyalty, } \\
\text { patriotism, self- } \\
\text { sacrifice }\end{array}$ & $\begin{array}{l}\text { Obedience, } \\
\text { deference }\end{array}$ & $\begin{array}{l}\text { Temperance, } \\
\text { chastity, } \\
\text { piety, } \\
\text { cleanliness }\end{array}$ \\
\hline
\end{tabular}

FIGURE 1. Moral Foundations Theory (Haidt 2012: 125)

Note that only two of the five practical values in Moral Foundations Theory relate directly to prosociality: Care and Fairness. Recall that I defined two primary elements of prosociality: empathy and fairness (see chapter 2). The social value of Care seems 
identical to what I have called empathy, and the social value of Fairness, unsurprisingly, seems identical with what I have called fairness. ${ }^{10}$

That these modules are innate does not mean that they are universal or immune to cultural variation. It means they are aspects of the brain that are prewired but flexible and subject to change; as Haidt puts it, they are "organized in advance of experience" (Haidt 2012: 131, Marcus 2004: 40). Cultural pressures can "shrink or expand the current triggers of any module" (Haidt 2012: 124). For example, in recent decades Westerners have extended compassion to animals to a greater degree, and reduced disgust at many sexual activities.

Haidt hypothesized that liberals value the Care and Fairness foundations more strongly than the other three, whereas conservatives value Loyalty, Authority, and Sanctity more highly. Between 2007 and 2011 Haidt and his colleagues collected responses from 132,000 subjects to an online questionnaire testing the strength with which subjects value each of the five foundations. The results confirm the hypothesis: the more liberal a person is, the more highly she values Care and Fairness, and the more conservative she is, the more highly she values Loyalty, Authority, and Sanctity (Fig. 2). Thus the degree to which people value empathy and fairness, the prosocial values, depends on their degree of liberalism. (If prosociality correlates with moralism, we would expect moralism to correlate with liberalism; in fact, as I show in section 4.7, the opposite is the case.)

\footnotetext{
${ }^{10}$ Haidt notes that conservatives value Fairness highly, but it is fairness as proportionality, the principle that people should get what they deserve based on what they have done (2012: 138). Liberals on the other hand value Fairness as equality. It is the liberal conception of Fairness as equality that I identify with fairness.
} 


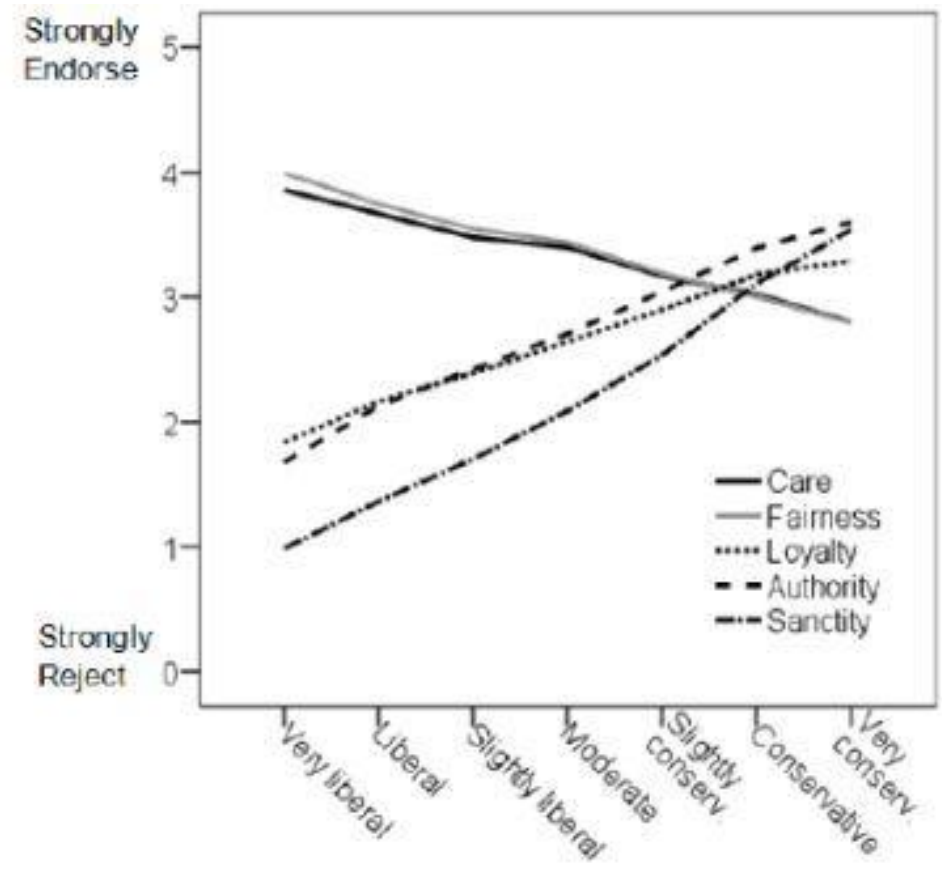

FIGURE 2. Scores on the Moral Foundations Questionnaire (Haidt 2012: 158)

Haidt's research thus indicates that among humans there are a limited number of social values, held with varying degrees of strength. ${ }^{11}$ Practically all people hold the five social values in Haidt's survey; those values thus constitute what Dale Dorsey describes as "robust species-wide regularities" (Dorsey 2008: 18), characteristics that are not universal but apply to almost all humans. We can therefore take the practical values of Moral Foundations Theory as evidence for the relevant range of practical values of people in general.

The fears surrounding moral skepticism are in part based on the assumption that the values that entail reasons for prosociality are subject to great variation among persons; without morality, it is thought, people will not be prosocial as their social values are not strong enough, in most cases, to motivate them in the absence of a belief in moral facts.

\footnotetext{
${ }^{11}$ Haidt and colleagues are open to the possibility of there being other foundations, the most likely candidate being "Liberty/Oppression".
} 
Haidt's evidence suggests that this is false. Practically all people hold prosocial values, but there is not sufficient evidence to justify the view that practically all people believe in moral facts, let alone sufficient evidence to justify the view that people's prosocial values are dependent on any belief in moral facts (see section 3.3). The time to hold that a belief in morality underlies people's social values is the time when evidence to support that belief is produced. In the absence of such evidence it is just as reasonable (and I would say prima facie more reasonable) to hold that, as Haidt suggests, where people's moral beliefs are prosocial they are a codification and/or rationalization of their antecedent prosocial intuitions and values. It is reasonable to assume then, that people in general have prosocial values independent of any belief they may have in moral facts, and that morality is thus not necessary for prosociality.

\subsection{Evidence from the Character of Moral Skeptics}

A final area of empirical evidence that belief in morality is not necessary for prosociality is the character of moral skeptics. Unfortunately no studies have been done, as far as I know, on the degrees of prosociality of moral skeptics. In the case of many moral skeptics there is little to go on, and it is possible to mention only a few leading moral skeptics here, but I believe there are significant indications that moral skeptics are not devoid of prosociality in their personal affairs or in their consideration for the interests of others, in which case morality cannot be necessary for prosociality.

The first philosopher to elaborate theories of moral skepticism in the last 100 years was Bertrand Russell, who, according to Charles Pigden, originated both emotivism and moral error theory, each of which he held to be true at different times (Pigden 1996:

$182,201)$. Russell was an early supporter of women's right to vote, an anti-war activist 
imprisoned for pacifist activism during World War I, a co-founder of the Campaign for Nuclear Disarmament, a human rights activist, and an ethical vegetarian (Ryan 1988). Russell's Nobel Prize in literature was awarded "in recognition of his varied and significant writings in which he champions humanitarian ideals and freedom of thought" (Nobelprize.org).

Moral error theorist J. L. Mackie has been described as follows: “Courteous, genial, modest and unpretentious, he was a patient, dedicated teacher and a wise, conscientious administrator" (Menzies 2012). Importantly, his belief in moral error theory did not prevent him elaborating a normative utilitarian theory, one based on "the flourishing of human life" (Mackie 1977: 169-200), holding as he did that second order moral skepticism does not entail or require first order skepticism about prosocial practical reason (Mackie 1977: 16).

Moral skeptic James Flynn has been a lifelong campaigner on social justice issues, starting with the US Civil Rights movement of the 1960s, and an active member of the left wing New Zealand Alliance Party. Although he believed in moral facts for most of his life and thought them a great potential aid for furthering humane and egalitarian ideals, he came to regard moral facts as not only nonexistent but a weaker basis for defending humane ideals than morally skeptical alternatives (Flynn 2000: 3). When Flynn stopped believing in morality his belief in practical reasons for prosociality, and his activism, were unabated.

Moral error theorists Richard Garner and lan Hinckfuss have been among the strongest critics of morality (Garner 1994, 2007, Hinckfuss 1987). Both philosophers have strong objections to morality on prosocial grounds. Garner holds that "informed and 
compassionate amoralism offers a better chance to create the kind of world we want to inhabit than does any moral system ever invented" and that amoralism would involve a reduction in suffering and an increase in happiness and contentment (Garner 1994: 3). He characterizes the fundamental human question as "how to plant ourselves firmly on the path of creation, cooperation, and healthy competition, rather than the path of destruction, unhealthy cooperation, and lethal competition" (Garner 1994: xi). Hinckfuss's aim is to "work towards a new altruistic society", and he is opposed to morality in large measure because he believes it to cause more harm than good (Hinckfuss 1987: 5). Hinckfuss was heavily involved in the Australian Labour party, and an ex-colleague of his describes him as "passionately interested in peace studies and conflict resolution" (Joyce 2014).

Likewise, moral skeptic Joshua Greene views morality as problematic for prosociality (as well as helpful in many ways). He advocates utilitarianism for instrumental reasons, as the means by which common ground can be found between groups with competing social values (Greene 2013: 291).

Moral error theorist Charles Pigden has spent what he calls "an excessively large portion" of his life in political work, supporting left-wing social democracy and human rights groups (Philosopedia.org).

Thus these prominent moral skeptics have decidedly prosocial lives and attitudes, and advocating for such attitudes has been an important aspect of their work. This evidence is not sufficient to establish a positive correlation between moral skepticism and prosociality, and there are undoubtedly moral skeptics who have predominantly 
antisocial attitudes and behaviour: the Marquis de Sade stands out as an example, a moral skeptic who physically and sexually abused prostitutes (Thomas 1976: 44-47). There are other moral skeptics, notably Nietzsche, whose social views are perhaps too complex to describe as simply prosocial or antisocial (Leiter 2013: 2). Nevertheless, a single moral skeptic with strongly prosocial views and behaviour would be sufficient to demonstrate that belief in morality is not necessary for prosociality. Beyond that, there is a tendency for morally skeptical philosophers to be strongly prosocial.

\subsection{Conclusion}

There is a tendency to assume that a belief in morality is necessary for prosociality. This is in large part due to a failure to distinguish between the two meanings of morality, one concerning belief in moral facts and the other concerning prosociality.

I have shown that belief in morality is not necessary for prosociality, in three ways. First, I showed that the historical evidence indicates that there is no positive correlation between morality and prosociality; societies have become radically more prosocial without an increase, and perhaps with a decrease, in morality. Second, I showed that evidence from Jonathan Haidt reveals that prosocial moral judgements are the result of, not the cause of, prosocial intuitions, and that practically all people hold the prosocial values of empathy and fairness that underlie those intuitions. There is no reason to think that moral skeptics are an exception. Lastly, I showed that philosophical moral skeptics have tended to be strongly prosocial. These arguments are sufficient to show that the view that belief in morality is necessary for prosociality is unjustified. In the next chapter I will argue that neither is it sufficient for prosociality. 


\section{Chapter Four: Morality is not a Sufficient Condition of Prosociality}

\subsection{Introduction}

Having shown in chapter 3 that morality is not a necessary condition of prosociality, I will now argue that neither is it a sufficient condition of prosociality. As discussed in the introduction, the fears surrounding moral skepticism are often to be expressed in such a way as to imply that morality itself is sufficient for prosocial behaviour, and morality is often treated as synonymous with prosociality. As with the previous chapter I have the discomforting feeling of having an easy target: it seems likely to me that these views would not stand up to the critical reflection of those who hold them. Nevertheless, the assumptions described are widespread and persistent, and it is thus worth putting them to rest.

Further, a good argument can be made that morality is not only insufficient for prosociality but an obstacle to it. Steven Pinker expresses this view in Better Angels of Our Nature. He notes that "violence is often caused by a surfeit of morality and justice", and that "evildoers always think they are acting morally" (2011: 84, 494). Hitler, for example, had a point of view that Pinker calls "highly moralistic" (2011: 495). Pinker writes that "a lot of our violence comes from destructive ideologies ... For better or worse - usually worse - people are often willing to trade off material comfort for what they see as spiritual purity, communal glory, or perfect justice" (2011: 676). Pinker's summary of the effects of morality is damning: 
victimless crimes and misdemeanours, and the targets of ideological genocides, they would surely outnumber the fatalities from amoral predation and conquest. The human moral sense can excuse any atrocity in the minds of those who commit it, and it furnishes them with motives for acts of violence that bring them no tangible benefit. (2011: 622)

Though Pinker recognizes that morality can promote prosociality as well as antisociality, he writes that the suffering "that has been visited on the world by people motivated by a moral cause" is "incalculable", and suggests that "the net contribution of the human moral sense to human well-being may well be negative" (2011: 622).

The evidence from chapter 3 showed that there is not as much to fear from moral skepticism as moralists often suppose; the evidence from this chapter shows that there is not as much to favour in morality as moralists tend to think.

In section 4.2 I will examine whether those with Antisocial Behaviour Disorders lack morality; if they do not, then morality is not sufficient for prosociality as such people have the former without the latter. Section 4.3 discusses Hinckfuss's arguments against the prosociality of morality, most of which, I will suggest, are not well-supported by the empirical evidence. An argument of Hinckfuss's that is well supported is that morality is an obstacle to conflict resolution. In section 4.4 I discuss the phenomenon of moral conviction, in which a belief that a position is morally right obstructs judgement and is taken to provide a mandate to further ends by antisocial means. Finally, in section $4.5 \mathrm{I}$ propose that of the foundational social values proposed by Haidt, three are predominantly, though not entirely, antisocial: Loyalty, Authority, and Sanctity. I suggest that there is a correlation between these values and moralism, which thus implies a correlation between moralism and the antisocial values. I conclude that morality is not 
sufficient for prosociality and that there is good reason to think that it does more harm than good. ${ }^{12}$

\subsection{Don't Psychopaths Lack Morality?}

We saw in chapter 2 that empathy and fairness are the primary elements of prosociality. It could be though that antisocial people lack empathy and fairness and morality. If that is the case, then it could be that those who do have morality are prosocial, and if so, morality is sufficient for prosociality. I will argue that that is not the case.

Just as there is little evidence as to whether people in general believe in moral facts, there is little evidence as to whether antisocial people believe in moral facts. There are some indications however. Psychologists have done little in the way of testing psychopaths for belief in moral facts (the studies by Jonathan Glover discussed below being the only example I know of) but they have tested them for what they call moral reasoning. Two primary paradigms have been used to assess moral reasoning in psychopaths, the moral dilemma paradigm of Lawrence Kohlberg (which I'll refer to as the Kohlberg test) and the moral/conventional task of Elliot Turiel (Turiel 1983, Colby and Kohlberg 1987, Kohlberg 1981, Kohlberg, Levine, and Hewer 1983).

In the Kohlberg test the participant is presented with a hypothetical moral dilemma and asked how the person in the scenario should act and why. The more complex the participant's response, the higher her level of moral reasoning is believed to be (Blair, Mitchell, and Blair 2005: 56-57). The most well-known Kohlberg test example is of a husband who breaks into a pharmacy to steal an anticancer drug for his wife who is

\footnotetext{
${ }^{12}$ There are also some indications that morality is not sufficient for prosociality in research by Eric Schwitzgebel and colleagues, which shows that moral philosophers (who are overwhelmingly moralists) are not especially prosocial (Schwitzgebel 2009, 2013, Schwitzgebel and Rust 2009, 2010, 2013, Schwitzgebel et al. 2012, Rust and Schwitzgebel 2013). It is not possible to discuss that evidence here.
} 
dying of cancer (Baron-Cohen 2011: 77). The evidence from Kohlberg tests is mixed; early studies showed that levels of moral reasoning are lower among psychopathic offenders than non-psychopathic non-offenders, but later studies instead compared psychopathic offenders to non-psychopathic offenders and found no difference in moral reasoning. Blair and colleagues suggest that the Kohlberg test indexes IQ and socioeconomic status rather than moral reasoning per se. (Blair, Mitchell, and Blair 2005: 57).

Nevertheless, it seems reasonable to think that the evidence from Kohlberg tests indicates that psychopaths aren't characterized by a lack of belief in morality. Kohlberg studies ask respondents what a person should do and why; if psychopathic respondents did not believe in morality surely indications of that would have surfaced. Although we would not expect any sophisticated metaethical responses, we would expect some indication of such a belief to appear in the results, such as perhaps indications of belief in laissez-faire behaviour. It might be thought that in their responses psychopaths are reasoning about the prosocial aspects of the scenarios rather than the moral aspects, but as they are characterized precisely by a lack of prosociality that is very unlikely. Thus the evidence from Kohlberg tests on psychopaths, though not strong, is at least an indication that they do not have an unusual lack of belief in morality.

The other widely used test of moral reasoning is the moral/conventional distinction task, in which the participant is presented with stories involving either moral or conventional transgressions and is asked to make a series of judgements about them, such as how bad the transgressions are and why, and most importantly whether it would be okay to commit the act if there were no rule about it. (Blair, Mitchell, and Blair 2005: 57-58). 
Moral transgressions in these tests are actions defined by their consequences for the interests and welfare of others, such as hitting another person or damaging her property. Conventional transgressions are actions defined by their consequences for the social order, such as talking in class or wearing opposite-sex clothes (Blair, Mitchell, and Blair 2005: 57-58).

Healthy individuals distinguish between conventional and moral transgressions from the age of 39 months and do so in several ways. They tend to hold that moral transgressions are more serious than conventional transgressions, that they are wrong because of the distress caused to the victim, and that they are wrong regardless of whether or not an authority figure has made a rule against them (Blair, Mitchell, and Blair 2005: 58).

Psychopaths have considerable difficulty with the task, but it is not clear why (BaronCohen 2011: 78).

Children with psychopathic tendencies, adults with psychopathy, and other antisocial populations do generally regard moral transgressions as more serious than conventional transgressions. However, such populations are far less likely than comparison individuals to make reference to the victim of the transgression when justifying why moral transgressions are bad ... In addition, when the rules prohibiting the transgressions are removed, such populations are far less likely to make the distinction between moral and conventional transgressions that is seen in healthy individuals. (Blair, Mitchell, and Blair 2005: 58-59)

I suggest the differences between the responses of psychopaths and the general population can be explained by differences in degrees of empathy. The lack of consideration of the victim in distinguishing moral from conventional acts indicates a lack of empathy, not a disbelief in moral facts. The failure to recognize the irrelevance of rules may have the same source; it seems likely that to normal individuals the existence 
of a rule that forbids harming a person is irrelevant, as empathy forbids harming others. To people with low empathy, where harming a person is concerned the existence of a rule has some relevance as the harm is not taken into consideration. Thus normal people's empathy means they see a problem with harms that are not proscribed by authority, and psychopaths' lack of empathy means that they tend not to.

Further, Haidt points out that the moral/conventional distinction is largely restricted to liberal, developed societies (Haidt 2012: 9-14); so people can believe in moral facts without making the moral/conventional distinction, which exists only within certain cultural frameworks. Difficulty with the task thus does not indicate a lack of belief in moral facts, but difficulty with a particular aspect of liberal developed culture. Even within liberal developed societies it is easy to compose scenarios in which people view transgressions as moral rather than conventional but where no harm takes place, such as Haidt and colleagues' test stories of sibling incest or of a person having sexual intercourse with supermarket poultry (Haidt and Hersh 2001, Haidt 1993).

The difficulty psychopaths have with Turiel's moral/conventional task thus can be reasonably attributed to a lack of empathy. There is no indication from the Turiel test that psychopathic respondents in general lack belief in moral facts.

My interpretation of the results of the Kohlberg and moral/conventional distinction tests is supported by evidence from a series of interviews the philosopher Jonathan Glover conducted with psychopaths at Broadmoor Prison, a high-security psychiatric facility, as part of a project carried out by psychiatrist Gwen Adshead. He sought to investigate, among other things, whether the interviewees were amoralists, by which he means those "utterly self-interested and prepared to trample ruthlessly on anyone else", 
and/or conceptual amoralists, by which he means those who have prosocial dispositions but no belief in moral obligations:

\begin{abstract}
The pure "conceptual" amoralist might not be selfish. He might often care about other people and act toward them with benevolence and even generosity. But he does this because he wants to, not because of thoughts that he ought to do so or about moral obligations. To "moral" uses of words like "ought," "right," "wrong," "duty," and "obligation," he will react as Oscar Wilde did when asked if he was patriotic: "Patriotism is not one of my words." (Glover 2014: 14)
\end{abstract}

By conceptual amoralist Glover seems to mean a moral error theorist or moral justification skeptic (see section 1.3).

Glover found that his interviewees had very strong self-interest, a severe lack of empathy, and poor reasoning skills. ${ }^{13}$ They did not, however, reject moral concepts: "For the most part they did have a moral vocabulary of right and wrong, good and bad, fair and unfair. And for many of them, certain moral concepts and thoughts in particular were deeply embedded in their outlook" (Glover 2014: 24). Prominent among these was command morality, the belief that it is morally right to follow and morally wrong to disobey what a particular authority commands (Glover 2014: 28-31, 37).

The evidence from the Kohlberg and moral/conventional distinction tests thus gives no reason to think that psychopaths do not believe in moral facts, and Glover's interviews suggest that they do. It seems likely then that the most antisocial people believe in morality. If so, morality is not sufficient for prosociality.

\footnotetext{
${ }^{13}$ Psychologist Kevin Dutton suggests that psychopaths with good reasoning skills make excellent CEOs and don't end up in Broadmoor (Dutton 2012).
} 


\subsection{Hinckfuss's Instrumental Arguments against Morality}

In his short book The Moral Society (1987), Ian Hinckfuss argues that morality is, overall, harmful to human wellbeing. Hinckfuss acknowledges that there is little scientific evidence with which to make judgements about the instrumental value of morality, but holds that some provisional conclusions can be reached. I will look at these conclusions briefly and argue that all but one are unjustified. It may seem an odd strategy to present and refute arguments for my own position, but as The Moral Society is the most substantial argument against the instrumental value of morality it is necessary to discuss it in order to give the issue proper treatment, and to distinguish the strong instrumental arguments against morality from those that are weak.

Hinckfuss follows the distinction between morality, the belief in facts about right and wrong, and prosociality, voluntary behaviour intended to benefit others, that I identified in chapter 1 , referring however to altruism rather than to prosociality $(1987: 1,2.2) .{ }^{14}$ Hinckfuss doesn't define altruism, but his meaning seems to be sufficiently close to that of prosociality to justify replacing his term with mine for clarity in this section. He gives several reasons to support the view that morality is antisocial rather than prosocial.

The thrust of these arguments is that the moral society - the society in which people believe in moral facts - is hierarchical, elitist, and authoritarian. Hinckfuss contends that the moral society involves a group of powerful elites who are regarded as moral authorities, a group that shapes the beliefs of the less powerful to their own ends. This system supports inequality, in which the moral elites control a disproportionate amount of wealth and power. This in turn makes society prone to violent revolution.

\footnotetext{
${ }^{14}$ References to The Moral Society are to chapter and section numbers.
} 
At the top of the moral society sit the moral leaders:

[T]here is a widespread belief throughout the [moral] society that some people are morally better than others and there is a widespread desire that these morally better people ought to dominate or actually rule the society. (Hinckfuss 1987: 3.2)

Hinckfuss regards Edmund Burke's pride in this system as paradigmatic: "We fear God; we look up with awe to kings; with affection to parliament; with duty to magistrates; with reverence to priests; and with respect to nobility" (Hinckfuss 1987: 3.2).

People in the moral society look to moral leaders for moral guidance "in the same way as morally trained children do", seeking and receiving moral instruction "from their elders, priests, newspaper editors, television commentators, radio announcers, doctors, lawyers, magistrates, university lecturers, union organizers, people in uniform or perhaps even their mates down at the public house" (Hinckfuss 1987: 2.3). This system involves a hierarchy at the pinnacle of which will be "those whose moral injunctions spread furthest: the controllers of the mass media, be that the pulpit, radio or television" (Hinckfuss 1987: 2.4). The elites in this society train the population to follow their moral prescriptions through reward and punishment. The rewards include "smiles, honours, property, economic security, power and privilege", and the punishments include "frowns, snubs, deprivation of income, deprivation of possessions, imprisonments and physical violence" (Hinckfuss 1987: 2.5). However, the structure of the moral society ensures that most people cannot be morally good; as a result the majority are regarded as moral failures, which causes denigration and guilt.

The moral elite are dominated by those who most strongly believe themselves to be virtuous: 
In fact, such moral self-confidence is a necessary condition for entry into the moral elite. For with such self-confidence, it is easy to believe that what one wishes for oneself is morally permissible, and how one wants others to behave is morally obligatory. A good person will not want what is wrong. (Hinckfuss 1987: 2.4)

Thus the assumption of moral elites that they are exemplary leads them to equate the way they want others to live with moral obligations (Hinckfuss 1987: 2.4). However, the moral injunctions of the moral elite serve their own interests rather than those of society:

$[T]$ he injunction 'Thou shalt not steal' is more in the interest of those that have rather than those that have not. The injunction to be patriotically loyal is clearly more in the interests of those citizens who are in positions of power rather than those who are already powerless and exploited ... The injunction to keep one's promises clearly favours those who have the power to elicit promises by either covert or overt threat - those who are top dog when the contract is being signed. (Hinckfuss 1987: 4.7)

The moral society thus favours the interests of the rich and powerful over those of the poor and weak. This creates large scale economic inequality, as the moral society enables "either subconscious or deliberate but morally sanctioned exploitation of the rest of society by the moral elite", inequality and exploitation that can provoke violent revolution (Hinckfuss 1987: 3.5).

The most striking thing about Hinckfuss's picture is how little it accords with contemporary Western democracies. Firstly, it is not the case that the rich and powerful or the media are regarded as moral leaders by the rest of society. A 2012 Gallup poll asked Americans "Please tell me how you would rate the honesty and ethical standards of people in these different fields - very high, high, average, low, or very low?" (2012a). 
$54 \%$ of respondents rated members of Congress low or very low, and only $10 \%$ rated them high. Senators did only slightly better, with $45 \%$ rating them low or very low and only $14 \%$ rating them high. Journalists, business executives, and bankers received low or very low ratings from $24-30 \%$ of respondents, average ratings from $45-50 \%$ of respondents, and high or very high ratings from $21-28 \%$ of respondents, slightly less than the number of respondents giving them the lowest ratings. Clergy did better, being rated as high or very high by $52 \%$ of respondents and as low or very low by only $9 \%$. However, the ratings of these supposed moral leaders pale in comparison with those of nurses, at $85 \%$ high or very high, and pharmacists, at $75 \%$ high or very high. Doctors, engineers, and dentists also did well at $70 \%, 70 \%$, and $62 \%$ high or very high respectively. Thus the rich and powerful and those with public platforms are generally regarded as of low moral standing, while those who are rated most highly are typically well paid but not rich (particularly in the case of the most highly rated, nurses), have no special political power, and have little public voice. When was the last time we heard a public moral statement by a person speaking as a dentist? Rather than the rich, powerful, and influential being thought of as having high moral standards, that designation is reserved for those whose professions are especially prosocial: nurses, doctors, dentists, and teachers. ${ }^{15}$ The phenomenon of moral leadership simply does not exist in the way Hinckfuss portrays.

Similarly, there is little to support Hinckfuss's view that reward and sanction are heavily based on morality. In modern Western democracies morality plays little or no role in the creation of criminal legislation, which is overwhelmingly based on creating desirable

\footnotetext{
${ }^{15}$ A poll by the UK consumer group Which? had similar results, showing that only $7 \%$ of respondents trust politicians and journalists, while $11 \%$ trust bankers. Teachers, doctors, and nurses were trusted by $69 \%$, $80 \%$, and $82 \%$ of respondents respectively (2012b).
} 
social outcomes. Even seeming exceptions such as limits on abortion and gay marriage and adoption are overwhelmingly discussed in terms of personal and social outcomes rather than moral standards, except in religious circles. ${ }^{16}$

It is also not clear that morality plays a significant role in criminal justice. ${ }^{17} \mathrm{New}$ Zealand has a typical Western criminal justice system. There are five rationales for sentencing under New Zealand law: just desert, deterrence, incapacitation, rehabilitation, and restitution (Ministry of Justice 1997). Just desert sounds like a moral concept, but it is important to realize that it is not the same thing as moral desert. There are two principles underlying the application of just desert in sentencing. One principle is the expression of public censure; under this consideration a sentence "is deserved because the wrongdoing must be publicly condemned" (Ministry of Justice 1997: 3.1.1). This is not the same thing as moral desert; it may be necessary or desirable that wrongdoing be publically condemned regardless of moral desert, for example as a deterrent or as part of rehabilitation. The other principle underlying the application of just desert is the restoration of social equilibrium (Ministry of Justice 1997: 3.1.1). Under the social equilibrium view, all members of a law-abiding society benefit from that society, but when a person breaks the law she imposes a cost on others and an unfair advantage on herself, a benefit which is not available to the law-abiding. Punishment is intended to redress that imbalance. Thus it is not clear that purported moral facts play a significant role in criminal justice, as Hinckfuss believes.

\footnotetext{
${ }^{16}$ An exception is the USA, but given the highly religious nature of that society it seems likely that the US is not so much Hinckfuss's moral society as it is a religious society.

${ }^{17}$ This argument is based on my (2013a).
} 
As for reward, those who are regarded as having the highest standards of behaviour are highly but not extravagantly paid in some cases - doctors, engineers - and moderately paid in others - nurses and teachers. As such people help others but are not strongly identified with positions on moral issues it seems far more likely that they are rewarded for their prosociality than for their supposed morality.

Given the unlikelihood of the existence of a moral elite roughly identical with the rich and powerful, there is no reason to think that inequality is a product of the moral society rather than of other social and economic factors.

A more promising argument from The Moral Society is that morality is an obstacle to conflict resolution. Hinckfuss makes the reasonable suggestion that conflicts between parties should be resolved by “(a) sorting out any conceptual confusions between them relevant to the conflict, (b) finding out the facts of the case relevant to the conflict, and (c) if it is still necessary, devising ways of solving their mutual problem" (Hinckfuss 1987: 4.4). Where people believe there to be moral obligations in play, that belief is likely to be an obstacle. "For moral considerations to be effective in resolving a dispute in any way at all, satisfactory or otherwise, all parties must agree on what their moral values and obligations are"; otherwise "the dispute may develop into mutual denigration leading to one of the disputants feeling morally justified in ignoring the desires of the other party" (Hinckfuss 1987: 4.2). They may even feel obliged to treat the other party harshly (Hinckfuss 1987: 4.2). If the parties agree on their moral values, the conflict may be resolved if their moral values are utilitarian, that is, if they aim to maximize satisfaction of both parties. This will not always be the case, and if a party's interests will 
be better satisfied by another moral principle that can be intuited to be overriding they will likely intuit that principle (Hinckfuss 1987: 4.2).

There is evidence that Hinckfuss is right about the obstructive role of morality in conflict resolution. Groups can have selfish reasons for favouring some moral values over others, a phenomenon Greene calls biased fairness (Greene 2013: 67). Biased fairness is sufficiently obstructive to conflict resolution that parties may be more likely to reach a satisfactory solution if they think selfishly rather than morally.

A study by Harinck and colleagues (2000) involved pairs of strangers negotiating over the penalties for four realistic hypothetical criminal cases, with the members of each pair randomly assigned the roles of defense lawyer and prosecutor (Greene 2013: 86-88). There were a number of possible outcomes for the four cases each pair negotiated over, with two of the cases allowing for "win-win" outcomes, and two allowing only "zero sum" outcomes. It was possible for negotiators to make concessions on less important cases in order to gain concessions on more important cases; thus both sides could do well if they were willing to make concessions. Some pairs were told to think about the negotiation in purely selfish terms, under which they would try to get lighter or heavier penalties in order to advance their careers, while other pairs were told to think about the negotiation in moral terms, under which defense lawyers were told that a lighter penalty would be more just and prosecutors were told that a heavier penalty would be more just. The selfish participants did better in reaching win-win outcomes than the moral participants. Selfishness allowed negotiators to make concessions to achieve a net gain, and to understand that their opponents will only make concessions that achieve a net gain for them; morality seemed to require that negotiators reject making the 
concessions necessary for the best outcomes, as those concessions did not track moral desert. Greene concludes that "Biased fairness is sufficiently destructive that, in some cases, we're better off putting morality aside and simply trying to get a good deal" (Greene 2013: 88). ${ }^{18}$ If so, this lends support to Hinckfuss's instrumental argument against morality.

Thus Hinckfuss's theory of the moral society is unconvincing, but his argument that morality obstructs conflict resolution has some evidential support and gives reason to think that morality is not only insufficient for morality but in some cases an obstacle.

While Hinckfuss's moral society bears little resemblance to ours, it bears a stronger resemblance to Western societies of the past. Edmund Burke's description above is not true of our time, but may well have been true of his. As the course of history since Burke's time has seen a great increase in prosociality and a probable decrease in morality (see section 3.3) it may be that we live in a more prosocial society because we live in a less moral one.

\subsection{Moral Conviction}

A significant factor in the obstruction of conflict resolution and the exacerbation of conflict is moral conviction. Moral conviction is a strong belief that something is morally right or wrong (Skitka and Mullen 2002: 36). Moral conviction forms the basis for moral mandates, the specific attitudes or stands that people develop out of a conviction that something is morally right or wrong (Skitka and Mullen 2002: 37). I will present evidence

\footnotetext{
${ }^{18}$ Not included in the study were pairs of negotiators seeking the most prosocial outcomes; I predict that such pairs would succeed as well as or better than the selfish negotiators.
} 
that moral conviction is antisocial, before briefly discussing and refuting an argument in its favour from Matthew Pianalto.

Psychologists Linda Skitka, Elizabeth Mullen, and David Houston argue that when people hold moral mandates they have little concern about how those mandates are achieved, as long as they are achieved. Thus when people are pursuing a morally mandated end, commitments to procedural safeguards and due process are eroded (Skitka and Mullen 2002: 35): “if people's desire for vengeance is morally mandated, they have little concern for how their vengeance is achieved" (Skitka and Mullen 2002: 38, Skitka and Houston 2001). "[A]ttitudes and behaviours that the perceiver believes are morally mandated will always be seen by the perceiver as justified and for the greater good", Skitka and Mullen write, in part because when people respond with moral conviction they have a need to reaffirm their belief that, in contrast to their opponents, they are "authentically good and moral" (Skitka and Mullen 2002: 37).

A study by Skitka and Houston (2001) of Americans' reactions to the Elián González case demonstrated the role moral mandates play in the justification of means by ends. Elián González was a 5-year-old boy found floating off the US coast in an inner tube. He was the sole survivor of a capsized boat that had been carrying him, his mother, and others during an attempt to reach the United States from Cuba. A widely publicized debate ensued about whether he should be returned to his father in Cuba or put in the care of relatives in the US. After months of legal proceedings and failed negotiations, Elián was taken from his US relatives' home by the authorities by force and returned to his father in Cuba. 
The degree to which people had a moral mandate about how the case should be resolved emerged as the strongest predictor of people's subsequent acceptance of the resolution of the case, as well as whether they believed it had been fairly or unfairly resolved. The results were very clear: People who had a moral mandate were much more concerned that the "right" outcome was achieved than with whether it was achieved by means of a fair or unfair process. (Skitka and Mullen 2002: 38-39)

Skitka and Mullen found in a later study that the reason for the moral mandate effect is that people with moral mandates "react with anger when outcomes are inconsistent with their moral point of view, which, in turn, colors perceptions of both outcomes and procedures" (Mullen and Skitka 2006: 629). When people in the study had a moral mandate, they appeared to suspend judgments of procedural and outcome fairness until they knew the outcome of the procedure. If the outcome supported a person's moral mandate, she would regard the procedure and outcome to be fair. If, however, an outcome went against a person's moral mandate, she would become outraged, and this would colour her perception of the fairness of the procedure and outcome. "The form of this outrage was quite specific: Anger at outcomes that challenged perceivers' moral convictions, not anger at flawed procedures, accounted for the effects of moral mandates on judgments of procedural and outcome fairness" (Mullen and Skitka 2006: 640).

Similarly, a study by Maarten Zaal and colleagues examined the relationship between holding moral convictions and engaging in hostile and benevolent forms of collective action (Zaal et al. 2011). Zaal and colleagues distinguish between prevention focus and promotion focus in convictions. Prevention focus "indicates a concern with safety and the fulfilment of duties and responsibilities, also referred to as 'oughts'" (Zaal et al. 
2011: 673). Prevention focus is related to questions of morality and immorality and so seems to relate to belief in moral facts. Promotion focus by contrast "indicates a concern with gain and the achievement of growth and accomplishment goals rather than duties and responsibilities. Promotion-oriented individuals are motivated to pursue ideals, or maximal goals". Zaal et al. do not view promotion focus as strongly related to moral conviction "because moral considerations function as 'oughts' and not as 'ideals"” (Zaal et al. 2011: 673).

The studies by Zaal et al. examined the relationship between prevention focus and promotion focus and the support for benevolent and hostile collective action in groups of Dutch women. The women were given information that women are paid substantially less than men for the same work and receive fewer opportunities for promotion (Zaal et al. 2011: 674,678$)$. They found that under prevention focus individuals were more motivated to engage in both benevolent and extreme, hostile forms of collective action. "This was even the case when these same individuals viewed these hostile forms of collective action as inherently immoral. Thus, for prevention-oriented individuals, the ends (social change) appeared to justify the means (hostile forms of collective action)" (Zaal et al. 2011: 685). As prevention focus is associated with morality, this indicates that perceived moral mandates promote antisociality.

Thus moral conviction and the moral mandate effect go some way to explaining the appalling record of morality outlined above by Pinker (as well as many examples of people going to extraordinary lengths to support morally mandated prosocial ends). Not only does morality not help people resolve conflict or assess the fairness of procedures, 
it obstructs conflict resolution, creates anger when moral outcomes are not achieved, and gives moralists licence to achieve their ends.

People who bomb abortion clinics or who, like the Weathermen, engaged in violent protests against the Vietnam War, may have very different political orientations but are fundamentally alike. Both are or were motivated by deep moral convictions. (Skitka and Mullen 2002: 39)

Philosopher Michael Pianalto argues that although moral conviction has a "long historical catalogue" of "catastrophic, vicious, and insane convictions" and can motivate "atrocious acts", it also has instrumental value that derives from its relationship to integrity, and from its potential to motivate prosocial as well as antisocial acts (Pianalto 2011: 381). I agree with the uncontroversial view that moral conviction has the potential to motivate prosocial acts, but that does not mean that moral conviction tends to motivate prosocial acts more than those which are antisocial. I will thus leave that aside and discuss Pianalto's first point, that there cannot be integrity without moral commitments.

Pianalto holds that a lack of moral commitments entails a lack of integrity:

\footnotetext{
A person without any such convictions simply goes with the flow. If society expects him to treat others kindly, he does so; if society expects him to abuse others, he does what's expected ... By contrast, the person of conviction (sometimes) exhibits a kind of autonomy and self-investment. This person's convictions may be conventional or radical, but the difference is that in the person of conviction, his or her actions flow from his or her character and a deep sense of what is right and good; one's actions are a part of who one is and what one stands for. (Pianalto 2011: 384)
}

This is unconvincing. If moral facts exist they may well be independent of who a person is and what they stand for, unless moral facts are necessarily subjective; as there are a 
substantial number of non-subjectivist moralists (Kantians, non-naturalists, moral rationalists), this cannot be taken for granted.

The commitments Pianalto speaks of seem to be not moral but prosocial convictions. This captures his description of such commitments as being concerned with "kindness" or "abuse" towards others. Belief in moral facts is not a necessary condition of kindness towards others and refraining from abuse, but kindness towards others and refraining from abuse are prosocial acts. Therefore the commitments he describes are not unavailable to moral skeptics.

If a person is a moral skeptic, the convictions she has about the kinds of actions she wants herself and others to undertake can only follow from her personal values; in that case they are "a part of who one is and what one stands for". Speaking for myself, I discount the importance of moral facts in part because of my strong commitment to particular prosocial outcomes. If I were to discover that it is a moral fact that we should discriminate against women or homosexuals, or that we should cause unnecessary suffering to animals, I would deliberately and very happily do what was morally wrong and treat women and gays with equality and refrain from causing unnecessary suffering to animals. The prosocial commitments of moral skeptics are based on their person values and thus involve no loss of integrity.

For a moralist on the other hand, moral convictions may be quite independent of her personal values. For example, a moral philosopher once told me that he was a vegetarian because he believed it was a moral fact that he should be; but that he didn't care about the wellbeing of animals. His behaviour was thus divorced from his values, apart from his value of conforming to whatever morality turns out to require. If a person 
believes that she should act in accordance with moral facts even if they disagree with her personal values - which most forms of morality require - she would seem to have a lack of integrity in Pianalto's sense, as there is a disjunction between her personal values and the kinds of actions she is prepared to undertake.

Thus moral conviction is neither necessary nor sufficient for integrity; it is not necessary, as the moral skeptic can have strong prosocial convictions on the basis of deeply-held values, and it is not sufficient, as the moralist can have moral convictions that diverge from her deeply-held values. Integrity is thus not sufficient justification for moral conviction, and does not outweigh the dangerous tendencies that moral conviction involves.

\subsection{Loyalty, Authority and Sanctity as Antisocial Values}

\subsubsection{Introduction}

Hinckfuss notes that many philosophers assume that prosocial people have a reason to favour morality, that

moral behaviour will always coincide with altruistic behaviour. That assumption would be valid if the only beliefs in moral obligations implied that one ought always to behave as if one were kindly disposed to all other people. But it is clearly false that all moral beliefs are of this kind ... Some people have beliefs in their moral duty to their god, their sovereign, their country or their political ideals and such morality could (and frequently does) run counter to such altruistic inclinations such people have. (Hinckfuss 1987: 2.2)

In other words, some moral values are prosocial but others are antisocial. I identify the primarily antisocial moral values as those Haidt's Moral Foundations Theory calls Loyalty, Authority, and Sanctity (see section 3.4). I will argue that there is good reason to 
think that these values are on balance antisocial, and to think that there is a correlation between the strength with which such values are held and belief in moral facts.

I will not argue that Loyalty, Authority, and Sanctity are necessarily antisocial. Rather, I will argue that unlike the values of Care and Fairness they are largely antisocial. Care and Fairness appear to have few antisocial dimensions, in conjunction and in balance: although a person who has strong empathy and little sense of fairness might favour her loved ones at a high cost to others and a person with a strong sense of fairness and little empathy might act to achieve equality at the cost of decreasing the wellbeing of all concerned, there seem to be no ill effects of a person having a high degree of empathy and a strong sense of fairness (see chapter 2$)^{19}$

Loyalty, Authority, and Sanctity can be directed to prosocial ends. However, unlike Care and Fairness, Loyalty, Authority, and Sanctity are not directly concerned with people's welfare and interests, and when moral convictions exist that hold these values to be morally mandated the persons holding them are likely to regard themselves as being justified in furthering them by antisocial means. This provides a reasonable explanation of why morality may in general do more harm than good.

The primary prosocial dimension of Loyalty is that it facilitates cooperation within groups. The primary antisocial dimension is that it places the interests of one's own group or over those of others. The primary prosocial dimension of Authority is an aspect of social stability, in which people acknowledge that teachers, police officers, and civic authorities (among others) have a good understanding of the situations in which our personal judgement should be suspended to achieve prosocial outcomes, such as what

\footnotetext{
${ }^{19}$ For an argument against the prosociality of empathy, and responses, see (Bloom et al. 2014).
} 
we should do following a natural disaster, how we should drive, and whether or not we should vaccinate children. The primary antisocial dimension of Authority is that those in power may not have prosocial intent or may be mistaken as to the means to achieve prosocial ends, so that support of and obedience to authorities are harmful.

There may be prosocial dimensions of Sanctity, but if so I do not know what they are. It would be argued by some that the sanctity of human life is such a dimension as it protects certain people from harm; but it tends to include as people things like zygotes and blastocysts, and give them priority over the wellbeing and interests of women, and to ignore the wishes and interests of terminally ill people who wish to end their suffering through assisted suicide. In such cases the sanctity of human life is a value that places metaphysically questionable principles over the needs and wishes of feeling persons. The other primary antisocial dimensions of Sanctity are that it can include a hierarchical ontology of persons (as in the Indian caste system) and that it bases codes of behaviour on highly questionable metaphysical beliefs.

I suggest that Authority and Loyalty are primarily prosocial only within particular groups; once we have a world that must be shared by multiple, interacting groups, and while those groups have different, conflicting authorities and loyalties, Loyalty and Authority will do more harm than good when valued above Care and Fairness. ${ }^{20}$

It is important to note that where there are prosocial dimensions of Loyalty and Authority those dimensions can be motivated by the values of Care and Fairness. In the case of Loyalty, concern for other group members can be motivated by empathy and

\footnotetext{
${ }^{20}$ For a detailed argument that morality is prosocial within groups but antisocial between groups see (Greene 2013).
} 
fairness without the need to believe that one's own group has any special qualities or privileges. In the case of Authority, respect for the roles of those with positions of authority and expertise can be motivated by the knowledge that those roles are necessary for a well-functioning society and the general welfare that results. Loyalty and Authority can thus be held and promoted to the extent that they are prosocial, that is, to the extent that they accord with empathy and fairness. There is no need for them to be held as values independently of empathy and fairness, and where they are, we can expect antisocial outcomes. ${ }^{21}$ In section 4.5.3 I will argue that the antisocial values correlate with moralism.

\subsubsection{Pinker on the Antisocial Values}

Pinker notes that the dramatic changes for the better in practical values since the Enlightenment he calls the Rights Revolutions involve a shift away from the values of power, tradition, and religion (2011: 398), and "often a decisive rejection of instinct, culture, religion, and standard practice", to be replaced by "empathy and reason" (2011: 475). I don't think it's a stretch to say that in terms of Moral Foundations Theory, "power" as a value is roughly equivalent to Authority, "tradition" and "culture" involve Loyalty and Authority, "religious practice" involves Sanctity, Authority, and Loyalty, and "empathy and reason" are roughly equivalent to Care and Fairness (Pinker holds that a result of the application of reason to social values reveals that there is no justification for giving preference to particular persons' interests; this is a view of Peter Singer's that Pinker draws on heavily (Singer 2011, Pinker 2011: 175, 580, 648-650)).

\footnotetext{
${ }^{21}$ I assume the reader is sufficiently familiar with the history of nationalism, tribalism, authoritarianism, and purity codes to make recounting the horrors of the values of Authority, Loyalty, and Sanctity when not directed to the ends of Care and Fairness unnecessary. For familiar examples, see Pinker (2011: 326-327, $449,478,522,523,524-525,559)$ and Glover (2001: 57-59, 157, 328).
} 
Thus the prosocial improvements of recent centuries correlate with a great weakening of the values of Loyalty, Authority, and Sanctity, and a great strengthening of the values of Care and Fairness.

As noted in section 3.4, the values of Loyalty, Authority, and Sanctity are conservative values, whereas Care and Equality are liberal values. If the conservative values are antisocial, we would expect a positive correlation between prosociality and liberalism. This is in fact the case:

The Rights Revolutions are liberal revolutions. Each has been associated with liberal movements, and each is currently distributed along a gradient that runs, more or less, from Western Europe to the blue American states to the red American states to the democracies of Latin America and Asia and then to the more authoritarian countries, with Africa and most of the Islamic world pulling up the rear ... the numbers show that the movements have reduced many causes of death and suffering and made the culture increasingly intolerant of violence in any form. (Pinker 2011: 475476)

Pinker identifies as the two primary traits that reduce violence empathy and reason, which are roughly identical to the two sides of prosociality, empathy and fairness (though reason also involves the reduction of false beliefs about the natural world that support antisociality, such as the belief in witchcraft). Pinker describes the increase in empathy and in the application of reason to social values in terms taken from Peter Singer, the expanding circle and the escalator of reason: "The first involves occupying another person's vantage point and imagining his or her emotions as if they were one's own. The second involves ascending to an Olympian, superrational vantage point ... and considering one's own interests and another person's as equivalent" (Pinker 2011: 690). In these forms, Care and Fairness work against the other social values to reduce 
violence, involving "the movement away from tribalism [Loyalty], authority [Authority], and purity [Sanctity]" (Pinker 2011: 691). ${ }^{22}$

\subsubsection{The Correlation between Moralism and Antisocial Values}

We have seen that of the five values of Moral Foundations Theory, Care and Fairness are, in balanced combination, prosocial, whereas Authority, Loyalty, and Sanctity, are antisocial when not directed to the ends of Care and Fairness. In this section I argue that Authority, Loyalty, and Sanctity correlate with moralism while Care and Fairness correlate with moral skepticism.

It is possible that people who value Loyalty, Authority, and Sanctity hold them as social or practical values, not as moral values. The reader will recall that in chapter 2 I pointed out that Moral Foundations Theory does not examine belief in moral facts, and that as a result we are justified in thinking that, as practically all people hold Care and Fairness as values, people hold those values regardless of their views on moral facts. There is reason though for thinking that valuing Loyalty, Authority, and Sanctity has a positive correlation with moralism.

Haidt has found that while all five foundational values - Care, Fairness, Loyalty, Authority, and Sanctity - are held practically universally, liberals hold Care and Fairness to be of great importance and the other three values to be of little importance, whereas conservatives hold all five values to be roughly equal, and very conservative people hold Loyalty, Authority, and Sanctity to be more important than Care and Fairness (see Fig. 2,

\footnotetext{
${ }^{22}$ Glover found that the morality of psychopaths is strongly based on what Haidt calls the conservative view of fairness, as desert, rather than the liberal view of fairness, as equality (Haidt 2012: 138, Glover 2014: 36), and on command morality, which is roughly equivalent to placing a high value on Authority. Glover also found that psychopaths also have a severe lack of empathy (Care) and fairness as equality (Fairness). (See section 4.2.)
} 
p. 30; there is of course a liberal-conservative spectrum rather than a dichotomy). I believe there is good reason to think there is a tendency for conservatives to believe more strongly than liberals in moral facts. If so, there is a spectrum of values from very liberal, which involves valuing the prosocial values relatively highly, to being very conservative, which involves valuing the more antisocial values very highly, and this spectrum appears to positively correlate closely with belief in moral facts, with very liberal people having little or no belief in moral facts and very conservative people having a strong belief in moral facts. If so, there is a positive correlation between the antisocial values and moralism.

As with most things in metaethics, the empirical evidence is slim. There is, however, a widespread tendency for conservatives to stress the importance of "objective morality" which is not seen among liberals. While moral subjectivism and moral relativism are, in metaethics, not kinds of moral skepticism (as beliefs in relative or subjective moral facts are beliefs in kinds of moral facts) moral relativism and moral subjectivism are popularly regarded not as belief in relative or subjective moral facts but as laissez-faire morality, or forms of practical moral skepticism (Sinnott-Armstrong 2006: 12). The popular thought is that without objective or absolute morality anything goes. Thus to nonphilosophers objective morality tends to be regarded as necessary for a moral success theory and relative and subjective morality are regarded as forms of moral skepticism.

This statement from the website Catholic Online is typical: 
unalienable rights endowed upon all - which has guided real progress in human history. (Fournier 2014, my emphasis) ${ }^{23}$

The entry "Liberal" from the website Conservapedia is also typical, though (like the quote above) it seems a little mad to a person familiar with modern history:

Most liberals ... support the censorship and denial of Christianity because of its strong moral values. Liberals who are a part of the secular left prefer atheism over the Christian faith, as atheism has no objective morality to hinder its big government plans. This lack of an objective morality, or moral relativism, was used as one of the main justifications by the Nazis and the Communists for their crimes against humanity. (My emphasis.)

The Catholic Education Resource Center tells us:

By her emphasis on the objectivity of moral principles the Church comes into direct conflict with most of the intellectual currents of the day. You have heard of "situation ethics", "existential ethics" and "the new morality". These tags refer to moral systems that are based on the relativity of values. What they say in the concrete is that any act, no matter what it is - stealing, adultery, fornication, murder, terrorism - can be just and good depending on the intention of the perpetrator and the circumstances of the act. (Baker 2014, my emphasis)

The website The Conservative Woman tells us of conservative philosopher Roger Scruton:

Scruton should be installed as the 'public philosopher'. His insights provide a much-needed contrast to the revered liberal orthodoxy of our day, which urges us all onto ever-bigger delusions regarding the virtues of big government and subjective moralities. (My emphasis.)

And it expresses the view that the absence of moral objectivism involves a laissez-faire approach to behaviour:

\footnotetext{
${ }^{23}$ The empirical claims in this and the following quotes are far-fetched at best, but it is the metaethical views expressed that are relevant.
} 
Nowadays, 'choice' seems to be used as a way out of the confines of morality. Somehow, if something is your choice, then it must be the right choice... There is no objective moral order; what is right or wrong is simply what you decide for yourself to be so.

There is a near endless supply of such conservative identification with belief in moral facts. The tendency is so strong that "moral values" is sometimes synonymous with "conservative values". For example, a study of reasons for voting choices in the 2004 US presidential election describes gay marriage and abortion as "moral issues", and war and the economy as "non-moral issues" (Hillygus and Shields 2005); but there's nothing about war and the economy that removes them from the realm of moral facts under any moral success theory I can think of. Rather, moral issues are identified as those social issues with which conservatives are most concerned.

There's nothing in principle stopping liberals from arguing for gay marriage and abortion rights as moral issues, but in practice this seldom happens. The study above identifies viewing gay marriage and abortion as moral issues with being opposed to them. Likewise, USA Today reported of the 2004 election that "President Bush's victory, the approval of every anti-gay marriage amendment on statewide ballots and an emphasis on 'moral values' among voters showed the power of churchgoing Americans in this election and threw the nation's religious divide into stark relief" (Associated Press 2004). Again moral issues are identified as conservative issues.

In contrast, it is very difficult to find liberals (other than moral philosophers) extolling the importance of moral facts. Liberal author Sam Harris is an exception, but Harris himself holds that liberals tend not to believe in moral facts, and the point of his book 
The Moral Landscape is largely to persuade them they are wrong. Harris states for example:

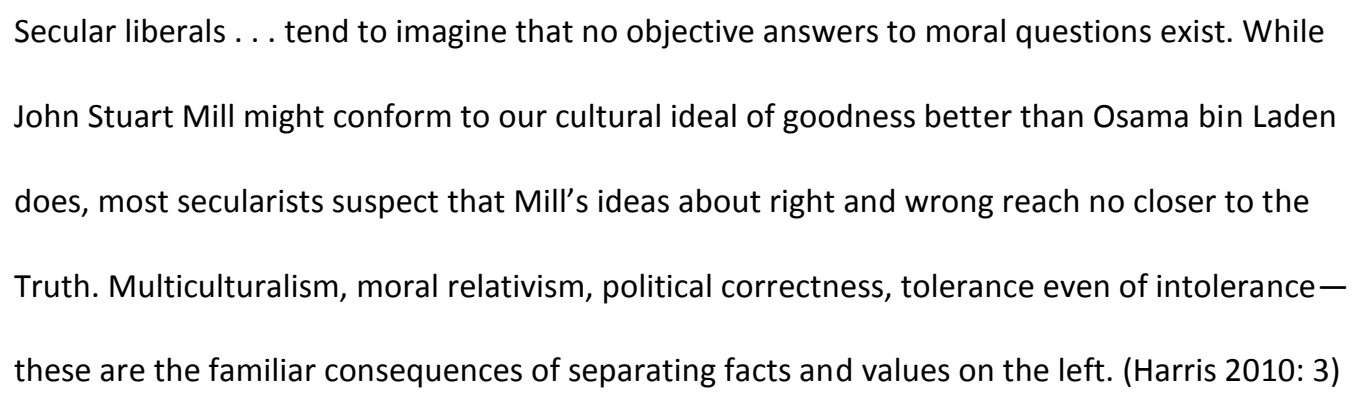

And Harris tells us that "not knowing what is right - or that anything can ever be truly right - often leads secular liberals to surrender their intellectual standards and political freedoms with both hands" (Harris 2010: 3, my emphasis).

It thus seems reasonable to conclude that there is a positive correlation between conservatism and moralism, and that as conservatism involves giving greater weight to Loyalty, Authority, and Sanctity than to Care and Fairness there is a positive correlation between moralism and the antisocial values. The existence of this correlation would not be falsified by the existence of many liberals - such as most moral philosophers - who believe in moral facts, or indeed by the existence of conservatives who do not believe in moral facts; I suggest that such people are outliers. Thus moralism appears to correlate positively with antisocial values and moral skepticism with prosocial values.

\subsection{Conclusion}

Thus there is a correlation between belief in moral facts and holding the predominantly antisocial values. While this is a state of affairs that liberal moralists will no doubt wish to reform - an endeavour which moral skeptics are likely to support - the fact remains that those who hold that morality is sufficient for prosociality, or that there is a positive 
correlation between morality and prosociality, are mistaken. Morality is not a sufficient condition of prosociality and there is good reason to think that, overall, it is an obstacle to it. This should help allay the fears surrounding moral skepticism.

In part 2 I will turn to giving a positive account of prosocial practical reason for moral skeptics. 
Part Two: Living Without Morality 


\section{Chapter Five: Humean Constructivism}

\subsection{Introduction}

We have seen that morality is neither necessary nor sufficient for prosociality, and that prosociality is thus not precluded by moral skepticism. The task remains of providing an account of how moral skeptics can make reflective decisions about prosocial actions - as skeptics cannot employ morality as a guide to answering normative questions, what are they to use?

I thus turn now from empirical philosophy to metaethics and practical reason. I will argue that Humean constructivism offers an account of practical reason that generates robust, stable, and deep prosocial normative reasons for prosocial moral skeptics and allows for the rigorous application of reason to values. I outline the theory in this chapter, and in chapter 6 show how it enables the application of rationality to values to determine practical reasons. ${ }^{24}$

Little has been written on Humean constructivism. The term appears to have been first used by Carla Bagnoli, in a passing mention (2002: 20), and gets another passing mention in Valerie Tiberius's (2008: 189) Since then three papers have been written on the topic by Sharon Street (Street 2008, 2010, 2012), one by James Lenman (2010), and one, unpublished, by Dale Dorsey (2008). Given these slim pickings, and given that only three of the papers attempt to give an account of what Humean constructivism consists of (Lenman 2010, Street 2010, 2012), Humean constructivism remains a theory in

\footnotetext{
${ }^{24}$ This chapter is based on a section of my (2013b).
} 
outline only. Further, Street and Lenman use Humean constructivism to refer to very different theories.

The version of Humean constructivism discussed here is Sharon Street's (2010, 2012). According to Street, constructivism holds that "the truth of a normative claim consists in that claim's being entailed from within the practical point of view" (Street 2010: 367). The practical point of view is occupied when a person values something:

$[T]$ he practical point of view is the point of view occupied by any creature who takes at least some things in the world to be good or bad, better or worse, required or optional, worthy or worthless, and so on - the standpoint of a being who judges, whether at a reflective or unreflective level, that some things call for, demand, or provide reasons for others. (Street 2010: 366).

Street identifies two main categories of constructivism, restricted constructivism and metaethical constructivism. Restricted constructivist views

specify some restricted set of normative claims and say that the truth of a claim falling within that set consists in that claim's being entailed from within the practical point of view, where the practical point of view is given some substantive characterization. (Street 2010: 367)

Rawls's theory of justice is such a restricted constructivist view, one in which the practical point of view has substantive characterization as the "original position", in which various judgments "implicit in the public political culture of a liberal democratic society" are embedded (Street 2010: 368).

In contrast to restricted constructivist views, metaethical constructivist views hold that "the truth of a normative claim consists in that claim's being entailed from within the practical point of view, where the practical point of view is given a formal 
characterization" (Street 2010: 369). A formal characterization of the practical point of view "does not itself presuppose any substantive values but rather merely explicates what is involved in valuing anything at all" (Street 2010: 369). Metaethical constructivist views may be Kantian or Humean. Under Kantian metaethical constructivism moral conclusions follow from within any practical point of view given a formal characterization: "moral values are entailed from within the standpoint of any valuer as such" (Street 2010: 369). Thus any person has reasons to act in a moral way (Korsgaard 1996: 125). Humean constructivist views deny that moral conclusions follow from within any practical point of view; "Instead, these views claim, the substantive content of a given agent's reasons is a function of his or her particular, contingently given, evaluative starting points" (Street 2010: 370). Thus under a Humean constructivist view practical reasons are only reasons entailed by the contingently-given practical point of view in combination with the non-normative facts.

Humean constructivism is, as Street sees it, anti-realist: "if one accepts metaethical constructivism, then one is an anti-realist about value in an important and traditional sense, holding that value is an attitude-dependent property" (Street 2012: 41). Whether or not attitude-dependence, or subjectivism, is a sufficient condition of anti-realism is highly contentious, and it is not possible to discuss the question here (See Joyce 2009: 1 for an overview). I will stipulatively follow the tradition Street refers to and hold here that subjectivism, and thus Humean constructivism, are forms of anti-realism.

\subsection{Values and Desires}

The Humean tradition of practical reason speaks of desires rather than values, but this is misleading. Desires exist on a spectrum from the most superficial to the most profound, 
from the desire to have a piece of chocolate, to the desire to be with the person one loves, to the desire to stay alive or see an end to world hunger. Thus the talk of desires tends to make the evaluative content of Humean views seem superficial and arbitrary: there is no clear distinction between desires that are fleeting, of little importance in relation to our other desires, and associated with a narrow range of emotions, and those that are life-long, of great importance in relation to our other desires, and associated with a wide range of affective attitudes. The lack of distinction between ends of the spectrum can lead anti-Humeans to regard the Humean view as inadequate to account for reasons for prosociality, as those reasons appear to be no stronger or more profound than our reasons for eating chocolate or having naps.

Street's Humean constructivism breaks from the Humean tradition in speaking of values rather than desires: "[I]f value is indeed conferred about the world by our attitudes . . . then it's the attitude of valuing, and not the attitude of mere desire, that does the conferring" (2012: 43). ${ }^{25}$ In this way Humean constructivism draws on the Kantian tradition as much as the Humean one (Street 2010: 370).

Street identifies three main differences between values and desires: discipline, the range and depth of associated emotional experience, and structural complexity. I'll discuss these in turn.

Firstly, Street holds that valuing is characterized by a discipline that desiring lacks (Street 2012: 43). She uses an example of Korsgaard's to illustrate this, in which a Civil War soldier is to have his leg sawn off without anaesthetic to save his life (Street 2010: 43,

\footnotetext{
${ }^{25}$ Street uses "valuing" interchangeably with "normative judgement" and "taking oneself to have a reason" (Street 2012: 44).
} 
Korsgaard 1997). The soldier desires to live, and knows that to live he must have his leg sawn off, but has no desire to have his leg sawn off. He desires the end, but not the means to that end. Contrast this with the language of valuing. If the soldier values living, and knows that to live he must have his leg sawn off, he must value having his leg sawn off; that is, he takes himself to have a reason to have his leg sawn off, unless he is making some kind of conceptual error (Street 2012: 43). “Valuing an end, in contrast to merely desiring it, constitutively involves valuing what one is fully aware is the necessary means to that end" (Street 2012: 44). ${ }^{26}$

Secondly, "the state of mind of valuing is characterized by a much broader array of conscious experience than is the attitude of mere desiring" (Street 2012: 44). Desire is associated with a narrow range of feelings which are characterized by a lack of depth and complexity, such as the feelings we have when thirsty, crave chocolate, or are sexually attracted to a stranger in a photograph. In contrast, valuing "is characterized by all the range, nuance, and depth of human emotion and feeling", and "can be directed at things we simultaneously find unpleasant, terrible, anguish-inspiring, and so forth" (Street 2012: 44).

Thirdly, "the attitude of valuing is characterized by greater structural complexity than the attitude of mere desiring" (Street 2012: 44). Desiring is typically directed at a single object or state of affairs, such as having a donut, being rich, or being liked. Valuing, in contrast, "often involves experiencing very specific features of the world as "calling for" or "demanding" or "counting in favor of" other very specific things" (Street 2012: 44).

\footnotetext{
${ }^{26}$ I would add the proviso "when one is aware of valuing that end" - we may not always be aware of what we value. This is often apparent when a person suffers greatly on losing someone or something she had taken for granted. Thus while it seems odd to speak of a person desiring something without being aware of doing so (as desire implies some immediate motivational force) it does not seem odd to speak of a person valuing something without being aware of doing so.
} 
Thus my values might mean that I take my having received a favour from a person as calling for my agreeing to a favour she asks of me now, or that I take a person being young and inexperienced is as counting in favour of my being patient with her, states of mind that are "very different from simply wanting a donut" (Street 2012: 44).

An important difference between values and desires not specified in Street's account is that values generate practical reasons for having other values and desires in a way desires do not. For example, if I have a desire to smoke a cigarette, that desire entails that I have reasons for a number of actions (purchasing cigarettes, finding my lighter, and so on), but does not entail that I have reasons for other desires in a significant way. In contrast, if I desire a cigarette but value my health, that value entails a reason to not desire the cigarette. The value of health also entails reasons for having particular desires, such as a reason to desire exercising, for example. People often attempt to shape their desires in keeping with their values in this way: those who value health try to diminish their desires for cigarettes, indolence, and junk food and increase or generate desires for exercise and healthy food.

The lack of distinction between values and desires may be one reason why morality is thought necessary for prosociality. If our practical reasons depend on our desires, then our reasons for prosociality depend on attitudes that may be fleeting, superficial, and of little importance even in relation to our other desires. If reasons for prosociality are based on deeply-held values, however, we have less to fear from the contingency of practical reasons. 


\subsection{Humean Constructivism and Obligations}

Humean constructivism rules out two kinds of obligations. Firstly, it rules out external obligations, obligations that involve a kind of external reason. External reasons are those which cannot be reached by a sound deliberative route from the motivations within a person's subjective motivational set (Williams 1981: 101, 1995: 35). According to Humean constructivism, any practical reason must be entailed by the contingently-given practical point of view, and thus is an internal reason. Under Humean constructivism then, obligations can only be those involving internal reasons.

Secondly, Humean constructivism rules out obligations that have a certain, very high degree of practical authority. That degree of practical authority is famously hard to capture, ${ }^{27}$ and it is not possible to fully explore this here; but Christine Korsgaard describes it well as a reason for an action such that the action must be done: "obligation cannot exist unless there are actions which it is necessary to do" (Korsgaard 1996: 16, $34) .{ }^{28}$ I will stipulatively call such obligations robust obligations to distinguish them from obligations without such special practical authority.

Humean constructivism entails practical reasons, but does not entail robust obligations. To illustrate a reason entailed by a practical point of view, take Rawls's example of a person who values counting blades of grass above all else (Rawls 1999: 379-380, Street 2010: 367). The person has a reason but, I contend, not a robust obligation to buy a calculator. By analogy a person who values particular ends will, under Humean constructivism, have reasons but not robust obligations to perform certain acts as means toward those ends. To fail to take the necessary means to achieve one's

\footnotetext{
${ }^{27}$ See for example (Joyce 2012: 7).

${ }^{28}$ Similarly, Mackie speaks of a kind of practical authority involving "not-to-be-doneness" (1977: 40).
} 
contingently-given ends may be practically irrational, but we don't have a robust obligation to achieve our own ends within a Humean framework.

Thus according to Humean constructivism a person who highly values, say, furthering the interests of others will have a reason, but not a robust obligation, to be prosocial. Her practical point of view may involve other, stronger values than prosociality, which would then override her reason to further others' interests. If the strongest aspect of her practical point of view is to act prosocially and she does not do so she will be acting in a practically irrational way; but we do not have any robust obligation to be practically rational. It does not seem to be something a person must do, under Street's Humean constructivist view.

\subsection{Humean Constructivism and Moral Skepticism}

Humean constructivism is not a form of moral skepticism: it does not entail a commitment either way on whether moral judgements are beliefs, on whether any moral judgements are true, or on whether any moral judgements are justified. As a naturalist, subjectivist, and anti-realist metaethical position Humean constructivism rules out certain kinds of moral success theory, such as non-naturalist, realist, objectivist, and Kantian theories. While this might constitute moral skepticism in the view of some, the criteria for moral success are not well-established, and a naturalist, anti-realist, Humean may hold her view to constitute a moral success theory; this is the case for some expressivists, for example (Lenman and Shemmer 2012: 4, Lenman 2010). A moral skeptic will not accept that naturalist, anti-realist, Humean accounts of moral facts are successful, but can accept that naturalist, anti-realist, Humean accounts of practical reason are successful. The moral skeptic can therefore accept Humean 
constructivism as a theory of practical reason without viewing it as a moral success theory. Humean constructivism and moral skepticism are thus compatible.

\subsection{Conclusion}

Humean constructivism thus involves two negative claims and a positive claim:

Negative Claim One: There are no realist moral facts.

Negative Claim Two: There are no robust obligations. ${ }^{29}$

Positive Claim: The only practical reasons are those entailed by the contingentlygiven practical point of view in combination with the non-moral facts.

In chapters 2, 3, and 4 we saw that all but a very small number (perhaps $4 \%$ ) of people have prosocial values. We saw in section 4.5 that the prosocial values most likely correlate with moral skepticism rather than with moralism. Given then that moral skeptics are likely to have practical points of view with strong prosocial content, under Humean constructivism moral skeptics have strong prosocial practical reasons. In the next chapter I will discuss the nature of such reasons in more detail.

\footnotetext{
${ }^{29}$ Street herself does not make this claim, but as I argue above, it seems entailed by her view.
} 


\section{Chapter Six: Prosociality and Personal Practical Reason}

\subsection{Introduction}

We have seen that almost all people have strong prosocial values, including, and perhaps especially, moral skeptics (chapters 3 and 4). Under a Humean constructivist view, moral skeptics thus have strong reasons for prosociality. But how reliable are these reasons?

I am regularly asked by those who know I am a moral skeptic not only why I attempt to act prosocially, but also how I can make decisions about what to do and how I can favour particular normative social theories. The implication seems to be that without morality to provide guidance the moral skeptic is adrift - she may have good intentions, but her prosociality is not subject to analysis or support in the way that moral judgements are thought to be.

In this chapter I will describe how Humean constructivism can be the basis for the application of reason to our values by employing ideal observer theory, the theory under which a person has most reason to do what she would want herself to do if she were fully rational. While this theory has its critics, it may be the least controversial theory of non-moral practical reason, founded as it is on the instrumental conception of rationality under which agents have reason to take the necessary means to their ends (Wallace 2014: 4, Railton 1986: 166). I will argue that this approach provides a framework for deliberation about our practical reasons that allows us to shape not only our practical choices but some of our values themselves. I hope to thus demonstrate 
that the practical choices of the prosocial moral skeptic need not be arbitrary and can be the result of rational deliberation.

I will first introduce the role of reason in Humean normativity as presented by Williams and Railton, and discuss its application to prosociality for moral skeptics, in sections 6.2 and 6.3. I will then discuss Michael Smith's extension of ideal observer theory to morality in section 6.4, and explain why Smith's account does not amount to a successful account of moral reasons. Finally, in section 6.5 I will show how moral skeptics can disagree with others' normative views.

\subsection{Practical Reason in Non-Moral Reasons Internalism}

Humean constructivism is a form of reasons internalism. Reasons internalism is the view that $A$ has a reason to $\phi$ only if " $A$ could reach the conclusion that he should $\phi$ (or a conclusion to $\phi$ ) by a sound deliberative route from the motivations that he has in his actual motivational set - that is, the set of his desires, evaluations, attitudes, projects, and so on" (Williams 1995: 35), where the subjective motivational set is roughly equivalent to what the Humean constructivist calls the practical point of view. Given the contingency of the practical point of view, it may seem as if practical reason is not subject to rational criticism (a view attributed to Hume with some justification (Hume 1740/1978: 2.3.3.6)) especially for the moral skeptic, who places no substantive restraints on what reasons agents might have.

The most important reply to this charge is that developed in chapters 2, 3 and 4: the practical point of view of the vast majority of people, including and perhaps especially moral skeptics, does in fact include strong prosocial values, despite the contingency of 
that practical point of view. However, it is also important to note that under Humean views of normativity practical reasons are not exempt from rational scrutiny.

Williams identifies four requirements for an agent's having full practical rationality: having all true relevant beliefs, having no false relevant beliefs, having full knowledge of relevant elements in the agent's subjective motivational set, and deliberating correctly (1981: 102-103). This amounts to an expansion of Hume's view that as reasons consist of a belief-desire pair, false beliefs relevant to that desire constitute practical irrationality (Hume 1740/1978: 463, Joyce 2013: 364-365).

To illustrate the application of Williams's criteria to the prosocial moral skeptic, take the example of vegetarianism. Say that a prosocial moral skeptic, $M$, has a concern for others that entails valuing their wellbeing to the extent that she wishes to avoid causing them unnecessary suffering, and that this value is not overridden by any relevant stronger values. Say also that the production of meat causes animals unnecessary suffering, that the consumption of meat by $M$ is unnecessary, and that there is a causal link between the consumption and production of meat. If $M$ does not know that meat production causes suffering, or does not know that she does not need to eat meat, or does not know that there is a causal link between the consumption and production of meat, and $M$ regularly purchases and eats meat, $M$ is in a state of practical irrationality. ${ }^{30}$ She is acting in contradiction to her values, because of her lack of true beliefs and/or the presence of false beliefs. Thus for moral skeptics - as for others -

\footnotetext{
${ }^{30}$ Practical irrationality means only acting against one's best reasons, whether one knows what they are or not. It does not imply a failure of epistemic normativity, such as not knowing something one would reasonably be expected to know.
} 
practical reason requires at least seeking information relevant to their values, as deliberately achieving ends requires knowing the means to those ends.

To illustrate Williams's third criterion, knowledge of one's own practical point of view, take the example of a fellow vegan with whom I was discussing the ownership of animals. My fellow vegan held that more important to her than animal suffering was whether animals are owned or not, as she felt that being owned is a more significant kind of harm. ${ }^{31}$ When given the theoretical situation in which an unowned animal is being tortured and that torture can be ended by gaining ownership of the dog, my fellow vegan said she would feel it important to purchase the dog. She thus concluded that she values the hedonistic wellbeing of animals more than their not being owned. The moral skeptic can likewise explore the content of her practical point of view through exercises in imagination and deliberation.

Williams outlines other possibilities for rational deliberation, all of which, being aspects of practical rationality rather than moral rationality, are available to the moral skeptic (Williams 1981: 104-105). One of these is the ordering of values by priority: having a reason to do something does not preclude having stronger reasons to do other things, which means conflicts between values can be resolved to some extent by deciding which one a person considers most important, as in the above example of a person who values both the freedom of animals and their hedonistic wellbeing. A second application of rationality is deliberation as to how multiple elements of the practical point of view can be satisfied, for example by time-ordering. A third is finding what Williams calls "constitutive solutions", for example finding what would be an effective available means

\footnotetext{
${ }^{31}$ This view may seem odd, but it has been popularized among vegans by Gary Francione (2008).
} 
to help political prisoners if one is concerned for their wellbeing and the promotion of democracy. Fourthly, one can use imagination to explore the outcomes of pursuing particular values; if a person values the wellbeing of animals to the extent that she wishes to avoid causing them unnecessary suffering, for example, she can imaginatively explore what it would be like to stop eating animal products, and consider the effects this might have in relation to her other values, such as her value of conventionality or of being as little trouble as possible at social gatherings. Williams also suggests the possibility of a person pursuing a course of action to gain a concrete sense of what it involves; a person who values the environment and the wellbeing of future generations to the extent that she wishes to minimizes greenhouse gas emissions, for example, might try not driving to work to find what it entails and determine its practicality. More complex information can be gained by pursuing a course of action as well; if a person wants to help the homeless but doesn't know how, volunteering for an organization that works with homeless people can be a way to learn what effective means of helping might be, even where the person is skeptical about the effectiveness of the particular organization she volunteers for: it is a foot in the epistemic door, so to speak.

Lastly, Williams points out that elements of the practical point of view can be removed by finding that a belief is false. For example, if a vegetarian learns that animals are not caused unnecessary suffering through meat production she may then lose the value she places on vegetarianism. I suggest that elements of the practical point of view can also be removed by focus on the desire side of the belief-desire pair. If a person desires to smoke, but also values her health, she can, through deliberation, arrive at the conclusion that her health is of greater value to her than smoking, and work to remove her desire 
to smoke by the normal means used to break the addiction to cigarettes, including a mental focus on the benefits of health and the drawbacks of smoking. Desires can also be added in accordance with values: a person who enjoys indolence but values her health can create a desire to exercise by "making" herself exercise regularly until she enjoys it, and by deliberately calling to mind the desired benefits of exercise and the undesired costs of indolence. Similarly, in the area of prosociality, a person who enjoys spending as much as possible of her disposable time watching what she regards as superficial television programmes but also values helping others can generate a desire to help others by "making" herself volunteer somewhere regularly until she enjoys it (it is often though not always the case that a value becomes a felt desire when stimulated through regular action), and focussing on the desired benefits of helping others perhaps feeling useful, being respected and liked, contributing to the wellbeing of others and of society, having integrity between values and actions, being able to think of oneself as a good and generous person - and the undesired costs of not doing so perhaps feeling useless, lacking integrity between values and actions, not being able to think well of oneself, and failing to work towards the kind of society one wants to live in. Thus a wide range of possibilities for rational deliberation and exploration are available to the prosocial moral skeptic, and there is no reason to think the moral skeptic's practical choices are arbitrary, unjustifiable, or based on fleeting desires. They can be as reasoned, coherent, justified, and based on deep, stable values as the moralist's can. Some of the moralist's tools are also available to the moral skeptic. For example, the prosocial moral skeptic, valuing both impartiality and the happiness of others, may value maximizing happiness and minimizing suffering. She can then engage in similar 
deliberative processes to the utilitarian, such as determining what constitutes happiness and suffering, what the means to maximizing happiness and minimizing suffering are, and decide on courses of action accordingly without the need to ascribe moral factuality to the conclusions of those deliberations.

Thus the moral skeptic can come to see she has prosocial reasons she was not aware of, come to see that she does not have antisocial reasons she thought she had, gain insight into what her deepest values are, and generate or eliminate desires and values to further her prosociality. The degree to which such practical deliberation is a process of self-knowledge should not be underestimated. ${ }^{32}$ What is involved in morally skeptical practical rationality is a very examined life, and thus, Socrates might say, one very much worth living.

\subsection{Practical Reason in Ideal Observer Theory}

The applications of rationality Williams describes suggest that we have most reason to do what we would want ourselves to do if fully rational. This approach leads naturally towards an ideal observer theory.

Ideal observer theory, in which the right action is one that would be approved of by an observer in ideal conditions, has a long history in Humean normative views, going back to Hume himself. ${ }^{33}$ Peter Railton (1986) employs ideal observer theory to provide an account of non-moral practical reason that offers a concise definition of practical

\footnotetext{
32 "It is entirely possible, and hardly infrequent, that an individual live out the course of a normal life without ever recognizing or adjusting to some of his most fundamental interests" (Railton 1986: 176). ${ }^{33}$ Ideal observer theory is attributed to Hume by, among others, Roderick Firth (1952: 336-341), Ronald Glossop (1967), Jonathan Harrison (1976: 114), and John Rawls (1971: 185-188). For a convincing argument that Hume did not hold an ideal observer theory, see Sayre-McCord (1994).
} 
rationality available to the moral skeptic. ${ }^{34}$ He notes that subjective interests (roughly identical to Williams's subjective motivational set and Humean constructivism's practical point of view) are not sufficient to determine what he calls non-moral goodness as they "frequently reflect ignorance, confusion, or lack of consideration", the kinds of flaws that Williams's proposed kinds of deliberation are intended to address.

Thus Railton proposes the notion of an objectified subjective interest.

Give to an actual individual $A$ unqualified cognitive and imaginative powers, and full factual and nomological information about his physical and psychological constitution, capacities, circumstances, history, and so on. $A$ will have become $A+$, who has complete and vivid knowledge of himself and his environment, and whose instrumental rationality is in no way defective. We now ask $A+$ not what he currently wants, but what he would want his non-ideal self $A$ to want or more generally, to seek - were he to find himself in the actual condition and circumstances of A. (Railton 1986: 173-174)

This amounts to an explication of Williams's requirements for full rationality: that an agent has all true relevant beliefs, no relevant false beliefs, full knowledge of her subjective motivational set, and correct deliberation.

As an example, Railton gives a traveller, Lonnie, who is feeling ill, and as a result has a craving for a familiar drink, milk. Lonnie desires to drink milk, but Lonnie-Plus (the fully rational version of Lonnie) would know that Lonnie is suffering from dehydration which would be alleviated by drinking water and worsened (in Railton's example) by drinking milk. Thus it is non-morally good for Lonnie to drink water, which he does not desire, rather than milk, which he does desire.

\footnotetext{
${ }^{34}$ For an earlier, moral account of ideal observer theory see (Firth 1952).
} 
Following this account of non-moral goodness Railton proposes that " $X$ is non-morally good for $A$ if and only if $X$ would satisfy an objective interest of $A^{\prime \prime}$, where an objective interest of $A$ is one that $A+$ would want $A$ to have (1986: 176).

Railton's example of non-moral goodness determined by higher-order desires shows irrationality on Lonnie's part only in holding a relevant false belief and not holding all relevant true beliefs, but we can assume (given widely-accepted Humean premises about practical reason) that Lonnie-Plus's full rationality would involve the other aspects of rationality Williams describes as well, such as full knowledge of his practical point of view and the relative importance of its elements.

The moral skeptic can thus employ Railton's account as a concise definition of what it is to have a practical reason, including a prosocial practical reason: put very simply, she has reason to do what she would want herself to do if fully rational. Railton himself describes this as "a notion that perfect moral skeptics can admit" (1986: 186).

\subsection{Smith's Moral Ideal Observer Theory}

\subsubsection{Introduction}

Railton uses his ideal observer theory as the basis of an account of moral realism, in which he proposes a reforming definition of moral goodness as "what would be rationally approved of were the interests of all potentially affected individuals counted equally under circumstances of full and vivid information" (1986: 190). Michael Smith offers an ideal observer account of practical reason very similar to that of Railton that he claims accounts for moral reasons: "To say that we have a normative reason to $\phi$ in certain circumstances $C$ is to say that we would want ourselves to $\phi$ in $C$ if we were fully 
rational" (Smith 1994: 182). This raises a question which the rest of this chapter will address: Why doesn't the account of prosocial practical reason given above amount to a moral success theory? If it does, it cannot be a view coherently held by moral skeptics, and my attempt to employ it in the service of moral skepticism will have failed.

Railton's view of moral realism involves an explicitly reforming account of morality (1986: 204), so the grounds for accepting or rejecting it seem to lie with the practicality and instrumentality of its acceptance. Smith's account by contrast is intended to show that ideal observer theory involves moral facts. Further, Smith's account is directly counter to Humean views of normativity, as Smith holds that under ideal observer theory Humean normativity is not the only kind of normativity: there are practical reasons that are entailed by beliefs alone rather than belief-desire pairs. It is Smith's account I address here, as it has the greater promise of showing that the account of practical reason I have offered is inappropriate for moral skeptics on the grounds that it actually refutes moral skepticism. A further benefit of investigating Smith's view is that, I will argue, some problems he raises with Humean normative views can be resolved by Humean constructivism's distinction between values and desires.

\subsubsection{Smith on Values and Desires}

Unlike the account I have given above (sections 5.2, 6.2, and 6.3), Smith's account marks a clear distinction between desires and values. He holds that values cannot be reduced to desires as Davidson (1980), Lewis (1989), and other Humeans suggest, because we can have desires that are not our values. Smith's primary reason for this is that our desires and values can conflict. For example, he says, a kleptomaniac may steal despite having resolved not to steal (Smith 1994: 133, Ayer 1982: 20); a heroin addict may take 
heroin though he does everything in his power not to take heroin (Smith 1994: 134, Frankfurt 1982: 87) ; a woman may have a sudden desire to drown her crying baby in the bath, despite valuing her child's life; and a generally benevolent squash player who loses shamefully may suddenly wish to smash her opponent in the face (Smith 1994: 134, Watson 1982: 101). In these cases agents desire certain things in contradiction to their values, and in spite of their values. From this Smith concludes that we may value something without desiring it and that values thus cannot be reduced to desires.

What this argument fails to appreciate sufficiently is firstly, the extent to which it is possible to have conflicting desires and desires of different strength; and secondly, that as persons exist over time, that a desire is paramount to a person at a particular point in time does not preclude her having another, even stronger, contradictory desire most of the time. Thus that a person desires to take heroin and also values not taking heroin does not mean that her values are not a kind of desire. It is perfectly possible to desire to take heroin and desire not to take heroin, and for the person's value to be a desire of the second kind; and perfectly possible for the desire to take heroin to be a temporary aberration, something the person feels, for example, in withdrawal or sudden despair, in contradiction to her temporally predominant desire not to take heroin. She may for example have a deep, stable, and long-lasting desire to have a happy and fulfilled life; she may also, through an unfortunate series of events, have become addicted to heroin or terribly depressed. The desire to take heroin is paramount and overwhelming at particular times, when it overrides her value of having a happy and fulfilled life or her 
belief that one is possible, but it does not follow that her value of her life is a belief and not a desire, as Smith would have it. ${ }^{35}$

As discussed in section 5.2, Humean constructivism holds that desires and values are on a spectrum of dispositional states, but that it is useful to differentiate between them. Under this view desires are often fleeting, are typically of little importance in relation to other desires, and are associated with a narrow range of emotions, whereas values are typically long-standing (even life-long), of great importance in relation to a range of desires, and associated with a wide range of affective attitudes. Values thus exist on the same spectrum of dispositional states as desires, but are characterized by greater discipline, greater range and depth of associated emotional experience, and greater structural complexity (Street 2012: 42-44). Importantly, we tend to think of a desire as a felt dispositional state whereas a value need not be felt, though it often is - for most of the time I don't feel the value I place on living a long life, as it seldom comes to mind, but I nevertheless do value living a long life, and that value is a kind of desire. Humean constructivism thus provides a framework that accounts for the difference Smith notes between values and desires while justifying the Humean view that values and desires are both dispositional states.

To use an example of Smith's, a woman who loves her children but loses her temper with her crying baby may have a sudden desire to harm it. But this desire is fleeting, of

\footnotetext{
${ }^{35}$ Smith holds that the addict values, but does not desire, giving up heroin. It's perfectly possible for a heroin addict to not value the effects of going without heroin, but Smith's example is of a person who does everything in his power to not take heroin, so we can assume she does have desires such as to live a long and fulfilled life. It is possible that this hypothetical person tries to quit heroin because of a desireindependent belief that her living a long and fulfilled life is valuable; but Smith cannot hold that this desire-independent belief exists just because the addict tries to quite heroin, unless he specifies that she has no desire to give up heroin, in which case the example would help his argument no better than simply stipulating that there can be desire-independent beliefs about what we should do, which would beg the question against Humean normativity.
} 
little importance in relation to her other desires (she does not, let us say, have a desire to cause harm in general, let alone to her child), and perhaps involves a single affective attitude, such as anger or frustration. She can nevertheless at the same time value the wellbeing of her baby, because the desire to harm it is a short-term aberration in the long-standing, stable, deep, and affectively-complex dispositional state which constitutes her value of the child's wellbeing. This is clear when we consider how practical reason applies in such cases. Under a Humean constructivist view, the woman has a reason to drown her baby, namely that doing so would satisfy a sudden urge. But as she will continue to exist after she has drowned her baby, when her long-standing value of her child's wellbeing - along with the many complex affective states it involves - will return to the forefront of her mind, she has a stronger reason not to drown her baby. Under a straightforward maximizing Humean view of practical reason drowning the baby would be practically irrational.

We can thus see that Smith's categorization of value as something completely distinct from desire and something other than a dispositional state is unjustified: that values are not always strongly felt and not always motivationally overriding does not mean they are not a kind of desire.

Smith's view of value underlies his claim that practical reasons are categorical: he claims that the categorical nature of practical reasons is shown by their independence from dispositional states, as, he claims, in cases such as the frustrated mother above (Smith 1994: 174). But as we have seen, such cases do not involve the independence of practical reasons from dispositional states, but involve only short-lived, unstable, affectively-narrow aberrations in dispositional states. Smith thus fails to show that 
practical reasons are categorical. This means that a key step in his move from ideal observer views of practical reason to moral facts fails, as he holds that categoricity is a necessary component of morality (Smith 1994: 84, 85).

\subsubsection{Smith on Desire Satisfaction Maximization}

Smith argues that Humean normativity is flawed in its maximizing approach to desire satisfaction. He holds that the Humean can't justify harmonizing first- and higher-order desires by changing first- rather than higher-order desires as, for example, David Lewis suggests (Lewis 1989), as maximizing desire satisfaction does not involve discrimination between the orders of desires, and sometimes a first-order desire will be stronger than contradictory higher-order desires.

I agree that this is the case. However, Humean normativity need not rely on the distinction between different orders of desire. If we take the Humean constructivist approach we can distinguish instead between desires and values, and hold that where desires and values conflict we have most reason to resolve that conflict in favour of values.

Recall that values are on the same spectrum of dispositional states as desires, but tend to be longer-lasting, more stable over time, have greater affective range and depth, and affect a wider range of other desires. So under the Humean constructivist conception of practical reason satisfaction of the practical point of view will tend to be maximized by harmonizing desires with values, rather than the other way around.

To again use an example of Smith's, a decent person who becomes frustrated playing squash and feels a sudden desire to smash her opponent in the face will not maximize 
satisfaction of her practical point of view by giving that desire preference over her values, as the immediate gain from fulfilling her desire to attack her opponent will not outweigh the long-lasting losses from losing a friend and the reputation of being a decent person, being prosecuted for assault, feeling dreadful for having acted terribly, spending time in prison, and so on - losses incurred because she values her friend's life, being liked, loved and respected, being able to regard herself as a decent person, and living in freedom with her family rather than in prison. Similarly, in the example of the loving parent who becomes enraged with her child, she will not maximize satisfaction of her practical point of view by drowning the baby, as when her rage ends she will be guilty, distraught, bereaved, and face a long term in prison - costs incurred by her valuing her child's life, being a mother, being able to regard herself as a decent person, being liked, loved and respected, living in freedom with her family rather than in prison, and so on. It is these values which, under Humean ideal observer theory, mean that the squash player and the mother have most reason not to act with sudden violence: if they were fully rational and fully informed they would not want themselves to act violently, given the values they hold, as doing so will be detrimental to the ends within their own practical points of view.

According to Humean constructivism these things can go the other way: a person who, unlike most people, doesn't value the lives or wellbeing of her friends and family, thinking of herself as a decent person (or who is able to think of herself as a decent person despite being grossly violent), being liked and loved by others, or living in freedom rather than prison, might have most reason to smash her squash opponent in the face or drown her baby when enraged. Such people certainly exist - some 
psychopaths for example - so if Humean constructivism is correct the contingency of practical reasons may be an unpleasant fact. But it is important to remember that the vast majority of people do have values that outweigh their occasional desires towards significant violence, and that under Humean normativity such people have strong practical reasons against such actions.

\subsubsection{Smith and the Fully Egoistic Agent}

An important test of the ability of Smith's account of practical reason to provide moral reasons is its ability to deal with the theoretical possibility of a fully rational and fully antisocial agent, such as a fully rational person with only egoistic values. Like the Humean ideal observer theorist, Smith holds that a person has most reason to do that which she would want herself to do if she were fully rational. But in contradiction to Humean views, which hold that practical reasons depend on contingently-given values, Smith holds that all fully rational persons would want themselves to act in what he calls platitudinously morally correct - effectively, prosocial - ways, regardless of their practical points of view. Humeans give counter-examples such as Gibbard's Ideally Coherent Caligula (Gibbard 1999: 145), Putnam's Rational Nazi (Putnam 1981: 212), or Hume's own Sensible Knave (Hume 1751/1983: 81), fully rational agents with only egoistic and antisocial values. Humean views hold that "one can indeed value torturing others above all else and be entirely coherent in doing so" (Street 2010: 371, cf. Williams 1981: 112). ${ }^{36}$ Smith holds that such agents do in fact have non-egoistic reasons to act in characteristically moral ways. If he is correct, Humean constructivism is false.

\footnotetext{
${ }^{36}$ There is support for Humean views from empirical psychology, which has found that psychopaths often have a high degree of rationality (Lilienfeld and Arkowitz 2007).
} 
Smith's theory, like other ideal observer theories, holds that what the agent has reason to do is what she would want herself to do were she fully rational. Thus, he says, when considering whether the fully egoistic person has most reason to act egoistically, we ask whether if a fully rational agent were in the position of the fully egoistic agent including having the agent's complete lack of prosocial values - she would want herself to act egoistically. The Humean, as we have seen, would say that she would: a fully rational agent who has only egoistic values has no reason to act prosocially (though she might act prosocially as a means to her own gain).

Smith's first argument against the Humean view is as follows:

[T] he flaw in [the successful criminal's] reasoning lies in the premise from which he begins: that he has a normative reason to gain wealth no matter what the cost to others. For, as we have seen, this is equivalent to the claim that fully rational creatures would want that, if they find themselves in the circumstances of the successful criminal, then they gain wealth no matter what the cost to others. And the successful criminal's opinion notwithstanding, it seems quite evident that we have no reason to believe that this is true. Fully rational creatures would want no such thing. (Smith 1994: 195)

But it does not seem quite evident to the Humean at all, or she would not be a Humean. The Humean holds that we do have reasons to believe the fully rational and fully egoistic person would want to enrich herself without concern for others, those reasons constituted by the arguments for Humean normativity (keeping in mind that for the fully rational agent to be in the circumstances of the successful criminal would involve having the values and desires that the criminal has). Those arguments can't be countered by simply stating that it's evident that they're false. 
Smith specifies that his appeal to obviousness is not intended to disprove the Humean view, as, he admits, "Perhaps we are all mistaken about what fully rational creatures would want." But he suggests that we are as justified in dismissing the rationality of the egoistic person out of hand as we are in thinking that the sun will rise tomorrow despite the opinions of prophets of doom (Smith 1994: 195). However, that the sun will rise tomorrow is a view with a vast amount of very solid evidence to support it, and proclamations of the imminent end of the world have little-to-nothing in the way of rational justification. Arguments against Humean normativity have nothing like the weight of evidence behind the view that the sun will rise tomorrow, and arguments for Humean normativity have a great deal more justification than eschatological proclamations, so the analogy does not hold. Further, it is not clear who the "we" are who all think that fully rational persons without prosocial values have prosocial reasons. Again, Smith is directing his argument at the Humean position, and Humeans do not think that such persons have such reasons. It is not even clear that people in general have the anti-Humean view of normativity that Smith assumes they do (see for example (Sarkissian et al. 2011)).

Smith also holds that we have no reason to think that the successful, fully egoistic agent would be without reasons to act prosocially, as that agent can give no account of why her view should be privileged over those of others (1994: 195). However, Smith is presenting this point specifically against the views of practical reason put forward by Philippa Foot (1972) and Gilbert Harman (1985: 39-40) (Smith 1994: 193), and a fully egoistic agent can at least give either Harman's or Foot's accounts, the specific arguments Smith is addressing in this passage. Under these accounts the fully egoistic 
agent has reason only to act egoistically (again, acting prosocially for her own benefit aside). Smith needs to show why Foot's and Harman's accounts are wrong. By simply stating that the egoist can give no such account Smith is begging the question against them.

Finally, Smith holds that the fully egoistic agent is irrational in only acting egoistically because that agent disagrees with folk wisdom: "he rejects the very idea that the folk possess between them a stock of wisdom about such matters against which each person's opinions should be tested. And yet, ultimately, this is the only court of appeal there is for claims about what we have normative reason to do" (Smith 1994: 196).

Smith's theory of morality thus grounds moral reasons in rationality but holds folk wisdom to be the ultimate arbiter of rationality. This is odd for several reasons. Firstly, the process of reasoning and argument which Smith advocates as the means to determine moral facts (1994: 5-6, 187-189) becomes irrelevant, as all we in fact would need to know under Smith's theory is what folk wisdom says; for if we reasoned our way to a conclusion other than that of folk wisdom, we would have to view ourselves as wrong, or at least unjustified, as folk wisdom is the only court of appeal for questions about normative reasons. Secondly, that process of argument and deliberation which Smith advocates becomes unnecessary, as in most cases we already know what folk wisdom says, and for those issues for which we don't we need polls, not argument or reflection. Thirdly, Smith's view entails moral relativism, as folk wisdom varies between time and place. (Smith believes there has been moral progress (Smith 1993, 1994: 188), but as folk wisdom always and necessarily holds itself to be right, the judgment of folk wisdom will always be that it is an improvement on the past; so Smith cannot appeal to 
folk wisdom as evidence of moral progress.) But Smith's view is intended, among other things, specifically to refute moral relativism (1994: 34-35). Lastly, Smith's account of morality is intended to be in accord with platitudes about morality (1994: 37-39). But surely it is a platitude of morality that the majority of people, even the very great majority, is not always right about morality, and can be very wrong indeed. Surely it is a platitude of morality that everyone was wrong to have once thought slavery and the oppression of women right, for example. Perhaps the relevant platitude is that the popular moral consensus is right now; but I doubt that many people would hold that the popular consensus is even now the ultimate arbiter of moral questions.

It is clear that Smith doesn't believe that the popular consensus is always right: "Perhaps we are all mistaken about what fully rational creatures would want." But although this allows that a person who disagrees with the consensus can be right, it does not allow that she can be justified in believing herself to be right. If she can be justified in believing herself to be right, then, in contradiction to Smith, there is a court of appeal for normative questions more authoritative than folk wisdom. It is then such a court of appeal that Smith needs to employ in order to refute the Humean position, rather than folk wisdom.

The most charitable interpretation of Smith's argument from folk wisdom might be that it is not the popular consensus itself that show the impossibility of the fully rational antisocial agent, but the arguments that folk wisdom puts forward that do so (this would be in keeping with his view that convergence on moral questions indicates truth). Smith says that the flaw in the fully antisocial agent's thinking is that "he doesn't feel the force of the arguments that come from others" (1994: 196). This interpretation would not 
help Smith's argument however. If folk wisdom provides arguments that show that the fully egoistic agent is acting irrationally in being a successful criminal, Smith can use those arguments to counter the arguments of Foot, Harman, and Humeans in general, and need not appeal to folk wisdom. If there are a number of arguments supporting folk wisdom against the fully antisocial agent, Smith could at least provide that argument which he considers the strongest. As it is, Smith provides no such argument whatsoever, and thus leaves those who do not hold folk wisdom to be the ultimate arbiter of moral questions without reason to believe that there is a flaw in the rationality of the fully egoistic criminal.

\subsubsection{Conclusion}

Smith fails to show that ideal observer theory entails moral facts. The moral skeptic can thus employ ideal observer theory without contradiction. In addressing Smith's arguments against Humean normativity we have seen the virtues of the Humean constructivist account of value and desire.

\subsection{How Can Moral Skeptics Disagree With Others' Normative Views?}

If, as the Humean constructivist moral skeptic holds, our normative reasons depend on our contingently-given practical points of view, how can the moral skeptic disagree with others on normative questions under a Humean constructivist framework?

Dale Dorsey discusses a related issue in his paper Relativism and Constructivism: $A$ Humean Response (2008). Dorsey identifies the problem with moral relativism as the problem of efficacious criticism. "If Hitler, for instance, acted perfectly morally from the standpoint of his own framework, my concern is not that I can't genuinely disagree with him, but rather that my criticism of him is infelicitous". This is also a contributing factor 
to the fears surrounding moral skepticism; not only might we not have sufficient reasons for prosociality, it is thought, but if a person were somehow to have sufficient reasons for prosociality she would still have no justification for criticizing others with antisocial views.

However, this fear is based on the assumption that the values that entail reasons for prosociality are subject to a great width of variation among persons. If, as Humean constructivism holds, normative reasons are entailed by the practical point of view, then if we are unable to criticize a person's actions or beliefs by the standards of prosociality it can only be because that person does not have the values that entail reasons for her to be prosocial. Thus if there is such a thing as human nature, and that nature includes prosocial values, the problem of infelicitous criticism is greatly reduced, if not solved: practically all persons have prosocial values, so if we wish to criticize others or persuade them towards prosociality we can do so within the framework of their own practical point of view.

Hume saw some such human nature as necessary for moral discourse:

The notion of morals implies some sentiment common to all mankind, which recommends the same object to general approbation, and makes every man, or most men, agree in the same opinion or decision concerning it. It also implies some sentiment, so universal and comprehensive as to extend to all mankind, and render the actions and conduct, even of the persons the most remote, an object of applause or censure, according as they agree or disagree with that rule of right which is established. (ECPM IX.I.V.)

While it seems unlikely that any such universal values exist that entail reasons for all persons, it is possible that such values are sufficiently common to be what Dorsey calls 
"a robust species-wide regularity" (Dorsey 2008: 18). As we have seen in chapters 2-4, there is a very small percentage of people - psychopaths for example - who do not have prosocial values and thus do not have reasons for prosociality, but the great majority of people do have such values and so do have such reasons, and can be held to account for the harm or benefit they cause to others by their own standards. If so, there is no significant obstacle to our talking about what people should and should not do in regard to prosociality: such statements will be relative to values that practically all people have. $^{37}$

\subsection{Conclusion}

It is sometimes said that moral skepticism involves the inability to arrive at stable, reflective normative decisions. We have seen that this is not the case. Under a Humean constructivist framework the moral skeptic has substantial resources of deliberation and has ideal observer theory as a measure of normative reasons. Smith argues that ideal observer theory justifies moral facts, which would make it unavailable to the moral skeptic; we have seen though that Smith's argument for moral facts in ideal observer theory is unsuccessful.

\footnotetext{
${ }^{37}$ For an excellent account of the resources available to the prosocial moral skeptic in defending and critiquing normative views, see Flynn (2000).
} 


\section{Chapter Seven: A Case Study: John Stuart Mill}

\subsection{Introduction}

There is a common view that the utilitarian theory of John Stuart Mill is intended to be realist about moral value and to involve a strong kind of practical obligation (Korsgaard 1996: 51, 78, Skorupski 1989: 289, West 2007: 32, Sinnott-Armstrong 2014: 6, Brink 2008: 2.12). If this view is true, then Mill cannot be a moral skeptic. I will argue though that there are compelling reasons to think that Mill is a moral skeptic, as, I hold, he is a noncognitivist and a constructivist, not a realist, about value. ${ }^{38}$

Mill not only developed extremely influential normative theories - his theory of liberty and his version of classical utilitarianism - but was an active reformer, Member of Parliament, abolitionist, public intellectual, and early supporter of women's rights (Capaldi 2004: 306, 321, 334-339). Mill thus demonstrates that firstly, a moral skeptic can lead a strongly prosocial life; and secondly, that moral skeptics can develop prosocial normative theories compatible with moral skepticism.

This chapter argues for two negative theses and two positive theses. The negative theses are firstly, that Mill is not a moral realist, and secondly, that he does not believe in certain kinds of obligations, those involving external or robust obligations (for definitions of these terms see section 5.3). ${ }^{39}$ The positive theses are firstly, that Mill is a noncognitivist and thus a moral skeptic, and secondly, that his metaethical position can be interpreted as a Humean constructivist view. There are four aspects of this argument:

\footnotetext{
${ }^{38}$ This chapter is based on a section of my (2013b).

${ }^{39}$ For some moralists disbelief in such obligations is sufficient for moral skepticism (Korsgaard 1996: 16, 34).
} 
Mill's noncognitivism, his view that moral theories are not capable of proof, his account of practical reasons for utilitarianism, and the constructivist nature of his argument for the value of happiness. I argue that a Humean constructivist reading of Mill's utilitarian theory is reasonable and strengthens Mill's argument from desire for the value of happiness, an important but notoriously weak aspect of his theory.

I will not argue that Mill saw himself as a noncognitivist or moral skeptic or had a conception of Humean constructivism or anything similar. It seems likely that his metaethical view is not thoroughly worked out at all and is indeterminate or perhaps even confused. However, his view involves, I hold, what we would now call noncognitivism, and is thus a kind of what we now call moral skepticism. And a Humean constructivist reading is consistent with so much of what Mill says about his theory that I believe it can serve at least to clarify Mill's view and to find coherence where it has previously been thought lacking. Thus I will argue that Mill's metaethical position includes several components that are not necessarily related - constructivism about value, noncognitivism, subjectivism, and the absence of external or robust obligations which are all features of, or compatible with, moral skepticism and Humean constructivism, and that Humean constructivism serves as a useful framework with which to understand Mill's metaethical views.

In arguing that Mill's position is constructivist about value, noncognitivist, subjectivist, and excludes external or robust obligations, I am not suggesting that these characteristics are each necessary or sufficient for Humean constructivism, but am instead taking an abductive approach. The question is, what metaethical view can best account for these characteristics? And I believe the answer is Humean constructivism. 
Rather than repeat my reservations about the coherence and determinacy of Mill's metaethical view throughout this chapter I will argue for a Humean constructivist reading without reiterating these qualifications, but would ask the reader to keep them in mind.

The final qualification to add is that I will not argue that any of Mill's views are true.

\subsection{Mill's Noncognitivism}

This section concerns my thesis that Mill is a moral skeptic, as noncognitivism is a form of moral skepticism (see section 1.3). ${ }^{40}$ Humean constructivism is anti-realist but neutral between anti-realist views of moral judgement; noncognitivism therefore does not imply Humean constructivism, but is compatible with it.

Mill is a prescriptivist noncognitivist, a view according to which moral judgments and statements are species of prescriptive judgements and statements, even where they appear to be indicative (van Roojen 2013: 2.2). It is important that commitments associated with other noncognitivist views are not necessarily entailed or required by the view I ascribe to Mill. Neither should Mill's prescriptivism be read as necessarily holding much in common with Carnap's or Hare's prescriptivist views (Carnap 1937, Hare 1952).

The argument that Mill is a noncognitivist has been made by several scholars, notably Alan Ryan: ${ }^{41}$

\footnotetext{
${ }^{40}$ This section is indebted to Christopher Macleod's (2013) argument against a noncognitivist reading of Mill.

${ }^{41}$ Ryan, and Henry West after him, do not use the term noncognitivism or refer to Mill as a noncognitivist, but that Mill is a noncognitivist seems the only reasonable interpretation of their position on his view of moral language. See also (Ryan 1974: 101-104).
} 
[T] he vindication of Mill's statement that there can be no proof of ultimate ends rests in the fact that a proposition like "Happiness is the supreme good" is not, as its grammatical form suggests, a statement at all, but an imperative- "Seek happiness"-and is not susceptible of either truth or falsity ... (Ryan 1970: 190)

Ryan's position is supported by Henry West:

Aren't there moral truths: It is wrong to kill, to steal, to deceive, to coerce, except in special circumstances? ... According to Mill's analysis of moral language, these are disguised as statements of fact, but are more like imperatives: thou shalt not kill; thou shalt not steal, etc. They are precepts or rules, rather than statements of fact. (West 2007: 31)

Ryan's and West's prescriptivist reading of Mill's metaethics is based on a straightforward reading of his statements: "morality itself is not a science, but an art; not truths, but rules"; the results of inquiry into morality "do not express themselves in the indicative, but in the imperative mood" (Mill 1844/1967: 319-320, System of Logic VI.xii.1). ${ }^{42}$

Mill's noncognitivism is based on his distinction between art and science. He holds that whereas science deals in truths and facts, art deals in precepts and rules (Mill 1844/1967: 312). Mill holds morality to be an art, and the language of morality to thus be properly prescriptive rather than descriptive:

The language of science is, This is, or, This is not; This does, or does not, happen. The language of art is, Do this; Avoid that. Science takes cognisance of a phenomenon, and endeavours to discover its law; art proposes to itself an end, and looks out for means to effect it. (Mill 1844/1967: 312)

\footnotetext{
${ }^{42}$ References to the System of Logic are by book, chapter, and section number.
} 
Against the noncognitivist reading of Ryan and West, Christopher Macleod argues not for a cognitivist interpretation but an agnostic one: "I do not believe there is a safe reading of Mill's metaethics on the basis of textual evidence" (Macleod 2013: 217). Macleod gives several reasons why the noncognitivist interpretation should not be accepted.

One reason is that ascribing noncognitivism to Mill is anachronistic (Macleod 2013: 217218). This objection might be justified if the ascription in question uses the term noncognitivism with all the implications of its modern usage; Mill did not think in modern metaethical terms. It seems reasonable however to use current terminology for convenience. It is possible to do so in order to identify and illuminate features of philosophers' thought - even, or perhaps especially, those they may not have been fully aware of - without ascribing to them beliefs they did not have. Just as absolute music has explanatory power in reference to Mozart's music even though the term was coined over 50 years after his death, concepts like noncognitivism may have explanatory power in regard to Mill's work even though he was not familiar with them.

A second objection to the proposed noncognitivism of Mill is that Mill referred to there being "propositions", "premises" and "assertions" of art (Macleod 2013: 215). Macleod suggests this indicates that Mill may have believed moral judgments to be truth-apt. However, although in Mill's view there are no rational justifications for ends, there are rational justifications for means (see section 7.3); as means is the area of practical reason to which Mill holds that rational justification applies, we can presume that means is the area of practical reason in which Mill holds that facts exist. 
Macleod gives the following quote as an example of Mill's reference to facts of art: "it is true, that in the largest sense of the words, even these propositions [of art] assert something as a matter of fact" (2013: 215, System of Logic VI.xii.5). That statement does not imply cognitivism when seen in context, however. Mill precedes the statement by saying:

Every art has one first principle, or general major premise, not borrowed from science; that which enunciates the object aimed at, and affirms it to be a desirable object... These are not propositions of science. Propositions of science assert a matter of fact: an existence, a coexistence, a succession, or a resemblance. The propositions now spoken of do not assert that any thing is, but enjoin or recommend that something should be. They are a class by themselves. A proposition of which the predicate is expressed by the words ought or should be, is generically different from one which is expressed by is, or will be. (System of Logic VI.xii.5)

It is here that Mill states what Macleod believes to imply cognitivism, that "it is true, that in the largest sense of the words, even these propositions [of art] assert something as a matter of fact". But Mill follows the statement by saying that "The fact affirmed in [these propositions of art] is, that the conduct recommended excites in the speaker's mind the feeling of approbation"(System of Logic VI.xii.5). Thus to summarize the passage, Mill states that ends are not the proper subject of science, but of art; that propositions of art are not descriptive, but prescriptive; but that propositions about ends do have descriptive content in a very broad sense, in that they affirm the fact that the speaker has certain approbative sentiments. This is entirely in accordance with noncognitivism and does not support a cognitivist reading of Mill.

Macleod also argues against Mill's noncognitivism from the lack of motivation. He claims that noncognitivism is a solution to problems that Mill didn't face: 
So, when Mill gives details of the motivations for drawing a distinction between art and science, they are not motivations for a noncognitivist position. Issues of queerness, motivational deficiency, and epistemic contact with the moral never arise. (Macleod 2013: 216)

It is true that Mill does not discuss these issues as motivations for his distinctions between art and science, but they are nevertheless issues of great importance to Mill, and it is thus possible that they underlie his noncognitivism. Mill discusses motivational problems at length (see section 7.4; chapter 3 of Utilitarianism is devoted to this topic), he discusses moral sense theory (U I.3), and he discusses moral queerness. Mill states for example that there is a

sort of mystical character which, by a tendency of the human mind of which there are many other examples, is apt to be attributed to the idea of moral obligation, and which leads people to believe that the idea cannot possibly attach itself to any other objects than those which, by a supposed mysterious law, are found in our present experience to excite it. (U III.4)

Roger Crisp writes that

Mill was an empiricist, who believed that our understanding of the world must be based ultimately entirely on the evidence of our senses. That is why he is so contemptuous of the moral sense view. The moral sense would have to be quite unlike any of the other senses, which have physical correlates. (Crisp 1997: 69)

And Mill argues against the position of "a person who sees in moral obligation a transcendental fact, an objective reality belonging to the province of "things in themselves"'” (U III.6). Mill thus does address "issues of queerness, motivational deficiency, and epistemic contact", and this seems sufficient to motivate a noncognitivist position on his part. 
There is then good reason to think that Mill is a noncognitivist, and thus a moral skeptic.

His noncognitivism is compatible with a Humean constructivist view.

\title{
7.3 Mill's View of Proof in Moral Theory
}

Humean constructivism holds that practical reasons are only those reasons entailed by the contingently-given practical point of view. There can then, according to this view, be no proof for any moral theory: there are no facts of the matter about whether a person should or should not hold the ultimate values she holds within her practical point of view. Mill's position on proof for moral theories is subjectivist and thus anti-realist, and is compatible with the Humean constructivist view.

Mill discusses the possibility of a proof of his theory early in Utilitarianism:

\begin{abstract}
It is evident that this cannot be proof in the ordinary and popular meaning of the term. Questions of ultimate ends are not amenable to direct proof ... If, then, it is asserted that there is a comprehensive formula, including all things which are in themselves good, and that whatever else is good is not so as an end but as a means, the formula may be accepted or rejected, but is not a subject of what is commonly understood as proof. $(U \mathrm{I} .5)^{43,44}$
\end{abstract}

Humean constructivism observes a distinction between means and ends: means are subject to proof, as which means will accomplish particular ends is a factual matter; but ultimate ends are not subject to proof, as they are contingently-given aspects of the particular practical point of view. (Non-ultimate ends can be shown to be entailed or not by ultimate ends, and so are subject to proof in that regard.) This is Mill's position, described in the System of Logic. As discussed in section 7.2, Mill makes the distinction

\footnotetext{
43 "U" refers to Utilitarianism. References to Utilitarianism are by chapter and paragraph numbers.

${ }^{44}$ This agrees with Hume's view that "the ultimate ends of human actions can never, in any case, be accounted for by reason, but recommend themselves entirely to the sentiments and affections of mankind, without any dependence on the intellectual faculties" (ECPM, Appendix I.V).
} 
between ends and means by referring to the province of the former as art and the province of the latter as science:

The art proposes to itself an end to be attained, defines the end, and hands it over to the science. The science receives it, considers it as a phenomenon or effect to be studied, and having investigated its causes and conditions sends it back to art with a theorem of the combinations of circumstances by which it could be produced. (System of Logic VI.xii.2)

Mill includes morality in this categorization as an art, not a science (System of Logic VI.xii.1). All arts have first principles, the ends they are to achieve, which are assumed rather than rationally demonstrated:

Every art has one first principle, or general major premise, not borrowed from science; that which enunciates the object aimed at and affirms it to be desirable. The builder's art assumes that it is desirable to have buildings; architecture (as one of the fine arts) that it is desirable to have them beautiful or imposing. The hygienic and medical arts assume, the one that the preservation of health, the other that the cure of disease, are fitting and desirable ends. (System of Logic VI.xii.5)

Mill uses the analogy of health again in Utilitarianism to argue that ultimate ends are assumed and not subject to proof or falsification: "The medical art is proved to be good by its conducing to health; but how is it possible to prove that health is good?" (U I.5). ${ }^{45}$ The principle of utility, then, is a principle that a person may or may not hold as an end, depending on her contingently-given practical point of view. Science can show how the end can be achieved, but cannot determine whether it should be an end or not.

Despite the impossibility of proving ends, and thus of proving the principle of utility, Mill writes that "Considerations may be presented, capable of determining the intellect

\footnotetext{
${ }^{45}$ Presumably Mill could answer this question himself, by saying that health is good because it produces happiness, but that there is no way to show that happiness is good because it is valued as an end in itself.
} 
either to give or withhold its assent to the doctrine" (U I.5). This Mill calls "a larger meaning of the word "proof"" (U I.5). ${ }^{46}$ The "assent" cannot be epistemological, in the sense of believing the principle of utility to be a fact, as Mill holds morality to be not a factual matter. It must be the practical meaning of "assent" that is in play: acquiescence, consent, or compliance. As Ryan writes,

what is envisaged is that, if the intellect is given enough information of one kind and another, the will will be determined in a utilitarian direction ... This view of Mill explains why he should be so concerned with the problems of the sanctions of the principle; in trying to prove the principle ... Mill is offering us motives which will induce us to live by it. (Ryan 1970: 208)

Mill's view of proof is thus in keeping with a Humean constructivist view, in which ultimate ends are aspects of the contingently-given practical point of view, and as such are not subject to proof or disproof. The nature of Mill's reasons for assent to the principle of utility is the subject of the next section.

\subsection{Mill's View of Practical Reason}

As discussed in section 5.3, under Humean constructivism there are practical reasons, but not external or robust obligations. Classical utilitarianism is sometimes thought to be greatly demanding (Sinnott-Armstrong 2014: 6), but I will argue that Mill's theory fits a Humean constructivist reading in excluding external or robust obligations.

It has been noted by several philosophers that Mill's theory does not involve the existence of a certain kind of obligation (or perhaps obligations at all). This has often been regarded as an unintentional failure on Mill's part. Ryan notes that Mill's justification of utilitarianism "is open to the Kantian objection that it may be an

\footnotetext{
${ }^{46}$ The clarity of Utilitarianism is not helped by Mill's continued use of the word "proof" in this sense.
} 
argument that will get us to want to do what, it may be, is right, but it cannot get us to see that we ought to do what is right" (Ryan 1970: 209). Korsgaard notes of the theory that "The bare fact that you accept the proof doesn't seem to obligate you to utilitarian conduct", and concludes that Mill fails to answer the question of why certain actions are necessary (Korsgaard 1996: 80, 85-86; cf. Crisp 1997: 82). David Brink notes that Mill attributes the existence of utilitarian practical reasons to the individual conscience, but does not address the question of whether or not people should have such consciences (Brink 2008: 2.12).

I contend that rather than trying to show that there are external or robust obligations and failing, Mill does not believe in such obligations at all, and this is the reason he makes no attempt to demonstrate their existence. As noted in the previous section what he does try to do, given his view that there is no proof for the principle of utility, is give us motives which will persuade us to follow it. This is in keeping with a Humean constructivist view, in which there are no external or robust obligations and in which practical reasons are entailed from the contingently-given practical point of view. Under this reading, Mill attempts to persuade the reader that her practical point of view entails reasons for utilitarianism.

Mill obscures his position on obligation by failing to clarify his terms. It is not immediately obvious whether by "obligation" Mill means the motivation for utilitarian action, or the authority and source of the principle of utility, which might provide reasons for utilitarian action other than those of motivation (Brink 2008: 2.12). However, the chapter in which Mill's discussion of the issues takes place is titled Of the Ultimate Sanction of the Principle of Utility (my emphasis), and Mill speaks only of factors that 
motivate utilitarianism and does not give any argument for the existence of external or robust obligations. He thus equates obligations with sanctions, which are enforcements of rules with reward or punishment, pleasure or pain (U III.1, West 2007: 69). ${ }^{47}$ It seems reasonable then to take Mill on his own terms: rather than trying to establish robust or external obligations for utilitarianism and failing, Mill is trying to establish motivations for utilitarianism. Whether he succeeds or fails cannot be addressed here; I suggest only that his argument be evaluated on its own terms.

Mill identifies two kinds of motivation for prosociality, internal and external (not to be confused with reasons internalism and externalism or motivation judgement internalism and externalism (Rosati 2006: 3.2, Darwall 1983: 54)). External motivations include "the hope of favor and the fear of displeasure from our fellow creatures or from the Ruler of the universe, along with whatever we may have of sympathy or affection for them, or of love and awe of Him" (U III.3). Given Mill's probable agnosticism ("[T]he whole domain of the supernatural is ... that of simple Hope" (Mill 1873/1964: 483)) and his tendency to pander to religious sentiments for fear of losing his audience (Wilson 2012: 160), we can reasonably ignore the theistic component. What is left for non-theists in the way of external motivation is the individual's concern for the approbation and disapprobation of others, and sympathy and affection for them; or "The whole force ... of external reward and punishment" and "all that the capacities of human nature admit of disinterested devotion" to others (U III.3). These reasons do not appeal to external obligations, but only to aspects of the contingently-given practical point of view.

\footnotetext{
${ }^{47}$ Crisp notes that "'Sanction' was a technical term in eighteenth and nineteenth-century ethics, defined by Bentham as a source of the pleasures and pains that motivate people to act" (Crisp 1997: 91).
} 
Mill identifies internal motivation - the "ultimate sanction" - as "a subjective feeling in our own minds" that consists of "a pain, more or less intense attendant on violation of duty, which in properly cultivated moral nature rises, in the more serious cases, into shrinking from it as an impossibility" (U III.5, III.3). This could be an indication of external obligations for a moral sense theorist, who might view conscience as knowledge about moral facts; as Mill was not a moral sense theorist (U I.3), there is no reason to think that the subjective feeling of "pain" that accompanies certain acts is such an indication. It is instead best understood as a product of the contingently-given practical point of view. It could be produced by the awareness that we have acted against our own practical reason, or the product of empathy, the awareness that we have done something harmful or failed to do something helpful, perhaps in contradiction to our stated values.

Mill holds that the conscience is based most strongly on benevolence, "the feeling of unity with our fellow creatures" (U III.2, III.10). Benevolence is thus the primary aspect of the practical point of view to which Mill appeals in promoting utilitarian practical reasons. Mill holds benevolence to be a natural product of the need to live in society ( $U$ III.10) and, with the external motivators, to be strengthened and honed by education:

\footnotetext{
The whole force therefore of external reward and punishment, whether physical or moral, and whether proceeding from God or from our fellow men, together with all that the capacities of human nature admit of disinterested devotion to either, become available to enforce the utilitarian morality, in proportion as that morality is recognized; and the more powerfully, the more the appliances of education and general cultivation are bent to the purpose. (U III.3)
}

Benevolence, the desire for reward and the fear of punishment are contingently-given aspects of the practical point of view. Mill's view of the motivations for utilitarianism 
thus fits a Humean constructivist reading: the source of utilitarian practical reasons is entailment by the practical point of view, practical reasons are proportionate to the strength with which people hold the values that entail them, and whether or not people hold utilitarianism as a practical point of view is not subject only to chance but is capable of reinforcement, enforcement, and cultivation. There is no appeal to, or justification of, external or robust obligations.

Mill accepts that his theory involves no external reasons, and thus that a person whose practical point of view does not include values that entail utilitarian reasons has no reasons for utilitarianism other than punishment and reward: "Undoubtedly this sanction [conscience] has no binding efficacy on those who do not possess the feelings it appeals to" (U III.5). Mill denies however that belief in external obligations has more motivational force than the subjective conscience:

There is, I am aware, a disposition to believe that a person who sees in moral obligation a transcendental fact, an objective reality belonging to the province of "things in themselves," is likely to be more obedient to it than one who believes it to be entirely subjective, having its seat in human consciousness only. But whatever a person's opinion may be on this point of ontology, the force he is really urged by is his own subjective feeling, and is exactly measured by its strength. ${ }^{48}$ (U III.6)

The problem then that the absence of external obligations may seem to propose for Mill's utilitarianism applies to other theories as well; although persons without conscience have no reasons for utilitarianism "neither will these persons be more obedient to any other moral principle than to the utilitarian one" (U III.5). Thus there is

\footnotetext{
${ }^{48}$ Recall that, as discussed in section 7.2, Mill does not believe in moral facts, so by "moral" in this and other passages he must mean something like "prosocial".
} 
no answer to the person who asks "why am I bound to promote the general happiness? If my own happiness lies in something else, why may I not give that the preference?" (U III.1). This difficulty will always present itself unless we have been shaped by education to have "the feeling of unity with our fellow creatures ... deeply rooted in our character" (U III.2).

To see in this a failed argument for external or robust obligations is a mistake. Mill speaks only of contingent, subjective motives for action - dismissing the idea of moral obligation as "a transcendental fact, an objective reality" - and accepts the contingency of utilitarian reasons that results.

This contingency might seem to make arguing for utilitarianism hopeless. Mill notes that "moral associations which are of artificial creation, when the intellectual culture goes on, yield by degrees to the dissolving force of analysis", and that utilitarianism would suffer the same fate "if there were no leading department of our nature, no powerful class of sentiments" to support it (U III.9). He goes on to say though that

there is this basis of powerful natural sentiment; and this it is which, when once the general happiness is recognized as the ethical standard, will constitute the strength of the utilitarian morality. This firm foundation is that of the social feelings of mankind - the desire to be in unity with our fellow creatures, which is already a powerful principle in human nature, and happily one of those which tend to become stronger, even without express inculcation, from the influences of advancing civilization. (U III.10)

Thus the social instincts are contingently-given, but that does not mean they are rare or arbitrary; they are a robust species-wide regularity, being not universal but held to varying and significant degrees by the great majority of people. 
There is though a motivation for utilitarianism even for those who are devoid of benevolence: " $[\mathrm{H}]$ owever imperfect may be their own practice, they desire and commend all conduct in others toward themselves by which they think their happiness is promoted"; "even if he has none of it [the feeling that the good of others must be attended to] himself, he is as greatly interested as anyone that others should have it" (U III.3, III.10). In this view the egoistic person's happiness is best served by a society which acts to promote happiness in general, as that is the means by which her happiness is most likely to be promoted. Support for utilitarian practical reasons is thus, if Mill is right, entailed even from an egoistic practical point of view.

Finally, there is in Mill's argument for utilitarianism a political perspective. Alan Ryan describes this as "a Hobbesian argument about the nature of the rules which selfinterested [persons] could agree to as rules to regulate their conduct with each other" (Ryan 1970: 196). Mill writes:
Now society between human beings, except in the relation of master and slave, is manifestly impossible on any other footing than that the interests of all are to be consulted. Society between equals can only exist on the understanding that the interests of all are to be regarded equally. (U III.10)

Thus Ryan suggests that Mill's answer to the question he gives in Utilitarianism - "If my own happiness lies in something else, why may I not give that the preference?" - is "largely to suggest that everyone else will simply combine to make sure that he does give the general happiness the preference" (Ryan 1970: 201). ${ }^{49}$ There is more to this aspect of Mill's argument than a Hobbesian view however; Mill precedes this argument by saying that "the social feelings of mankind - the desire to be in unity with our fellow

\footnotetext{
${ }^{49}$ For a detailed discussion of Mill's Hobbesian argument see (Ryan 1970: 196-201).
} 
creatures" are "already a powerful principle in human nature, and happily one of those which tend to become stronger ... from the influences of advancing civilization", which implies that our pleasure in being in harmony with others is a motive to consider their interests.

Thus Mill's reasons for the adoption of utilitarianism are benevolence, the fear of punishment and disapprobation and the desire of reward and approbation, the desire to live in a society in which one's happiness is promoted, the desire to live in harmony with others, and the need for rules which persons can agree to as a means to regulate their conduct in society. The strongest of these motives is a benevolent conscience, and the strength of a benevolent conscience can be improved by education and cultivation. There is no appeal to external or robust obligations. Mill's view of practical reasons fits a Humean constructivist view, in which practical reasons are only those reasons entailed by the contingently-given practical point of view in combination with the non-normative facts. These are also all reasons the prosocial moral skeptic can endorse.

Korsgaard wonders, given Mill's acceptance of the contingency of practical reason, what the point of his argument could be:

\footnotetext{
But on reflection, it is really very obscure what Mill thinks this argument can accomplish ... What the argument about the sanction actually seems to do is to prove that if there were any utilitarians then their morality would be normative for them. But why on earth should Mill's readers care about that? . . If they have already endorsed utilitarianism presumably they already find it normative. So what does Mill think he is doing? (Korsgaard 1996: 85)
}

It is true that Mill does not make this clear, but I believe a Humean constructivist reading provides some probable answers. 
Firstly, Mill believes that people do not always realize that their practical points of view entail utilitarian practical reasons. After noting that moral beliefs had, before utilitarianism, lacked a clearly identified first principle, Mill writes:

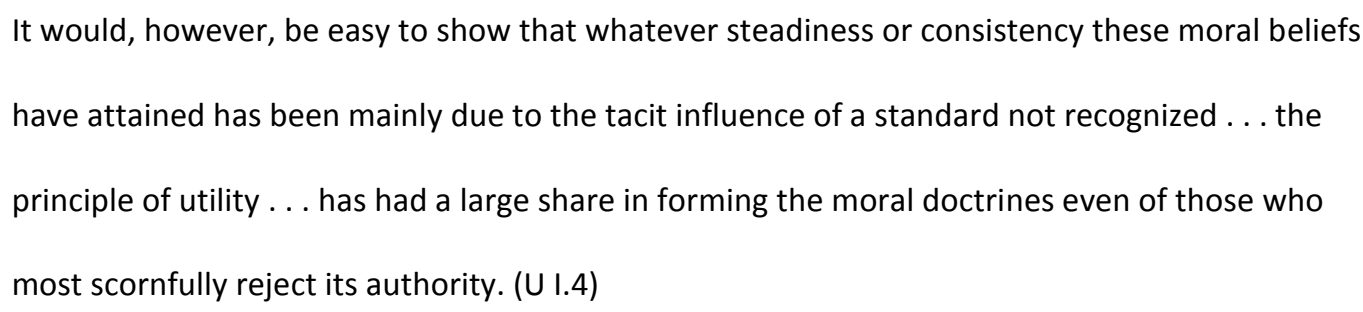

Thus non-utilitarians tend to be mistaken about the basis of their own judgements. This constitutes practical irrationality: we are unlikely to achieve our ends if we are mistaken as to what they are.

Secondly, Mill nowhere suggests that people's practical points of view are exclusively utilitarian; on the contrary, he acknowledges that the utilitarian conscience is "not innate but acquired" (U III.8), and that the utilitarian conscience can be strengthened by education and cultivation (U III.3). Mill can thus be read in part as urging people to cultivate their own utilitarian consciences and further utilitarianism through the education of others.

Finally, it must be remembered what Mill's purpose in promoting utilitarianism was. As Julia Driver writes, "If anything could be identified as the fundamental motivation behind the development of classical utilitarianism it would be the desire to see useless, corrupt laws and social practices changed" (Driver 2012: 12). The justifications for such laws and practices were, in Mill's view, non-utilitarian; if Mill could persuade his readers that their deepest social values were in fact utilitarian ones, he could persuade them to reject such justifications and support reform. Before utilitarianism, Mill tells us, ethics 
was "not so much a guide as a consecration of men's actual sentiments" (U I.4), and Mill is clear that our actual sentiments are not all benevolent; the "consecration" of such sentiments as moral obligations can only be detrimental in Mill's view, and the acceptance that happiness is the end of ethics only beneficial.

If Mill was, as I have argued, not attempting to persuade his readers of the existence of any robust or external obligations these several reasons seem sufficient to explain the purpose of his argument for the sanctions for utilitarianism, and are in keeping with a Humean constructivist view in which a person's practical rationality depends in part on her proper understanding of what her practical point of view involves. Mill seeks to persuade the reader that her practical point of view is, where social values are concerned, a utilitarian one. No appeal to moral facts is involved.

\subsection{Mill's Argument from Desire}

Mill's argument from desire for happiness as the only good has been subject to what one philosopher describes as "justified universal execration" (Quinton 1989: 64). This view is based on the understanding that Mill is a realist about happiness as a value (Korsgaard 1996: 51, 78, Skorupski 1989: 289, West 2007: 32), but fails to justify that realism.

I suggest that Mill does not fail to justify realism about the value of happiness, because he does not try; rather, Mill is a constructivist about value. Mill's argument is strong under a Humean constructivist reading, and this reading makes more sense of his position than the common view that he argues for realism and fails. 
I do not argue that it is decisive that Mill is committed to a constructivist view of value; as with most aspects of Mill's metaethics there is a significant degree of ambiguity and even obscurity. I will argue though that there are good reasons for a constructivist reading of Mill, and that such a reading makes sense of otherwise problematic aspects of his argument.

That Mill has a constructivist view of value makes his theory compatible with Humean constructivism, but does not commit him to it, though his view that desire is the basis of value is in keeping with a Humean approach. For brevity I will not repeat the qualifications expressed here, but would ask that the reader keep them in mind.

Mill's argument for utilitarianism involves three primary claims: ${ }^{50}$

1. The hedonic psychological claim: People solely value happiness for its own sake.

2. The hedonic metaphysical claim: Happiness is the sole good. Corollary: A right act is one which promotes happiness.

3. The utilitarian normative claim: Agents should act to promote happiness and reduce suffering.

Mill bases the utilitarian normative claim on the hedonic metaphysical claim, a move which is unproblematic. However, he bases the hedonic metaphysical claim on the hedonic psychological claim, a move which appears very problematic. An examination of

\footnotetext{
${ }^{50}$ These three claims do not represent the whole of Mill's argument, omitting most importantly the aggregation premise - that as each person's happiness is a good to that person the general happiness is a good to the aggregate of persons (U: 35-36), which is not relevant to my purposes here. For formulations of the complete argument see (Brink 2008: 2.11) and (Quinton 1989: 59-60).
} 
Mill's argument indicates that he had something very much like Humean constructivism in mind, and, if so, the problem is resolved. ${ }^{51}$

Mill sums up utilitarianism succinctly:

The creed which accepts as the foundation of morals "utility" or the "greatest happiness principle" holds that actions are right in proportion as they tend to promote happiness; wrong as they tend to produce the reverse of happiness. (U II.2)

This is a metaphysical claim, as it states that rightness exists and is equivalent to happiness-promotion. It is reasonable to assume that some positive practical reasons are implied by the existence of actions that are right and some negative practical reasons by the existence of actions that are wrong. If so, the statement can be reformulated as "Agents should act to promote happiness and to reduce unhappiness", the utilitarian normative claim.

While Mill's definition of the principle of utility is both metaphysical and normative, Mill founds it on a strictly metaphysical basis:

[T] he theory of life on which this theory of morality is grounded [is] that pleasure and freedom from pain are the only things desirable as ends; and that all desirable things . . . are desirable either for pleasure inherent in themselves or as means to the promotion of pleasure and the prevention of pain. (U II.2)

This is a statement of the hedonic metaphysical claim. Mill bases the hedonic metaphysical claim on the hedonic psychological claim:

[T] he sole evidence it is possible to produce that anything is desirable is that people do actually desire it ... No reason can be given why the general happiness is desirable, except that each

\footnotetext{
${ }^{51}$ I am leaving aside the question of whether the hedonic psychological claim is true.
} 
person, so far as he believes it to be attainable, desires his own happiness ... we have not only all the proof which the case admits of, but all which it is possible to require that happiness is a good: that each person's happiness is a good to that person, and the general happiness, therefore, a good to the aggregate of all persons. (U IV.3)

Mill thus bases the utilitarian normative claim on the hedonic metaphysical claim, which in turn is based on the hedonic psychological claim. The latter, highly problematic step is the one with which I am concerned. Mill's argument that happiness is desirable because people desire it is, on the face of it, very poor (as famously criticized by Moore (1903/1948: 66-67)). The word "desirable" does have a sense in which it means simply "capable of arousing desire", and in this sense if a person desires something it is desirable by definition. This does not seem to be the sense that Mill has in mind though, as it does not follow from this sense of "desirable" that what is desired is good. It is usually assumed that Mill has in mind the other sense of "desirable", meaning, as Moore put it, "what ought to be desired" (Moore 1903/1948: 67). But surely we cannot conclude what people ought to desire from what they do desire. Mill's hedonic psychological claim therefore appears incapable of supporting his hedonic metaphysical claim.

Mill's argument for the hedonic metaphysical claim is however strong if interpreted under a Humean constructivist view. Under Humean constructivism there are no values independent of the practical point of view, so any statement that something is valuable can only mean that it is valued within a practical point of view. Thus under Humean constructivism to say that $X$ is valuable means only that $X$ is valuable to some person or persons. There is no such thing as something that ought to be valued. Likewise under Humean constructivism to say that $X$ is desirable means only that $X$ is desirable to some 
person or persons. There is no such thing as something that ought to be desired. As

Street puts it, "Things are valuable ultimately because we value them" (2012: 40, cf. 2008: 207) . Likewise, things are desirable only because we desire them.

This is in fact what Mill's argument states. Here is the argument again with implications of the negative thesis - that there are no objective goods - in bold.

[T] he sole evidence it is possible to produce that anything is desirable is that people do actually desire it. If the end which the utilitarian doctrine proposes to itself were not, in theory and practice acknowledged to be an end, nothing could ever convince any person that it was so. No reason can be given why the general happiness is desirable, except that each person, so far as he believes it to be attainable, desires his own happiness ... we have not only all the proof which the case admits of, but all which it is possible to require that happiness is a good: that each person's happiness is a good to that person, and the general happiness, therefore, a good to the aggregate of all persons. (U IV.3)

I have added italics to highlight the important point that Mill claims not to have shown that happiness is an absolute or objective good, but only that each person's happiness is a good to that person. ${ }^{52}$ I have included in this version of the quote the sentence "If the end which the utilitarian doctrine proposes to itself were not, in theory and practice acknowledged to be an end, nothing could ever convince any person that it was so", commonly ignored in discussions of Mill's argument, which refers to Mill's view that ends are not subject to proof and again strongly implies a constructivist, not a realist, view of value.

\footnotetext{
${ }^{52}$ The problematic aggregation premise does not follow easily from this reading, but does not follow easily from any other reading I know of either. It is not possible to discuss possible solutions here, but a Humean constructivist reading doesn't hang on the aggregation premise; a Humean constructivist reading, like some other views, can hold that Mill is simply wrong that happiness is aggregative.
} 
A Humean constructivist interpretation of Mill's metaphysical premise renders an otherwise very weak argument coherent, as under a Humean constructivist view the hedonic psychological claim entails the hedonic metaphysical claim, which describes a practical point of view. That practical point of view entails utilitarian practical reasons, the utilitarian normative claim.

Although under Humean constructivism the practical point of view is contingently-given, Mill's hedonic psychological claim, if true, represents a characteristic of people in general - a robust species-wide regularity - which entails utilitarian practical reasons for practically all people, particularly under Mill's social-instinct and Hobbesian arguments discussed in section 7.4 in which all people have an interest in promoting a society which treats interests equally. Mill's hedonic psychological claim is an empirical claim that may be true or false; it is not possible to discuss that here. But if the premise is true, under a Humean constructivist reading his argument for utilitarianism is strong. A Humean constructivist reading of Mill is thus an attractive alternative to the common view that he holds a realist view of value which he badly fails to justify.

A realist interpretation of Mill's argument might hold that he does not see the desirable as being entailed by desiring, but rather, sees desiring as the only kind of evidence for the desirable, which has its status independently of what people value. There is an indication that this is Mill's view at the beginning of the chapter:

It has already been remarked that questions of ultimate ends do not admit of proof, in the ordinary acceptation of the term. To be incapable of proof by reasoning is common to all first principles, to the first premises of our knowledge, as well as to those of our conduct. But the former, being matters of fact, may be the subject of a direct appeal to the faculties which judge of fact - namely, our sense and our internal consciousness. Can an appeal be made to the same 
faculties on questions of practical ends? Or by what other faculty is cognizance taken of them? (U IV.1).

We might think then that Mill believes that there is some sense by which we can apprehend whether something is an ultimate end, and this sense is our desire.

However, Mill does not go on to say anything about a desirability that exists independently of people's desires. Although it is possible that Mill had an argument that desire is a guide to what is desirable but that desirability is not constituted by desiring, he makes no such argument. I believe charity requires that we assume that had Mill believed in such a realm of the desirable, one independent from people's desires, he would have mentioned it. If we take what Mill does say, rather than what he doesn't, we seem to have a constructivist view of value. This view means that Mill's comment that desire is the sole evidence for desirability in the way that seeing something is the only evidence for visibility and hearing something the only evidence for audibility is a mistake if taken as an exact parallel (U IV.3). But the analogy is commonly taken to not be intended as an exact parallel (e.g. Crisp 1997: 75, West 2007: 78).

Another possible argument against a constructivist reading of Mill's theory of value is that in chapter 2 of Utilitarianism he accepts that people's desires can go astray (U II.7). If desires can go astray, it would seem that the desirable cannot only be that which is desired. However, the manner in which they go astray, Mill believes, is in valuing pleasures of lower quality over pleasures of higher quality. The reason for his judgement that the higher pleasures are of higher quality is that they are desired more by those familiar with them; Mill believes that no one who has experienced both kinds of pleasures prefers the lower (U II.6). That there is something amiss in a person's 
preferring a lower desire to a higher one lies then, for Mill, only within the person's desire for pleasure: in preferring the lower desire she is pursuing pleasure of lower quality than can be attained elsewhere (U II.6, 8). The person thus holds a false relevant belief, that a lower desire gives more pleasure than a higher one. There is here no indication of any value lying beyond what people desire, and thus the practical irrationality Mill describes is in keeping with a constructivist interpretation. ${ }^{53}$

\subsection{Conclusion}

Mill is, then, a moral skeptic, holding that moral judgements cannot properly be factual, and he does not believe in external or robust obligations. He rejects the possibility of proof for moral theory, and sees no reasons for a person adopting utilitarianism other than her contingently-given values and the approbation, censure, reward or punishment she is subject to by others. Mill nevertheless promotes utilitarianism as a practical theory on the basis that people generally have benevolent sentiments and desire happiness. This seems a very slim basis indeed for the utilitarian normative claim. Under a Humean constructivist interpretation however, Mill's theory is robust. Mill appeals to the practical points of view of his readers, which he believes to involve a desire for happiness and, generally, a concern for the happiness of others. This practical point of view entails utilitarian practical reasons for practically all people, and also entails reason to support the cultivation of the utilitarian practical point of view through reward, sanction, cultivation, and education. A Humean constructivist reading of Mill's utilitarian theory is thus reasonable and presents the theory in a strong and coherent form. This

\footnotetext{
${ }^{53}$ This view in which a person's practical rationality lies in valuing what she would value if she were better informed is in keeping with the Humean ideal observer theory discussed in chapter 6.
} 
demonstrates the possibility of robust prosociality for moral skeptics under a Humean constructivist view, both in personal action and in developing normative social theories. 


\section{Chapter Eight: Conclusion}

A moral skeptic can expect to regularly encounter the assumption or charge that moral skepticism precludes sufficient justification for prosocial behaviour, such as consideration for the interests and welfare of others. This thesis has been an attempt to refute that view.

We have seen that a key factor in the view I respond to is the conflation of two meanings of morality. One meaning is prescriptive, and refers to moral facts. The other meaning is descriptive, and refers to behaviour ordinarily regarded as morally right, such as acting with concern for others. The failure to distinguish between the two meanings of morality facilitates the assumption that skepticism about moral facts involves or entails skepticism about practical reasons for the consideration for others. The first step in my argument was thus to distinguish between these two meanings, calling only the belief in moral facts morality and calling platitudinously moral behaviour prosociality.

Part 1 consisted of empirical philosophy. We saw in chapter 2 that the primary elements of prosociality are empathy and fairness, the absence of which is characteristic of Antisocial Behaviour Disorders. I then argued in chapter 3 that morality is not necessary for prosociality. We saw that dramatic historical improvements in prosociality have not been accompanied by an increase in morality, and have likely been accompanied by a decrease. We also saw that evidence from psychology indicates that practically all people hold the primary prosocial values of empathy and fairness, whether or not they believe in moral facts. Finally, we saw that the lives and characters of moral skeptics are 
not characterized by antisociality, and in some cases display unusually high degrees of prosociality. Thus we can have prosociality without morality.

Chapter 4 demonstrated that morality is not sufficient for prosociality. I first showed that psychopaths seem to believe in moral facts as much as people in general do. I then examined Hinckfuss's arguments that morality is antisocial. While most of these arguments are unsuccessful, there are good reasons to think Hinckfuss right that morality is an obstacle to conflict resolution. This and other antisocial outcomes result from the phenomenon of moral conviction, in which people who believe themselves to have a moral mandate tend to be unable to rationally evaluate the fairness of processes and tend to believe their ends justify antisocial means. Finally, we saw that three of the moral values of Haidt's Moral Foundations theory, Loyalty, Authority and Sanctity, correlate both with antisociality and with belief in moral facts. There is, therefore, good reason not only to think that morality is not sufficient for prosociality but also to think it is an obstacle to it. That morality is not only not necessary or sufficient for prosociality but often, and perhaps even mostly, an obstacle to it should allay the practical fears surrounding moral skepticism.

In part $2 \mathrm{I}$ addressed the question of how a moral skeptic can hold prosocial normative beliefs that are robust, stable, and formed by reason as well as by values. Chapter 5 offered Humean constructivism as an account of practical reason compatible with moral skepticism, one that offers a framework for the application of rationality to values. I developed this account in chapter 6 , showing how ideal observer theory, in reasons internalism and Railton's account of non-moral goodness, gives the moral skeptic rational criteria for prosocial practical reasons. 
Railton develops his ideal observer theory into a reforming account of moral facts, and Smith argues that ideal observer theory involves moral facts without the need for a reforming definition of morality. This raises the possibility that ideal observer theory in fact refutes moral skepticism and is thus not available to the moral skeptic. However, we saw that Smith's account fails to give an account of such facts, as it relies on unsuccessful arguments against Humean normativity and fails to show that a fully egoistic agent has reasons to act in what we would usually consider to be morally correct ways. In the final section of chapter 6 we saw that under Humean constructivism moral skeptics can disagree effectively with others' normative views.

Finally, chapter 7 offered a case study, that of J. S. Mill. Mill not only led an unusually prosocial life, but developed an extremely influential prosocial normative theory in his version of utilitarianism. We saw that Mill is a noncognitivist, and thus a moral skeptic. We also saw that his utilitarian theory can be read as having a Humean constructivist basis. Mill is thus an excellent example of how Humean constructivism offers an account of prosocial practical reason for the moral skeptic, including the ability to construct normative social theories.

Morality then, is not the same thing as prosociality, for which it is neither necessary nor sufficient, and to which it is often or even mostly an obstacle. The moral skeptic can, instead of relying on morality to generate prosocial reasons, employ Humean constructivism and the rational tools with which it is compatible, such as ideal observer theory. Given the grim history of morality as described by Stephen Pinker, it might well be a good thing if this approach became more common. 


\section{References}

Holly's Letter from America: Why does the BBC exile Britain's greatest philosopher Roger Scruton? The Conservative Woman, http://conservativewoman.co.uk/category/holly-hamilton-bleakley/.

Liberal. Conservapedia, http://www.conservapedia.com/Liberal.

2014. Liberalism Explained [cited 15 July 2014]. Available from

http://augustine1blog.wordpress.com/2014/07/04/liberalism-explained/.

2014. Congress Retains Low Honesty Rating. Gallup 2012a [cited 13 July 2014]. Available from http://www.gallup.com/poll/159035/congress-retains-low-honestyrating.aspx.

2012b. Politicians, Journalists and Bankers Least Trusted Professions. The Week, http://www.theweek.co.uk/uk-news/49114/politicians-journalists-and-bankersleast-trusted-professions.

Associated Press. 2004. Election reinforces USA's religious schism. USA Today, http://usatoday30.usatoday.com/news/politicselections/2004-11-04religion_x.htm.

Attwood, T. 2014. What is Asperger's Syndrome? www.tonyattwood.com.au [cited 1 July 2014]. Available from http://www.tonyattwood.com.au/index.php/aboutaspergers.

Ayer, A. J. 1982. "Freedom and Necessity." In Free Will, edited by Gary Watson, 15-23. Oxford: Oxford University Press. 
Bagnoli, C. 2002. "Moral Constructivism: A Phenomenological Argument." Topoi no. 21 $(1-2): 125-138$.

Baker, K. 2014. True Morality is Based on Objective Principles. Catholic Education Resource Center, http://www.catholiceducation.org/articles/religion/re0919.htm.

Baron-Cohen, S. 2011. The Science of Evil: On Empathy and the Origins of Cruelty. New York: Basic Books.

Batson, C. D. 1998. "Altruism and Prosocial Behaviour." In Handbook of Social Psychology, edited by D. T. Gilbert, S. T. Fiske and G. Lindzey, volume 2, 282-316. Boston, MA: McGraw-Hill.

Blackburn, S. 1984. Spreading the Word. Oxford: Oxford University Press.

Blackburn, S. 1993. Essays in Quasi-Realism. New York: Oxford University Press.

Blair, J., D. Mitchell, and K. Blair. 2005. The Psychopath: Emotion and the Brain. Malden, MA: Blackwell.

Bloom, P., P. Singer, L. E. O'Connor, J. W. Berry, M. LaFrance, N. Arpaly, C. Montross, B. H. Fried, L. Jamison, L. Christov-Moore, M. Iacoboni, S. B. Cohen, E. S. Bruenig, S. Harris, and J. Prinz. 2014. Against Empathy. Boston Review, http://www.bostonreview.net/forum/paul-bloom-against-empathy.

Brink, D. 2008. Mill's Moral and Political Philosophy. The Stanford Encyclopedia of Philosophy, http://plato.stanford.edu/entries/mill-moral-political/.

Capaldi, N. 2004. John Stuart Mill: A Biography. Cambridge, UK: Cambridge University Press.

Carnap, R. 1937. Philosophy and Logical Syntax. London: Kegan Paul, Trench, Trubner \& Co. 
Colby, A., and L. Kohlberg. 1987. The Measure of Moral Judgment. Cambridge, UK: Cambridge University Press.

Crisp, R. 1997. Routledge Philosophy Guidebook to Mill on Utilitarianism. London: Routledge.

Darwall, S. L. 1983. Impartial Reason. Ithaca, NY: Cornell University Press.

Davidson, D. 1980. "Intending." In Essays on Actions and Events. Oxford: Oxford University Press.

Doris, J., and S. Stich. 2014. Moral Psychology: Empirical Approaches. The Stanford Encyclopedia of Philosophy, http://plato.stanford.edu/archives/spr2014/entries/moral-psych-emp/.

Dorsey, D. 2008. Relativism and Constructivism: A Humean Response. University of Kansas.

Drake, N. 2013a. The "Funishment" Reductio against Hard Determinism, PHIL 409, Victoria University of Wellington, Wellington.

Drake, N. 2013b. Humean Constructivism in Utilitarian Metaethics, PHIL 489, Victoria University of Wellington, Wellington.

Driver, J. 2012. Consequentialism. Abingdon: Routledge.

Dutton, K. 2012. The Wisdom of Psychopaths: What Saints, Spies, and Serial Killers Can Teach Us About Success. New York: Farrar, Strauss and Giroux.

Finlay, S. 2008. "The Error in the Error Theory." Australasian Journal of Philosophy no. 86 (3):347-369.

Firth, R. 1952. "Ethical Absolutism and the Ideal Observer." Philosophy and Phenomenological Research no. 12 (3):317-345. 
Flynn, J. R. 2000. How to Defend Humean Ideals: Substitutes for Objectivity. Lincoln, Neb: University of Nebraska Press.

Foot, P. 1972. "Morality as a System of Hypothetical Imperatives." Philosophical Review no. $81(3): 305-316$.

Fournier, K. A. 2014. Beyond Liberal, Conservative, Progressive: The Need for a Morally Coherent Politics. Catholic Online, http://www.catholic.org/news/politics/story.php?id=53755.

Francione, G. L. 2008. Animals as Persons: Essays on the Abolition of Animal Exploitation. New York: Columbia University Press.

Frankena, W. 1970. "The Concept of Morality." In The Definition of Morality, edited by G. Wallace and A. D. M. Walker. London: Methuen.

Frankfurt, H. 1982. "Freedom of the Will and the Concept of a Person." In Free Will, edited by Gary Watson, 81-95. Oxford: Oxford University Press.

Garner, R. 1994. Beyond Morality. Philadelphia: Temple University Press.

Garner, R. 2007. "Abolishing Morality." Ethical Theory and Moral Practice no. 10 (5):499513.

Gert, B. 2011. The Definition of Morality. The Stanford Encyclopedia of Philosophy, http://plato.stanford.edu/entries/morality-definition/.

Gibbard, A. 1999. "Morality as Consistency in Living: Korsgaard's Kantian Lectures." Ethics no. 110 (1):140-164.

Glossop, R. J. 1967. "The Nature of Hume's Ethics." Philosophy and Phenomenological Research no. 27 (4):527-536.

Glover, J. 2001. Humanity: A Moral History of the Twentieth Century. London: Pimlico. 
Glover, J. 2014. Alien Landscapes? Interpreting Disordered Minds. Cambridge, MA: The Belknap Press of Harvard University Press.

Goodwin, G. P., and J. M. Darley. 2008. "The Psychology of Meta-Ethics: Exploring Objectivism." Cognition no. 106 (3):1339-1366. doi: http://dx.doi.org/10.1016/j.cognition.2007.06.007.

Greene, J. 2002. The Terrible, Horrible, No Good, Very Bad Truth about Morality and What to Do About It. Doctoral dissertation, Princeton University.

Greene, J. 2013. Moral Tribes: Emotion, Reason, and the Gap Between Us and Them. New York: The Penguin Press.

Haidt, J. 1993. "Affect, Culture, and Morality, or is it Wrong to Eat Your Dog?" Journal of Personality and Social Psychology no. 65: 613-628.

Haidt, J. 2001. "The Emotional Dog and its Rational Tail: A Social Intuitionist Approach to Moral Judgment." Psychological Review no. 108 (4):814-834.

Haidt, J. 2012. The Righteous Mind: Why Good People Are Divided by Politics and Religion. New York: Pantheon Books.

Haidt, J., F. Bjorklund, and S. Murphy. 2000. Moral Dumbfounding: When Intuition Finds No Reason. University of Virginia.

Haidt, J., and M. Hersh. 2001. "Sexual Morality: The Cultures and Reasons of Liberals and Conservatives." Journal of Applied Social Psychology no. 31: 191-221.

Hare, R. M. 1952. The Language of Morals. Oxford: Clarendon.

Harinck, F., C. K. W. d. DreuAnnelies, and E. M. V. Vianen. 2000. "The Impact of Conflict Issues on Fixed-Pie Perceptions, Problem Solving, and Integrative Outcomes in Negotiation." Organizational Behavior and Human Decision Processes no. 81 $(2): 329-358$. 
Harman, G. 1985. "Is There a Single True Morality?" In Morality, Reason and Truth, edited by David Copp and David Zimmerman. Totowa, NJ: Rwoman and Allanheld.

Harris, S. 2010. The Moral Landscape: How Science Can Determine Human Values. New York: Free Press.

Harrison, J. 1976. Hume's Moral Epistemology. Oxford: Oxford University Press. Heath, J., and B. Hardy-Vallée. 2015. "Why do People Behave Immorally When Drunk?" Philosophical Explorations no. 18 (1):1-20.

Hillygus, D. S., and T. G. Shields. 2005. "Moral Issues and Voter Decision Making in the 2004 Presidential Election." PS, Political Science \& Politics no. 38 (2):201-209. Hinckfuss, I. 1987. The Moral Society: Its Structure and Effects. http://www.bimbad.ru/docs/hinckfuss_ian_moral_society.pdf.

Huang, Y. 2008. "“Why be moral?” The Cheng Brothers' Neo-Confucian Answer." Journal of Religious Ethics no. 36 (2):321-353. doi: 10.1111/j.1467-9795.2008.00348.x. Hume, D. 1740/1978. A Treatise of Human Nature. Oxford: Oxford University Press. Hume, D. 1751/1983. An Enquiry Concerning the Principles of Morals. Indianapolis: Hackett Publishing.

Joyce, R. 2001. The Myth of Morality. Cambridge: Cambridge University Press. Joyce, R. 2009. Moral Anti-Realism. The Stanford Encyclopedia of Philosophy, http://plato.stanford.edu/archives/sum2009/entries/moral-anti-realism/. Joyce, R. 2012. Enough with the Errors! A Final Reply to Finlay. Victoria University of Wellington.

Joyce, R. 2013. "Irrealism and the Genealogy of Morals." Ratio no. 26 (4):351-372. doi: 10.1111/rati.12027. 
Joyce, R. 2014. Personal communication, 30 December 2014.

Joyce, R., forthcoming. "Moral Skepticism." In Skepticism: Antiquity to the Present, edited by D. Machuca and B. Reed. Bloomsbury.

Kohlberg, L. 1981. Essays on Moral Development. San Francisco: Harper \& Row.

Kohlberg, L., C. Levine, and A. Hewer. 1983. Moral Stages: A Current Formulation and a Response to Critics. Basel: Kargel.

Korsgaard, C. 1997. "The Normativity of Instrumental Reason." In Ethics and Practical Reason, edited by G. Cullity and B. Gaut. Oxford: Clarendon Press.

Korsgaard, C. M. 1996. The Sources of Normativity. Cambridge, UK: Cambridge University Press.

Leiter, B. 2013. Nietzsche's Moral and Political Philosophy. The Stanford Encyclopedia of Philosophy.

Lenman, J. 2010. "Humean Constructivism in Moral Theory." In Oxford Studies in Metaethics, Volume 5, edited by Russ Shafer-Landau. Oxford: Oxford University Press.

Lenman, J., and Y. Shemmer. 2012. "Introduction." In Constructivism in Practical Philosophy. Oxford: Oxford University Press.

Lewis, D. 1989. "Dispositional Theories of Value." Proceedings of the Aristotelian Society no. $63: 113-137$.

Lilienfeld, S. O., and H. Arkowitz. 2007. What "Psycopath" Means. It is Not Quite What You May Think. Scientific American, http://www.scientificamerican.com/article.cfm?id=what-psychopath-means.

Luengo Kanacri, B. P., C. Pastorelli, N. Eisenberg, A. Zuffianò, and G. V. Caprara. 2013. "The Development of Prosociality from Adolescence to Early Adulthood: The Role 
of Effortful Control." Journal of Personality no. 81 (3):302-312. doi: http://dx.doi.org/10.1111/jopy.12001.

Maclntyre, A. 1985. After Virtue: A Study in Moral Theory. 2nd ed. London: Duckworth. Mackie, J. L. 1977. Ethics: Inventing Right and Wrong. London: Penguin Books.

Mackie, J. L. 1980. Hume's Moral Theory. Abingdon: Routledge.

Macleod, C. 2013. "Was Mill a Noncognitivist?" The Southern Journal of Philosophy no. $51(2): 206-223$.

Marcus, G. 2004. The Birth of the Mind: How a Tiny Number of Genes Creates The Complexities of Human Thought. New York: Basic Books.

Menzies, P. 2012. Mackie, John Leslie (1917-1981). In Australian Dictionary of Biography: National Centre of Biography, Australian National University.

Mill, J. S. 1843/1974. "A System of Logic, Ratiocinative and Inductive. Being a Connected View of the Principles of Evidence and the Methods of Scientific Investigation." In The Collected Works of John Stuart Mill, v. 7-8, edited by J. M. Robson. Toronto: Toronto University Press.

Mill, J. S. 1844/1967. "Essays on Some Unsettled Questions of Political Economy." In The Collected Works of John Stuart Mill, v. 4, edited by J. M. Robson. Toronto: Toronto University Press.

Mill, J. S. 1863/2001. Utilitarianism. Indianapolis: Hackett Publishing.

Mill, J. S. 1873/1964. "Autobiography." In The Collected Works of John Stuart Mill, v. 1, edited by J. M. Robson. Toronto: Toronto University Press.

Miller, A. 2013. Contemporary Metaethics: An Introduction. 2nd ed. Cambridge, UK: Polity Press. 
Ministry of Justice. 2013. The Rationales and Goals of Sentencing (1/2) 1997 [cited 3

November 2013]. Available from http://www.justice.govt.nz/publications/globalpublications/s/sentencing-policy-and-guidance-a-discussion-paper/3.-therationales-and-goals-of-sentencing\#3.1.

Moore, G. E. 1903/1948. Principia Ethica. Cambridge: Cambridge University Press.

MoralFoundations.org. Self-scorable MFQ30, 2014 2014. Available from http://www.moralfoundations.org/questionnaires.

Mullen, E., and L. J. Skitka. 2006. "Exploring the Psychological Underpinnings of the Moral Mandate Effect: Motivated Reasoning, Group Differentiation, or Anger?" Journal of Personality and Social Psychology no. 90 (4):629-643. doi: http://dx.doi.org/10.1037/0022-3514.90.4.629.

Nobelprize.org. 2014. The Nobel Prize in Literature 1950 [cited 22 June 2014]. Available from http://www.nobelprize.org/nobel_prizes/literature/laureates/1950/index.html. Paletta, D. R. 2011. "Francis Hutcheson: Why Be Moral?" Journal of Scottish Philosophy no. 9 (2):149-159. doi: 10.3366/jsp.2011.0013.

Penner, L. A., J. F. Dovidio, J. A. Piliavin, and D. A. Schroeder. 2005. "Prosocial Behaviour: Multilevel Perspectives." Annual Review of Psychology no. 56 (1):365-392.

Philosopedia.org. 2014. Charles Pigden [cited 25 June 2014]. Available from http://philosopedia.org/index.php/Charles_Pigden.

Pianalto, M. 2011. "Moral Conviction." Journal of Applied Philosophy no. 28 (4):381-395. Pigden, C. R. 1996. "Bertrand Russell: Meta-Ethical Pioneer." Philosophy of the Social Sciences no. 26 (2):181-204. 
Pinker, S. 2011. The Better Angels of Our Nature: The Decline of Violence in History and Its Causes. London: Allen Lane.

Putnam, H. 1981. Reason, Truth and History. Cambridge: Cambridge University Press.

Quinton, A. 1989. Utilitarian Ethics. 2nd ed. London: The Macmillan Press.

Rachels, J. 2000. "Naturalism." In The Blackwell Guide to Ethical Theory, edited by Hugh LaFollette, 74-91. Oxford: Blackwell Publishing.

Railton, P. 1986. "Moral Realism." The Philosophical Review no. 95 (2):163.

Rawls, J. 1971. A Theory of Justice. Cambridge, MA.

Rawls, J. 1999. A Theory of Justice. Revised ed. Cambridge, MA: Harvard University Press.

Rosati, C. S. 2006. Moral Motivation. The Stanford Encyclopedia of Philosophy, http://plato.stanford.edu/entries/moral-motivation/.

Rust, J., and E. Schwitzgebel. 2013. "Ethicists' and Nonethicists' Responsiveness to Student E-mails: Relationships Among Expressed Normative Attitude, Self-Described Behavior, and Empirically Observed Behavior." Metaphilosophy no. $44(3): 350-371$.

Ryan, A. 1970. The Philosophy of John Stuart Mill. London: Macmillan.

Ryan, A. 1974. J. S. Mill. London: Routledge \& Kegan Paul.

Ryan, A. 1988. Bertrand Russell: A Political Life. New York: Hill and Wang.

Sarkissian, H., J. Park, D. Tien, J. Cole Wright, and J. Knobe. 2011. "Folk Moral Relativism." Mind \& Language no. 26 (4):482-505.

Sayre-McCord, G. 1994. "On Why Hume's "General Point of View" Isn't Ideal-and Shouldn't Be." Social Philosophy and Policy no. 11 (01):202-228.

Schroeder, W. 2000. "Continental Ethics." In The Blackwel Guide to Ethical Theory, edited by Hugh LaFollette, 375-399. Oxford: Blackwell Publishing. 
Schwitzgebel, E. 2009. "Do Ethicists Steal More Books?" Philosophical Psychology no. 22 (6):711-725.

Schwitzgebel, E. 2013. "Are Ethicists Any More Likely to Pay Their Registration Fees at Professional Meetings?" Economics and Philosophy no. 29 (3):371-380.

Schwitzgebel, E., and J. Rust. 2009. "The Moral Behaviour of Ethicists: Peer Opinion." Mind no. 118 (472):1043 - 1059.

Schwitzgebel, E., and J. Rust. 2010. "Do Ethicists and Political Philosophers Vote More Often Than Other Professors?" Review of Philosophy and Psychology no. 1 (2):189-199.

Schwitzgebel, E., and J. Rust. 2013. "The Moral Behavior of Ethics Professors:

Relationships Among Self-Reported Behavior, Expressed Normative Attitude, and Directly Observed Behavior." Philosophical Psychology (3):1-35.

Schwitzgebel, E., J. Rust, L. T.-L. Huang, A. T. Moore, and J. Coates. 2012. "Ethicists' Courtesy at Philosophy Conferences." Philosophical Psychology no. 25 (3):331340.

Sedikides, C., R. Meek, M. D. Alicke, and S. Taylor. 2014. "Behind bars but above the bar: Prisoners consider themselves more prosocial than non-prisoners." The British Journal of Social Psychology no. 53 (2):396-403.

Singer, P. 1969. Why Should I Be Moral?

Singer, P. 2009. Why We Should Be Moral. Big Think, http://bigthink.com/videos/whywe-should-be-moral.

Singer, P. 2011. The Expanding Circle: Ethics, Evolution, and Moral Progress. With a new afterword by the author. Princeton, NJ: Princeton University Press.

Sinnott-Armstrong, W. 2006. Moral Skepticisms. Oxford: Oxford University Press. 
Sinnott-Armstrong, W. 2014. Consequentialism. The Stanford Encyclopedia of

Philosophy,

http://plato.stanford.edu/archives/spr2014/entries/consequentialism/.

Skitka, L. J., and D. A. Houston. 2001. "When Due Process Is of No Consequence: Moral Mandates and Presumed Defendant Guilt or Innocence." Social Justice Research no. $14(3): 305-326$.

Skitka, L. J., and E. Mullen. 2002. "The Dark Side of Moral Conviction." Analyses of Social Issues \& Public Policy no. 2 (1):35-41.

Skorupski, J. 1989. John Stuart Mill. London: Routledge.

Smith, M. 1993. "Realism." In A Companion to Ethics, edited by Peter Singer, 399-409. Oxford: Blackwell.

Smith, M. 1994. The Moral Problem. Malden, MA: Blackwell Publishing.

Street, S. 2008. "Constructivism about Reasons." In Oxford Studies in Metaethics Vol. 3, edited by Russ Shafer-Landau, 207-245. Oxford: Clarendon Press.

Street, S. 2010. "What is Constructivism in Ethics and Metaethics?" Philosophy Compass no. 5 (5):363-384

Street, S. 2012. "Coming To Terms with Contingency: Humean Constructivism about Practical Reason." In Constructivism in Practical Philosophy, edited by Jimmy Lenman and Yonatan Shemmer. Oxford University Press.

Thomas, D. 1976. The Marquis de Sade. London: Weidenfeld \& Nicolson.

Tiberius, V. 2008. The Reflective Life: Living Wisely With Our Limits. Oxford: Oxford University Press.

Turiel, E. 1983. The Development of Social Knowledge: Morality and Convention. Cambridge, UK: Cambridge University Press. 
van Roojen, M. 2013. Moral Cognitivism vs . Non-Cognitivism. The Stanford Encyclopedia of Philosophy, http://plato.stanford.edu/cgibin/encyclopedia/archinfo.cgi?entry=moral-cognitivism.

Wallace, G., and A. D. M. Walker, eds. 1970. The Definition of Morality. London: Methuen.

Wallace, R. J. 2014. Practical Reason. The Stanford Encyclopedia of Philosophy, http://plato.stanford.edu/entries/practical-reason/.

Watson, G. 1982. "Free Agency." In Free Will, edited by Gary Watson, 96-110. Oxford: Oxford University Press.

West, H. R. 2007. Mill's Utilitarianism. London: Continuum.

Williams, B. 1981. "Internal and External Reasons." In Moral Luck. Cambridge, UK: Cambridge University Press.

Williams, B. 1995. "Internal Reasons and the Obscurity of Blame." In Making Sense of Humanity. Cambridge, UK: Cambridge University Press.

Wilson, F. 2012. John Stuart Mill. The Stanford Encyclopedia of Philosophy, http://plato.stanford.edu/archives/spr2012/entries/mill/.

Wright, C. 1996. "Truth in Ethics." In Truth in Ethics, edited by Brad Hooker. Oxford: Blackwell.

Zaal, M. P., C. V. Laar, T. Ståhl, N. Ellemers, and B. Derks. 2011. "By Any Means Necessary: The Effects of Regulatory Focus and Moral Conviction on Hostile and Benevolent Forms of Collective Action." British Journal of Social Psychology no. 50 (4):670-689. doi: 10.1111/j.2044-8309.2011.02069.x. 
Zaki, J., and J. P. Mitchell. 2013. "Intuitive Prosociality." Current Directions in Psychological Science (Sage Publications Inc.) no. 22 (6):466-470. doi: $10.1177 / 0963721413492764$. 